Prepared in cooperation with the U.S. Fish and Wildlife Service and The Nature Conservancy

Prepared in collaboration with Northeastern University

\title{
Assessment of Wave Attenuation, Current Patterns, and Sediment Deposition and Erosion During Winter Storms by Living Shoreline Structures in Gandys Beach, New Jersey
}

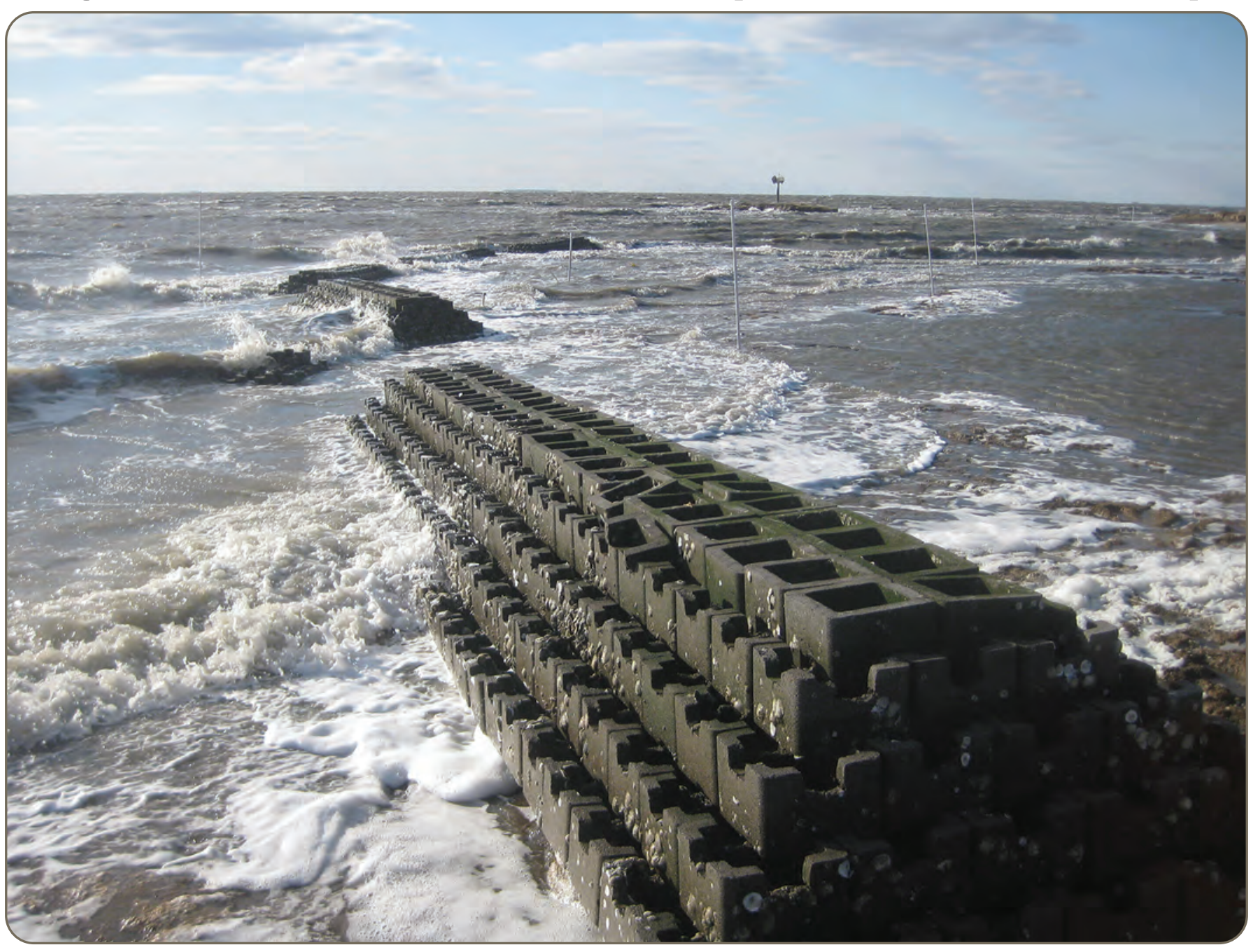

Open-File Report 2021-1040 
Cover. Oyster castles in Gandys Beach, New Jersey. Photograph by Hongqing Wang, U.S. Geological Survey. 


\section{Assessment of Wave Attenuation, Current Patterns, and Sediment Deposition and Erosion During Winter Storms by Living Shoreline Structures in Gandys Beach, New Jersey}

Hongqing Wang, William Capurso, Qin Chen, Ling Zhu, Lukasz Niemoczynski, and Gregg Snedden

Prepared in cooperation with the U.S. Fish and Wildlife Service and

The Nature Conservancy

Prepared in collaboration with Northeastern University

Open-File 2021-1040 


\section{U.S. Geological Survey, Reston, Virginia: 2021}

For more information on the USGS - the Federal source for science about the Earth, its natural and living resources, natural hazards, and the environment-visit https://www.usgs.gov or call 1-888-ASK-USGS.

For an overview of USGS information products, including maps, imagery, and publications, visit https://store.usgs.gov.

Any use of trade, firm, or product names is for descriptive purposes only and does not imply endorsement by the U.S. Government.

Although this information product, for the most part, is in the public domain, it also may contain copyrighted materials as noted in the text. Permission to reproduce copyrighted items must be secured from the copyright owner.

Suggested citation:

Wang, H., Capurso, W., Chen, Q., Zhu, L., Niemoczynski, L., and Snedden, G., 2021, Assessment of wave attenuation, current patterns, and sediment deposition and erosion during winter storms by living shoreline structures in Gandys Beach, New Jersey: U.S. Geological Survey Open-File Report 2021-1040, 37 p., https://doi.org/10.3133/ofr20211040.

Associated data for this publication:

Wang, H., Capurso, W.D., Chen, Q., Zhu, L., Niemoczynski, L.M., and Snedden, G., 2021, Field observation of current velocities (2018) in Gandys Beach, New Jersey with living shoreline structures: U.S. Geological Survey data release, https://doi.org/10.5066/P9N4NOWZ.

Wang, H., Zhu, L., Chen, Q., Capurso, W.D., Niemoczynski, L.M., Hu, K., and Snedden, G., 2020, Field observations and spectral evolution of wind waves in Upper Delaware Bay with living shorelines: U.S. Geological Survey data release, https://doi.org/10.5066/P9YEUNTM.

ISSN 2331-1259 (online) 


\section{Acknowledgments}

This report was prepared as a part of a multiple-year project funded by the National Fish and Wildlife Foundation (project no. 55032) to collect wave, current, and sediment data for the effectiveness assessment of living shoreline structures across the northeast and mid-Atlantic coasts. We are grateful to Moses Katkowski, Adrianna Zito-Livingston (The Nature Conservancy), Eric Schrading, Danielle Mcculloch (U.S. Fish and Wildlife Service), and Kelin Hu (Tulane University) for their assistance in field data collection. We thank Cody Johnson (U.S. Army Corps of Engineers) for constructive review of this report.

We also thank Chris Witzigman (U.S. Geological Survey [USGS]) for his assistance in field data collection. We would like to thank Todd Baumann (USGS) for laboratory analysis of the sediment samples and Peter Murdoch and Ronald Busciolano (USGS) for their guidance in field design and data analyses of this interdisciplinary project. We thank Rangley Mickey (USGS) for constructive review of this report. 



\section{Contents}

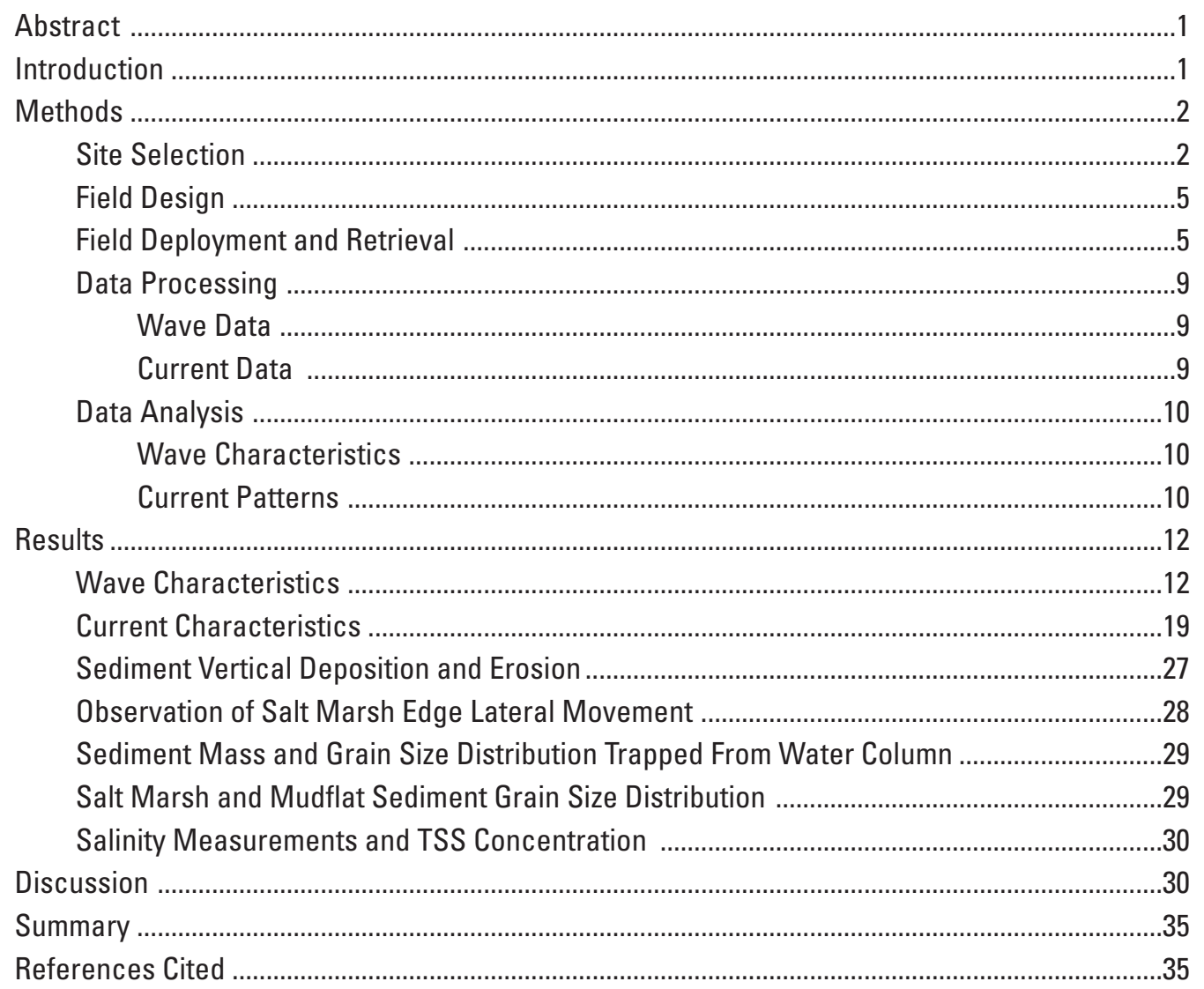

\section{Figures}

1. Maps showing location of the Gandys Beach/Money Island living shoreline project and study site on the New Jersey side of Delaware Bay .....................................3

2. Photographs showing Spartina alterniflora fragmentation, root debris, edge erosion, and gullies along the Gandys Beach shoreline, New Jersey ..............................

3. Photographs showing oyster castles in the Gandys Beach, New Jersey, living shoreline project area exposed at low tide and submerged at high tide .........................6

4. Maps showing locations of wave gages, tilt current meters, sediment trap/pin sets, marsh edge erosion pins, and marsh and mudflat sediment cores along the Gandys Beach living shoreline, New Jersey

5. Photographs showing wave gage, tilt current meter, elevation survey, sediment pin/trap set, marsh edge erosion pin, and camera deployed in the Gandys Beach, New Jersey, living shoreline study site

6. Graphs showing time series of raw data from tilt current meters 2 and 4, February to April 2018, in the Gandys Beach, New Jersey, living shoreline study area

7. Schematics showing a completely submerged tilt current meter and the relation between current speed and bearing angle 
8. Graph showing time series of current vector at tilt current meter 5 , February to April 2018, in the Gandys Beach, New Jersey, living shoreline study area .

9. Graphs showing time series of water depth and water level measured at six wave gages, February to April 2018, in the Gandys Beach, New Jersey, living shoreline study area

10. Graphs showing time series of zero-moment wave heights measured at six wave gages, February to April 2018, in the Gandys Beach, New Jersey, living shoreline study area

11. Graphs showing time series of peak wave periods measured at six wave gages, February to April 2018, in the Gandys Beach, New Jersey, living shoreline study area

12. Photographs showing wave action with water level at the oyster castles in the Gandys Beach, New Jersey, living shoreline study area at 9:00, 9:30, 10:00, and 11:00 a.m. on February 5, 2018

13. Graphs showing intergage comparisons of zero-moment wave heights in the Gandys Beach, New Jersey, living shoreline study area during February to April 2018

14. Graphs showing comparisons of zero-moment wave heights at wave gages 3 and 5 in four wind quadrants in the Gandys Beach, New Jersey, living shoreline study area

15. Graph showing relations among the relative freeboard and transmission coefficient from two previous studies and this study

16. Graphs showing time series of swell and wind sea zero-moment wave heights measured at six wave gages, February to April 2018, in the Gandys Beach, New Jersey, living shoreline study area .

17. Graphs showing intergage comparisons of swell and wind sea zero-moment wave heights measured at six wave gages in the Gandys Beach, New Jersey, living shoreline study area during February to April 2018

18. Graph showing time series of water depths at wave gage 4 in the Gandys Beach, New Jersey, living shoreline study area

19. Graphs showing time series of the mean current vector and the mean current speed during flood and ebb tides at tilt current meter 5, February to April 2018, in the Gandys Beach, New Jersey, living shoreline study area

20. Graphs showing time series of the mean current vector and the mean current speed during flood and ebb tides at tilt current meter 1, February to April 2018, in the Gandys Beach, New Jersey, living shoreline study area

21. Graphs showing time series of the mean current vector and the mean current speed during flood and ebb tides at tilt current meter 7, February to April 2018, in the Gandys Beach, New Jersey, living shoreline study area

22. Graphs showing time series of the mean current vector and the mean current speed during flood and ebb tides at tilt current meter 2, February to April 2018, in the Gandys Beach, New Jersey, living shoreline study area

23. Graphs showing time series of the mean current vector and the mean current speed during flood and ebb tides at tilt current meter 4, February to April 2018, in the Gandys Beach, New Jersey, living shoreline study area

24. Graphs showing time series of the mean current vector and the mean current speed during flood and ebb tides at tilt current meter 6, February to April 2018, in the Gandys Beach, New Jersey, living shoreline study area 
25. Map and graph showing a snapshot of currents at all tilt current meters during a flood tide on March 21, 2018, at 9:00 a.m., in the Gandys Beach, New Jersey, living shoreline study area

26. Map and graph showing a snapshot of currents at all tilt current meters during an ebb tide on March 19, 2018, at 2:00 p.m., in the Gandys Beach, New Jersey, living shoreline study area

27. Photograph showing vertical sediment erosion over the 2-month period from February to April 2018 at the benchmark location in the Gandys Beach, New Jersey, living shoreline study area . .27

28. Photographs showing lateral movement at the control sites pin4, pin5, and pin6 in the Gandys Beach, New Jersey, living shoreline study area

29. Schematic showing the marsh platform and toe and the proposed effective range at the oyster castle and control sites for wave power computation in the Gandys Beach, New Jersey, living shoreline study area

30. Graphs showing the mean water level and the effective ranges at the oyster castle site (wave gage 5) and the control site (wave gage 4), February to April 2018, in the Gandys Beach, New Jersey, living shoreline study area

31. Graph showing the mean effective wave power at wave gages 4 and 5 averaged over the four nor'easters and the 2-month deployment duration, February to April 2018, in the Gandys Beach, New Jersey, living shoreline study area

32. Graphs showing comparisons of the wave-induced bottom shear stress at wave gages 4 and 5 in all tide conditions, high-tide to mid-tide conditions, and low-tide conditions, February to April 2018, in the Gandys Beach, New Jersey, living shoreline study area

\section{Tables}

1. A summary of the instrument offsets for the six wave gages deployed in the Gandys Beach, New Jersey, living shoreline study area during February to April 2018

2. Sediment pin measurements and surface elevation change during February to April 2018 at pin/trap set locations in the Gandys Beach, New Jersey, living shoreline study area

3. Total sediment mass accumulated in sediment traps and sediment grain size distribution during February to April 2018 at mudflat and marsh sites in the Gandys Beach, New Jersey, living shoreline study area

4. Sediment grain size distribution in salt marsh and mudflat in the Gandys Beach, New Jersey, living shoreline study area during February to April 2018 


\section{Conversion Factors}

U.S. customary units to International System of Units

\begin{tabular}{|c|c|c|}
\hline Multiply & By & To obtain \\
\hline \multicolumn{3}{|c|}{ Length } \\
\hline inch (in.) & 2.54 & centimeter $(\mathrm{cm})$ \\
\hline inch (in.) & 25.4 & millimeter (mm) \\
\hline
\end{tabular}

International System of Units to U.S. customary units

\begin{tabular}{|c|c|c|}
\hline Multiply & By & To obtain \\
\hline \multicolumn{3}{|c|}{ Length } \\
\hline centimeter $(\mathrm{cm})$ & 0.3937 & inch (in.) \\
\hline millimeter $(\mathrm{mm})$ & 0.03937 & inch (in.) \\
\hline meter $(\mathrm{m})$ & 3.281 & foot $(\mathrm{ft})$ \\
\hline kilometer (km) & 0.6214 & mile (mi) \\
\hline kilometer (km) & 0.5400 & mile, nautical (nmi) \\
\hline meter (m) & 1.094 & yard (yd) \\
\hline \multicolumn{3}{|c|}{ Area } \\
\hline square meter $\left(\mathrm{m}^{2}\right)$ & 0.0002471 & acre \\
\hline square kilometer $\left(\mathrm{km}^{2}\right)$ & 247.1 & acre \\
\hline square centimeter $\left(\mathrm{cm}^{2}\right)$ & 0.001076 & square foot $\left(\mathrm{ft}^{2}\right)$ \\
\hline square meter $\left(\mathrm{m}^{2}\right)$ & 10.76 & square foot $\left(\mathrm{ft}^{2}\right)$ \\
\hline square centimeter $\left(\mathrm{cm}^{2}\right)$ & 0.1550 & square inch $\left(\mathrm{in}^{2}\right)$ \\
\hline square kilometer $\left(\mathrm{km}^{2}\right)$ & 0.3861 & square mile $\left(\mathrm{mi}^{2}\right)$ \\
\hline \multicolumn{3}{|c|}{ Volume } \\
\hline liter $(\mathrm{L})$ & 33.81402 & ounce, fluid (fl. oz) \\
\hline liter $(\mathrm{L})$ & 2.113 & $\operatorname{pint}(\mathrm{pt})$ \\
\hline liter $(\mathrm{L})$ & 1.057 & quart (qt) \\
\hline liter $(\mathrm{L})$ & 0.2642 & gallon (gal) \\
\hline liter $(\mathrm{L})$ & 61.02 & cubic inch $\left(\mathrm{in}^{3}\right)$ \\
\hline \multicolumn{3}{|c|}{ Pressure } \\
\hline kilopascal $(\mathrm{kPa})$ & 0.009869 & atmosphere, standard (atm) \\
\hline kilopascal (kPa) & 0.01 & bar \\
\hline
\end{tabular}

Temperature in degrees Celsius $\left({ }^{\circ} \mathrm{C}\right)$ may be converted to degrees Fahrenheit $\left({ }^{\circ} \mathrm{F}\right)$ as follows:

${ }^{\circ} \mathrm{F}=\left(1.8 \times{ }^{\circ} \mathrm{C}\right)+32$.

Temperature in degrees Fahrenheit $\left({ }^{\circ} \mathrm{F}\right)$ may be converted to degrees Celsius $\left({ }^{\circ} \mathrm{C}\right)$ as follows:

${ }^{\circ} \mathrm{C}=\left({ }^{\circ} \mathrm{F}-32\right) / 1.8$. 


\section{Datum}

Vertical coordinate information is referenced to the North American Vertical Datum of 1988 (NAVD 88).

Horizontal coordinate information is referenced to the North American Datum of 1983 (NAD 83), unless otherwise noted. Elevation, as used in this report, refers to distance above the vertical datum.

\section{Abbreviations}

$\begin{array}{ll}\text { COR } & \text { constructed oyster reef } \\ \text { GPS } & \text { Global Positioning System } \\ \text { LSS } & \text { living shoreline structure } \\ \text { NAVD 88 } & \text { North American Vertical Datum of } 1988 \\ \text { ppt } & \text { part per thousand } \\ \text { PVC } & \text { polyvinyl chloride } \\ \text { TCM } & \text { tilt current meter } \\ \text { TSS } & \text { total suspended solid } \\ \text { WG } & \text { wave gage }\end{array}$





\title{
Assessment of Wave Attenuation, Current Patterns, and Sediment Deposition and Erosion During Winter Storms by Living Shoreline Structures in Gandys Beach, New Jersey
}

\author{
By Hongqing Wang, ${ }^{1}$ William Capurso, ${ }^{1}$ Qin Chen, ${ }^{2}$ Ling Zhu, ${ }^{2}$ Lukasz Niemoczynski, ${ }^{1}$ and Gregg Snedden ${ }^{1}$
}

\section{Abstract}

This study was conducted by the U.S. Geological Survey and Northeastern University in cooperation with the U.S. Fish and Wildlife Service and The Nature Conservancy. This report summarizes field investigation and analysis of waves, current patterns, and sediment deposition and erosion along the Gandys Beach, New Jersey, salt marsh vegetated shoreline and mudflat, where living shoreline structures (for example, oyster reefs) were constructed to protect the marsh shoreline and enhance habitat for oyster and other species. Constructed oyster reefs (CORs, also known as oyster castles) provide shoreline protection and habitat for fish and shellfish communities via wave energy attenuation. However, the processes and mechanism of CORs on wave attenuation and current circulation remain unclear, thus limiting the assessment of COR effectiveness for shoreline protection. This report presents the results of the field investigation on wave characteristics, current patterns, and marsh edge erosion along a shoreline with CORs in Delaware Bay. To measure the effectiveness of these CORs, six pressure transducers, six tilt current meters, multiple sediment traps, and marsh edge erosion pins were deployed from February to April 2018 in Gandys Beach in upper Delaware Bay. The spatial variations of wave heights measured on both sides of the CORs indicate a strong dependence of wave attenuation on the ratio between the freeboard of the CORs and the offshore wave heights. It was found that swell energy originating from the Atlantic Ocean can penetrate the CORs without any dampening even when the CORs are emergent, whereas the wind seas are more impacted by the CORs. Tidal current velocity and circulation patterns near the CORs (for example, the current velocity was higher than 10 centimeters per second $[\mathrm{cm} / \mathrm{s}]$ and even up to $30 \mathrm{~cm} / \mathrm{s}$ in the gaps between the CORs compared to less than $10 \mathrm{~cm} / \mathrm{s}$ in the control area) differ from those in the control area without protection from the CORs and are greatly affected by the surrounding bathymetry. The combined effect of living shoreline structures on wave attenuation and changes

\footnotetext{
${ }^{1}$ U.S. Geological Survey.
}

${ }^{2}$ Northeastern University, Department of Civil and Environmental Engineering. in circulation patterns over the study period resulted in the reduction of shoreline erosion both vertically and laterally compared to that in the control area and also resulted in changes in the grain size distribution in both the water column and the salt marsh and mudflat areas.

\section{Introduction}

Living shoreline projects have been constructed along the northeast and mid-Atlantic coasts largely after the passage of Hurricane Sandy (2012) to restore and protect coastal ecosystems that are being influenced by climate change and sea level rise. Living shoreline projects utilize a variety of organic materials such as oyster reefs, wetland plants, and submerged aquatic vegetation (herein called living shoreline structures [LSS]) to stabilize shorelines and protect coastal marshes from erosion and to enhance habitat for oysters and other species (Manis and others, 2015; Sharma and others, 2016; Polk and Eulie, 2018; Chowdhury and others, 2019; Wiberg and others, 2019). Although the reduction of marsh erosion and the enhancement of habitat from LSS were expected, some unexpected negative ecological effects of living shoreline projects, especially in high-energy environments, occurred because of the complex interaction of the LSS with coastal physical processes and the variability of LSS properties (for example, Dugan and others, 2018). Dugan and others (2018) found that living shoreline projects may perform negatively in terms of habitat distribution, species assemblage, trophic structure, nutrient cycling, productivity, and connectivity (exchange and accumulation of organisms, sediment, and propagules between land and sea) depending on the characteristics (for example, location, crest elevation, width, and length) of the armoring structure and biophysical conditions of the shoreline (onshore and offshore). Thus, the metrics to evaluate the effectiveness of living shoreline projects should not solely rely on the utilization of biophysical descriptive indicators of environmental conditions or outcomes of implementation of living shorelines such as vegetation cover, water temperature, salinity, vertical accretion rates, and shoreline position. It is critical to study 
the interaction between coastal physical processes and the structural characteristics of LSS to achieve the comprehensive assessment of the long-term ecological effects of LSS. In terms of physical processes, hydrodynamic forcing (waves, currents, water levels) should be among the top priorities of coastal living shoreline studies to help understand the mechanisms of LSS in response to storm-induced wave and current stressors and ultimately protect coastal marshes and other habitats for fish and wildlife species (Theuerkauf and others, 2017; Polk and Eulie, 2018; Wiberg and others, 2019).

The success of living shoreline restoration projects in response to hurricanes and storms requires a better understanding of how the LSS reduce the impact of wave energy on marsh edges in estuaries and bays. Wave power is generally the most significant driving force on coastal erosion, although other local factors such as sediment texture and erodibility also play a role (for example, Sanford and Gao, 2018). Wave energy also determines the distribution of intertidal oyster reefs, thus affecting the effectiveness of LSS that use oyster reefs (Theuerkauf and others, 2017). Theuerkauf and others (2017) identified a wave exposure threshold for oyster reefs above which natural intertidal reefs would not occur. Wave and current characteristics in living shorelines such as wave height, wave frequency, and tidal crest stage have been recommended as part of the ecological performance metrics for the U.S. Department of the Interior's resilience projects funded through the Disaster Relief Recovery Act of 2013 by the Department's Metrics Expert Group (U.S. Department of the Interior Metrics Expert Group, 2015). However, wave- and current-related metrics have not been selected as the core ecological resilience metrics for assessment of living shoreline restoration. LSS such as constructed oyster reefs (referred to herein as "oyster castles") are generally thought to attenuate waves, but the biophysical processes and interaction of waves and structures across a gradient of low to high wave conditions under storms remain poorly understood. Without a better understanding of the role of LSS in reducing wave and current energy, existing living shoreline projects and adaptive management measures could not be successful, and long-term ecological benefits from LSS could not be achieved.

This study was conducted by the U.S. Geological Survey and Northeastern University in cooperation with the U.S. Fish and Wildlife Service and The Nature Conservancy. In this study, the research objectives are to (1) measure waves, currents, and sediment deposition and erosion in the salt marsh and tidal flat along the shoreline with and without LSS; (2) examine the role of LSS in wave attenuation, current change, and sediment deposition and erosion (vertically and horizontally) along the shoreline; and (3) understand the mechanisms and feedback between wave and current energy and onshore sediment dynamics with and without LSS during winter storm conditions. Specifically,

1. Do LSS attenuate onshore wave energy during the winter period significantly compared to that onshore without
LSS? What factors influence the effect of LSS on wave attenuation, transformation, and dissipation processes?

2. Do LSS change wave-induced and tidal circulation onshore behind or between structures during the winter period? What are the major factors that influence the flow field?

3. Are there any differences in marsh edge erosion (both horizontal and vertical) between shoreline with and without LSS under winter storm conditions? How will the marsh shoreline with and without LSS respond to wave- and current-induced sedimentation and erosion processes under storm conditions?

\section{Methods}

The U.S. Fish and Wildlife Service, The Nature Conservancy, the Partnership for the Delaware Estuary, New Jersey Department of Environmental Protection, Rutgers University, and other State and local agencies constructed 914 meters (m) (3,000 feet [ft]) of living shoreline and breakwater along the shoreline between Money Island Marina and Gandys Beach, New Jersey, in upper Delaware Bay (fig. 1) in 2016. The purpose was to restore salt marshes and adjacent uplands damaged by Hurricane Sandy (2012), as well as to improve the ability of the shoreline to withstand future storm surges and coastal erosion from large coastal storms. Three types of green infrastructure- oyster castles, shell bags, and coir logs-were used in the Gandys Beach/Money Island living shoreline project to retain or capture sediment to protect salt marshes (dominant species: Spartina alterniflora) from erosion. Oyster castles were mainly used as the LSS for the Gandys Beach shoreline restoration project. A premonitoring site visit of the entire living shoreline project area was conducted in July 2017 to select a representative section of the living shoreline for the field investigation on waves, currents, water levels, and sediment deposition and erosion and an elevation survey.

\section{Site Selection}

The shoreline erosion rate at the Gandys Beach project area is about $1.98 \mathrm{~m}$ per year based on historical maps (19302007) and varies with location and time period (Conrad, 2015). In the project area, shorelines are irregular and have variable orientation, elevation, mixes of salt marsh and sandy beach, and degree of vegetation fragmentation with different sizes of patches (fig. $2 A$ ).

Once $S$. alterniflora died and decayed, the roots were broken into small pieces and brought onshore by waveinduced currents (fig. 2A). Marsh scarps and gullies were observed along the shoreline in the project area (fig. $2 B$ ). The presence of gullies with marsh platform between them is a 


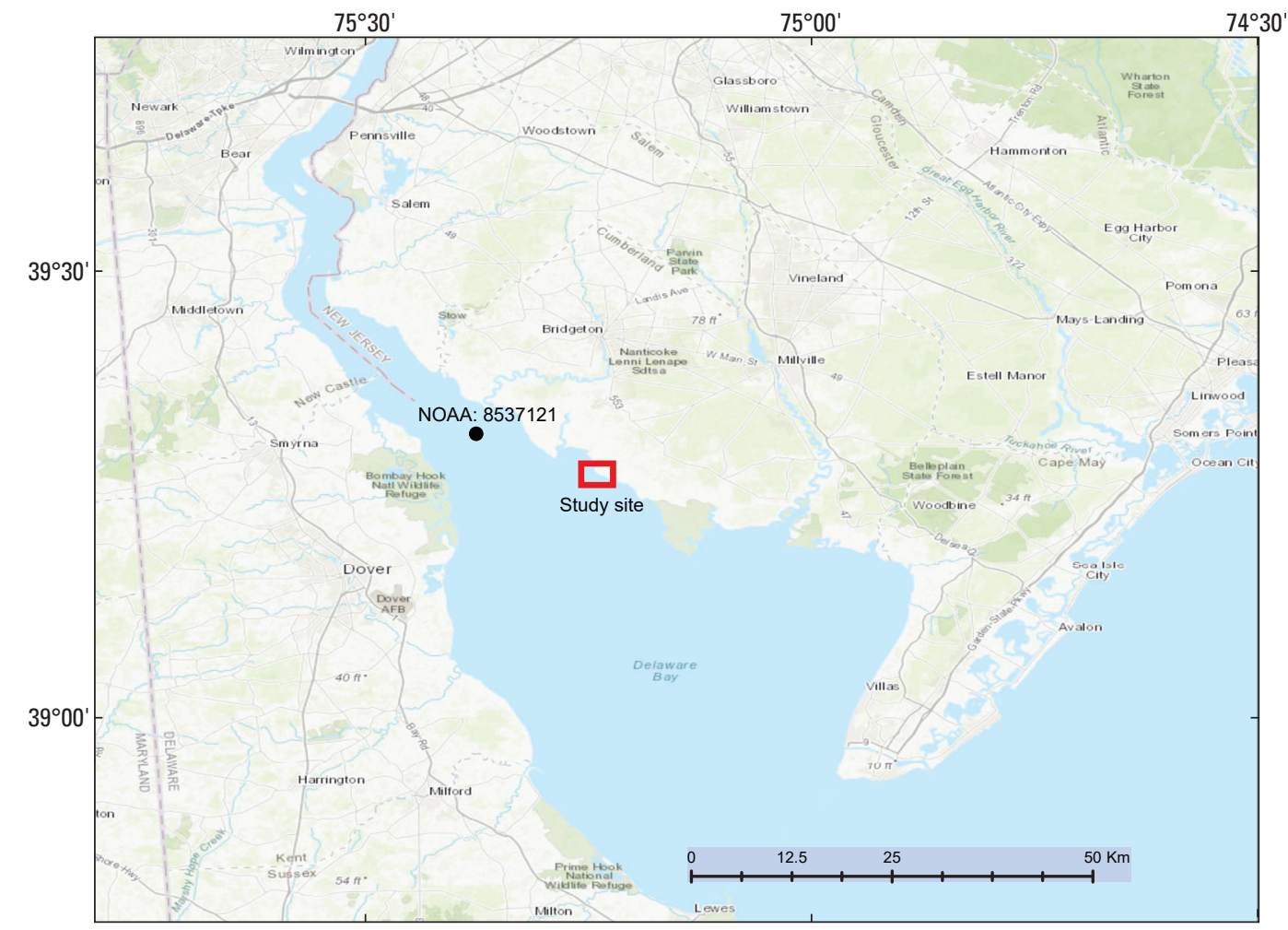

Map image is the intellectual property of Esri and is used herein under license. Copyright (C) 2020 Esri and its licensors. All rights reserved. World Geodetic System 1984.

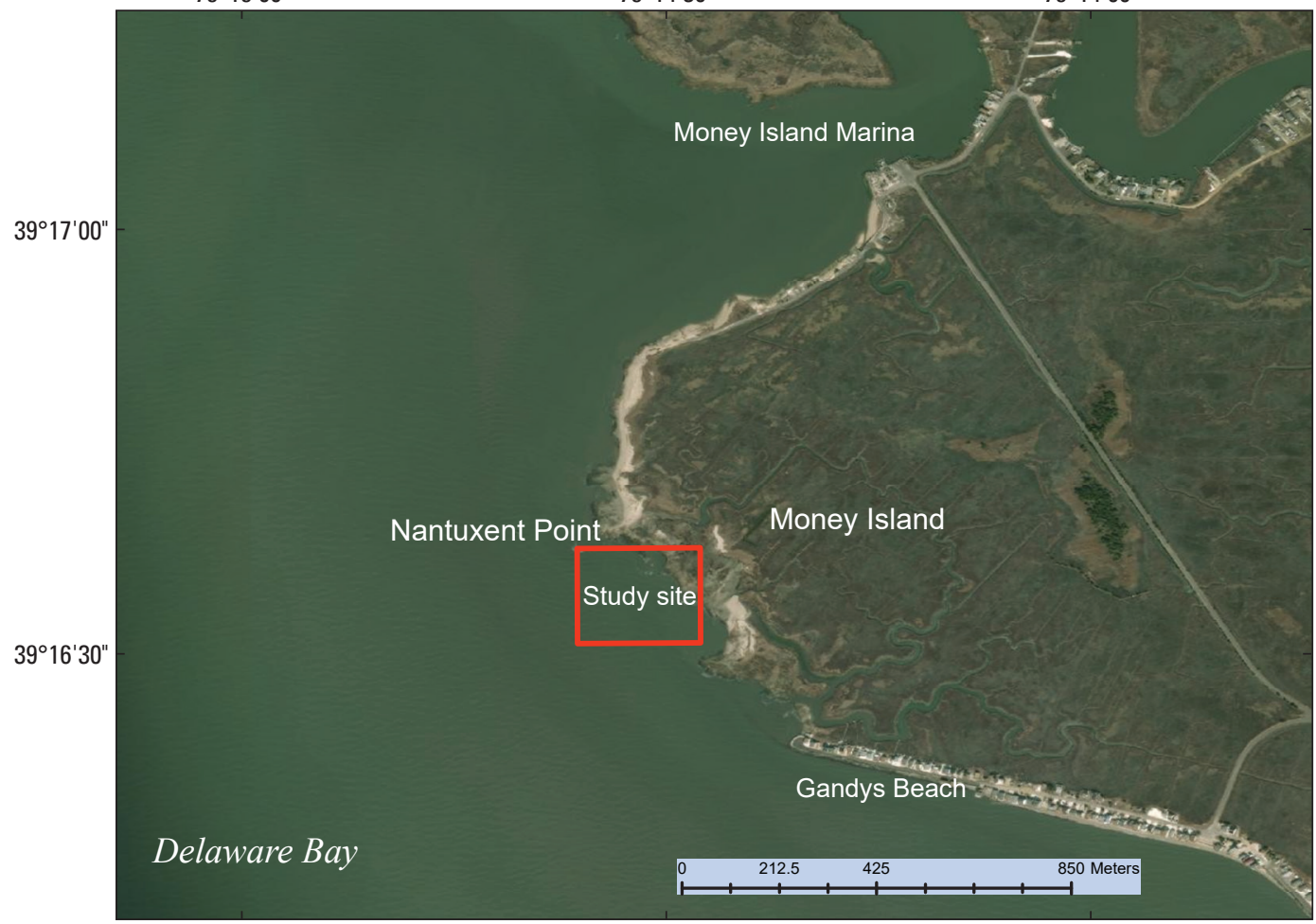

Map image is the intellectual property of Esri and is used herein under license. Copyright (C) 2020 Esri and its licensors. All rights reserved. World Geodetic System 1984.

Figure 1. Location of the Gandys Beach/Money Island living shoreline project and study site on the New Jersey side of Delaware Bay. NOAA, National Oceanic and Atmospheric Administration. 

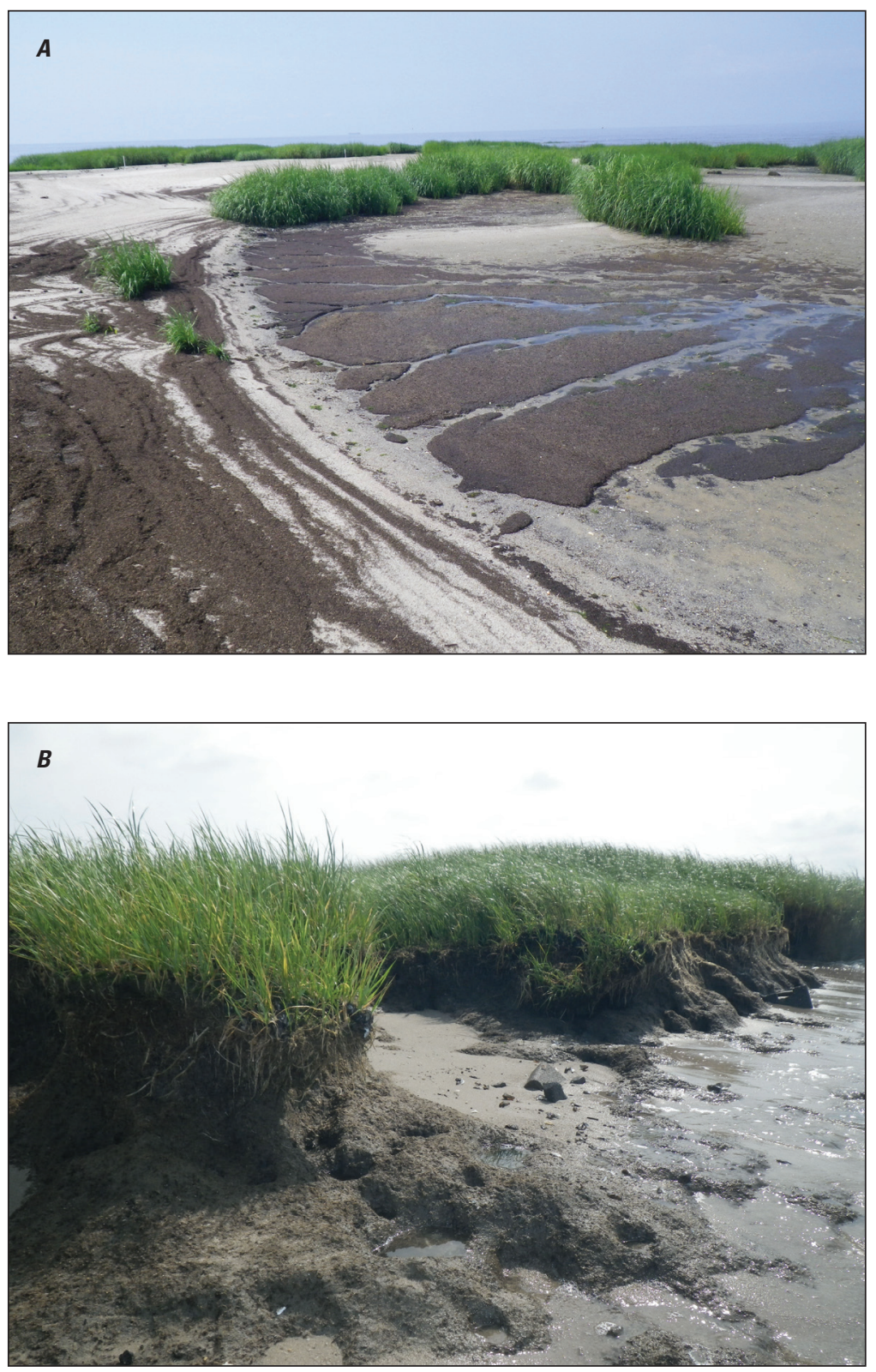

Figure 2. A, Spartina alterniflora fragmentation and root debris and $B$, edge erosion and gullies along the Gandys Beach, New Jersey, shoreline, photographed on July 14, 2017. Photographs by Hongqing Wang, U.S. Geological Survey. 
sign of fast erosion and is closely related to the concentration of incoming wave energy and relatively high bottom velocities (Priestas and Fagherazzi, 2011). Tides are predominantly semidiurnal with a mean tidal range of $1.72 \mathrm{~m}(5.63 \mathrm{ft})$ measured at a nearby National Oceanic and Atmospheric Administration tide station (8537121) in Ship John Shoal, N.J. (fig. 1).

A small cove southwest of Money Island, connecting Gandys Beach and Nantuxent Point, with oyster castles being used as the LSS was selected for field measurements of hydrodynamic forcing (waves, currents, water levels) and sediment deposition and erosion (fig. 1). The oyster castles in the study site measure about ( ) $5.5 \mathrm{~m}$ long, $\sim 1.8 \mathrm{~m}$ wide, and $\sim 0.8 \mathrm{~m}$ tall and are composed of five stacked layers. The selected study site undergoes a mesotidal range that can exceed $2 \mathrm{~m}$; the oyster castles can be fully exposed at low tide and submerged at high tide and during storms (fig. 3).

\section{Field Design}

The hypotheses for this study are (1) wave energy will be effectively attenuated by the oyster castles at mid and low tides compared with that in the control area, (2) waveinduced current velocity will be effectively reduced by the oyster castles compared with that in the control area, and (3) the marsh edge will show reduction in vertical and horizontal erosion or accumulation as a result of reduced wave-induced bed shear stress (erosive force) by the oyster castles. To test these hypotheses, two transects were established: an oyster castle transect (transect 1) and a control transect (transect 2) (fig. 4). Along the oyster castle transect, hydrodynamic forcing (waves, currents, water levels) was monitored offshore, nearshore (in front of the castles or in the gaps between the castles for current), and onshore (behind the castles). The hydrological forcing at locations with similar elevation/ bathymetric data as the oyster castle transect nearshore and onshore was simultaneously monitored along the control transect (fig. 4).

\section{Field Deployment and Retrieval}

Sensors for the hydrodynamic forcing (waves, current, water level) and instruments for sedimentation were deployed during January 29-February 2, 2018. The retrieval of the sensors and instruments was conducted during April 2-6, 2018. A check-up visit was conducted 1 month after deployment. During the study period, four winter storms (nor'easters) occurred: Riley on March 2, Quinn on March 7, Skylar on March 14, and Toby on March 21.

Six pressure transducers (or wave gages [WGs], Ocean Sensors Systems Inc., OSSI-010-003C) were deployed: WG1, WG3, WG5, and WG6 were placed along the oyster castle transect, whereas WG2 and WG4 were installed along the control transect (figs. 4A, 5A). WG2 and WG4 had similar elevations as WG6 and WG5, respectively; therefore, similar wave characteristics are expected and can be used to reflect the effects of the oyster castles. These WGs were sampled continuously at 10 hertz $(\mathrm{Hz})$ to take 20-minute ( $\mathrm{min}$ ) bursts every $30 \mathrm{~min}$ to measure water depth and wave heights and periods.

Seven tilt current meters (TCMs, Lowell Instruments LLC, six long TCMs, range of $0-80 \mathrm{~cm} / \mathrm{s}$, and one short TCM [TCM7], range of $0-75 \mathrm{~cm} / \mathrm{s}$ ), consisting of a tiltcorrected compass in a buoyant casing and attached to a concrete tile at the sediment surface, were installed around the oyster castles and along the two transects to measure the flow velocity and direction offshore and nearshore with and without the oyster castles during the two winter months (figs. 4A, 5B). One TCM (TCM3), placed between WG6 and WG2 to represent current conditions nearshore, went missing during the storms; therefore, TCM5 was used to examine the hydrodynamic conditions incoming from offshore to both the oyster castles and the shoreline in the control area, where the current conditions were monitored by TCM1 (fig. 4A). These TCMs were also sampled at $10 \mathrm{~Hz}$ with 20 -min bursts every $30 \mathrm{~min}$. Sensors' coordinates and elevation were measured by using Global Positioning System (GPS) receivers during the deployment. Additionally, the dimensions of the oyster castles (height, weight, and length), the gaps between the castles, and the topography and bathymetry in the study area were collected during the deployment, checkup, and retrieval by using a Static Global Navigation Satellite System survey with a horizontal accuracy of plus or minus $( \pm) 0.015 \mathrm{~m}$ $(0.05 \mathrm{ft})$ and a vertical accuracy of $\pm 0.03 \mathrm{~m}(0.10 \mathrm{ft})(\mathrm{fig} .5 \mathrm{C})$. Offshore WGs and TCMs were deployed by boat.

Sediment accumulation on marsh surface and in the

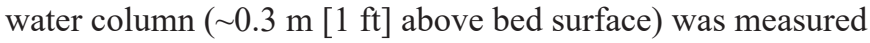
by the sediment pin/trap set approach (Chen and others, 2016; Nolte and others, 2019). The sediment pin/trap set was constructed by using a 1.25 -inch-diameter polyvinyl chloride (PVC) pipe (3 $\mathrm{m}[10 \mathrm{ft}]$ long) that is attached with a 4-inch-diameter PVC round snap-in drain with an opening for trapping settled suspended sediment. Eight sediment pin/trap sets were placed in the study area: four in marsh and mudflat area behind the oyster castles and four in marsh and mudflat area in the control area (figs. $4 B, 5 D$ ). The pin/trap sets were pushed down 0.91-1.22 $\mathrm{m}(3-4 \mathrm{ft})$ into the sediment, and the trap surface was measured at $\sim 0.3 \mathrm{~m}(1 \mathrm{ft})$ above bed surface. The coordinates of the pin/trap set were measured using GPS, and the elevation of the top of the traps was surveyed during deployment and retrieval to determine if any substantial land subsidence occurred during the 2 months of monitoring. During deployment and retrieval, the distances from the pin top to sediment surface were measured at three directions (north, south, and west; the trap was to the pin's east) so that the vertical sedimentation during the 2-month monitoring could be determined by subtracting the distance measured in deployment from the distance measured in retrieval: positive values indicating erosion and negative values indicating accretion. 

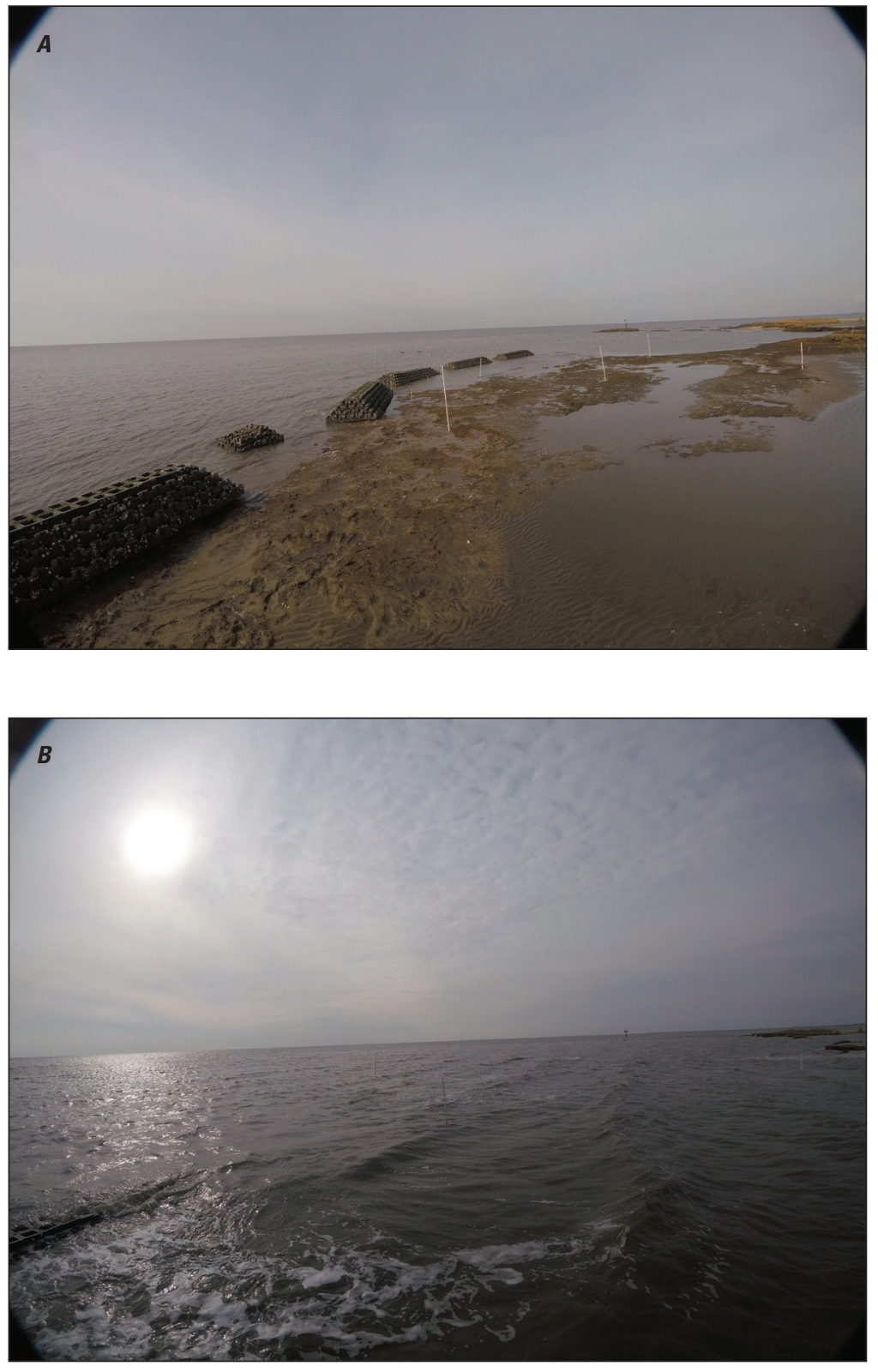

Figure 3. Oyster castles in the Gandys Beach, New Jersey, living shoreline project area $A$, exposed at low tide (Feb. 9, 2018, 10:30 a.m., with water level of -0.7784 meters, referenced to North American Vertical Datum of 1988 [NAVD 88]) and $B$, submerged at high tide (Feb. 9, 2018, 2:30 p.m., with water level of 0.3099 meters, NAVD 88). Photographs were taken using GoPro HER05 session camera. 


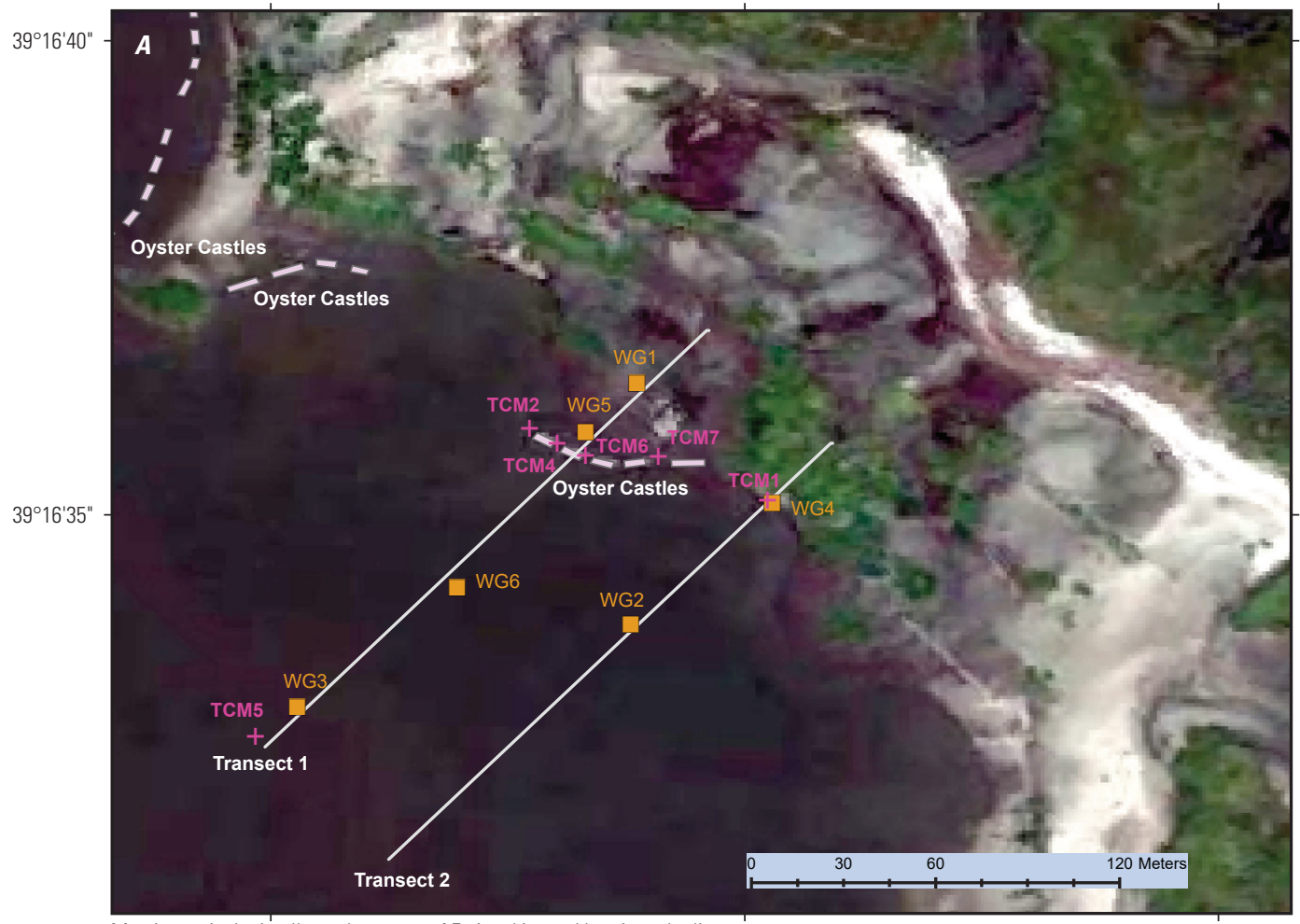

Map image is the intellectual property of Esri and is used herein under license. Copyright (C) 2020 Esri and its licensors. All rights reserved. World Geodetic System 1984

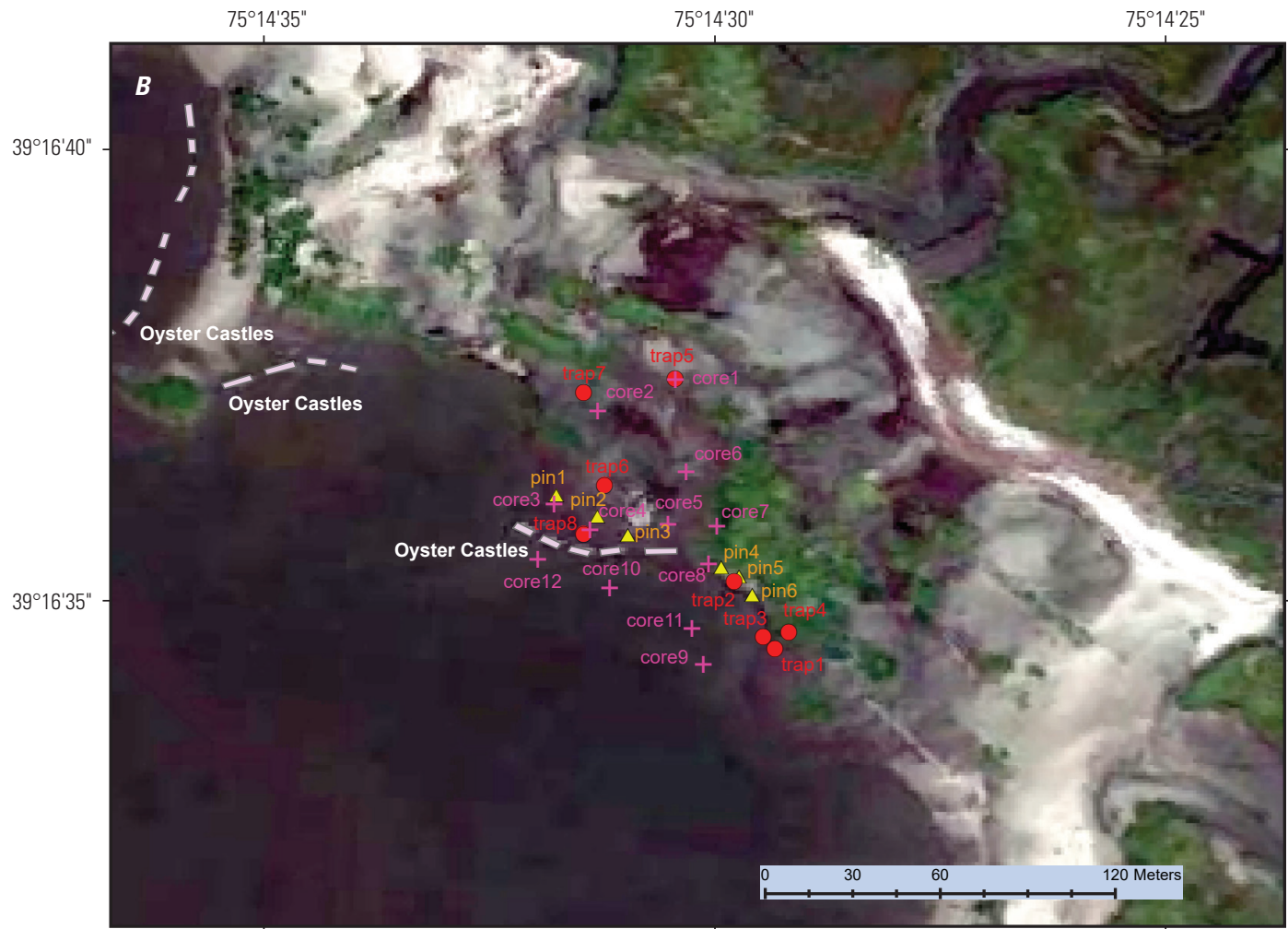

Map image is the intellectual property of Esri and is used herein under license. Copyright (c) 2020 Esri and its licensors. All rights reserved.

World Geodetic System 1984

Figure 4. Locations of $A$, wave gages (WG) and tilt current meters (TCM) and $B$, sediment trap/pin sets (trap), marsh edge erosion pins (pin), and marsh and mudflat sediment cores (core) along the Gandys Beach, New Jersey, living shoreline. 

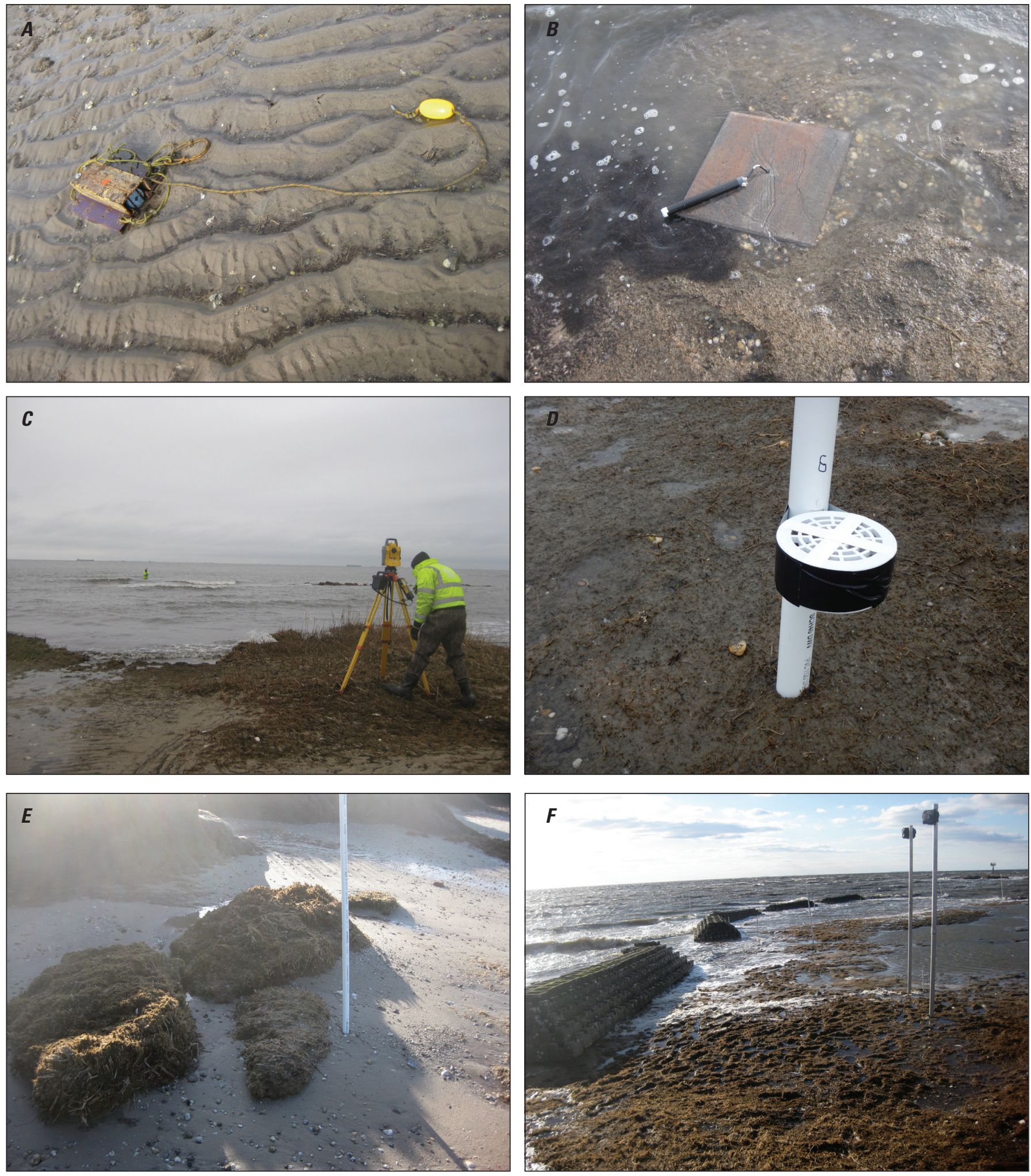

Figure 5. $A$, Wave gage, $B$, tilt current meter, $C$, elevation survey using Static Global Navigation Satellite System, $D$, sediment pin/trap set, $E$, marsh edge erosion pin, and $F$, GoPro HERO5 session cameras deployed in the oyster castle transect and in the control area in the Gandys Beach, New Jersey, living shoreline study area. Photographs by Hongqing Wang, U.S. Geological Survey. 
Six marsh edge erosion pins (1.25-inch-diameter PVC pipes) were placed in the study area to measure any marsh edge horizontal erosion during the 2-month monitoring period: three at marsh edge behind the oyster castles and three at marsh edge in the control area (figs. $4 B, 5 E$ ). These pins were installed next to identified marsh edge and were pushed down

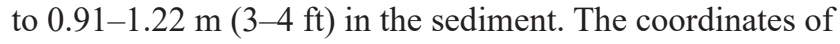
these marsh edge erosion pins were measured by using GPS. During the retrieval, the distances from marsh edge to pins were measured in three directions $(45,90$, and 225 degrees from marsh edge) to determine if marsh edge erosion occurred during the monitoring period. If marsh edge undercut was observed, the undercut distances from the marsh edge erosion pins were also measured.

During retrieval, a total of 12 sediment cores to a depth of $10 \mathrm{~cm}$ were also collected using a 1-inch-diameter soil corer in front of and behind the oyster castles (six cores) and in the control area (six cores) to determine any variation in sediment grain size distribution due to the protection of the oyster castles (fig. 4B). In addition, six 500-milliliter bottles of water samples (two collected from in front of the castles, two from behind the castles, two from the control area) were collected to measure the salinity and total suspended solid (TSS) concentration. The samples of the sediment traps, marsh cores, and water bottles collected during retrieval were shipped to the laboratory at the U.S. Geological Survey Lower Mississippi-Gulf Water Science Center for analyses on sediment mass, grain size distribution, salinity, and TSS by using the standard methodology (Guy, 1969). Two GoPro HERO5 session cameras (fig. $5 F$ ) were placed in the study site, one facing the oyster castles and one facing the control area, to take time-lapse photographs at 30-min intervals during daytime (7:00 a.m. to 5:00 p.m.) to show the wave and current dynamics during the 2-month winter period.

\section{Data Processing}

\section{Wave Data}

All wave data are published in a companion data release (Wang and others, 2020). The recorded water pressure ( $\left.\dot{p}^{\prime}\right)$ by the WGs consists of hydrostatic pressure, dynamic pressure, and atmospheric pressure. The raw water pressure data were converted to desired wave parameters by the following protocol. Firstly, the raw water pressure data were corrected by taking into account the instrument offset and atmospheric pressure, which are the differences between (1) the mean of the first or last several bursts of measurements (when instruments were exposed to air) and (2) the atmospheric pressure at the site during the corresponding time. The instrument offsets for all six WGs are listed in table 1.
Table 1. A summary of the instrument offsets for the six wave gages deployed in the Gandys Beach, New Jersey, living shoreline study area during February to April 2018.

[WG, wave gage; kPa, kilopascal]

\begin{tabular}{lclc}
\hline \multicolumn{1}{c}{ Wave gage } & $\begin{array}{c}\text { Offset } \\
(\mathbf{k P a})\end{array}$ & Wave gage & $\begin{array}{l}\text { Offset } \\
(\mathbf{k P a})\end{array}$ \\
\hline WG1 (precheck) & -100.00 & WG4 & -99.81 \\
WG2 & -101.31 & WG5 & -101.61 \\
WG3 & -101.17 & WG6 & -100.77 \\
\hline
\end{tabular}

Secondly, the corrected absolute pressure data $(\dot{p})$ was converted to gage pressure $(p)$ by subtracting the atmospheric pressure $\left(p_{a t m}\right)$ during the deployment as $p=\dot{p}-p_{\text {atm }}$. This gage pressure consists of the combination of hydrostatic pressure and dynamic wave pressure. This gage pressure was then translated to water depth $(h)$ as $h=p / \rho g$, where $\rho$ $\left(=1,014 \mathrm{~kg} / \mathrm{m}^{3}\right)$ is the seawater density, and $g\left(=9.81 \mathrm{~m} / \mathrm{s}^{2}\right)$ is the gravitational acceleration.

Thirdly, each burst of water depth was converted to free surface elevation based on linear wave theory and transformed to a wave energy spectrum through the Ocean Wave Analyzing Toolbox, OCEANLYZ (Karimpour and Chen, 2017). The key parameters in OCEANLYZ were set as below:

- NFFT for Fast Fourier Transform: $2^{14}$.

- Minimum frequency that swell can have: $0.04 \mathrm{~Hz}$.

- Maximum frequency that swell can have: $0.28 \mathrm{~Hz}$.

- Calculate a maximum frequency for applying pressure attenuation factor based on the water depth.

- Cut off spectrum below $0.04 \mathrm{~Hz}$.

- Cut off spectrum above $3 \mathrm{~Hz}$.

\section{Current Data}

All current data are published in a companion data release (Wang and others, 2021). The raw TCM data were downloaded using the MAT Logger Commander provided by Lowell Instruments LLC. Data for March 2-18 were missing for TCM2 and TCM4 (fig. 6) because these TCM anchors flipped during Nor'easter Riley. The raw measurements contain data that were recorded when the TCMs were not completely submerged or data that were beyond the recommended range. Therefore, the raw data needed to be further processed as described in the "Data Analysis" section. 
$\boldsymbol{A}$

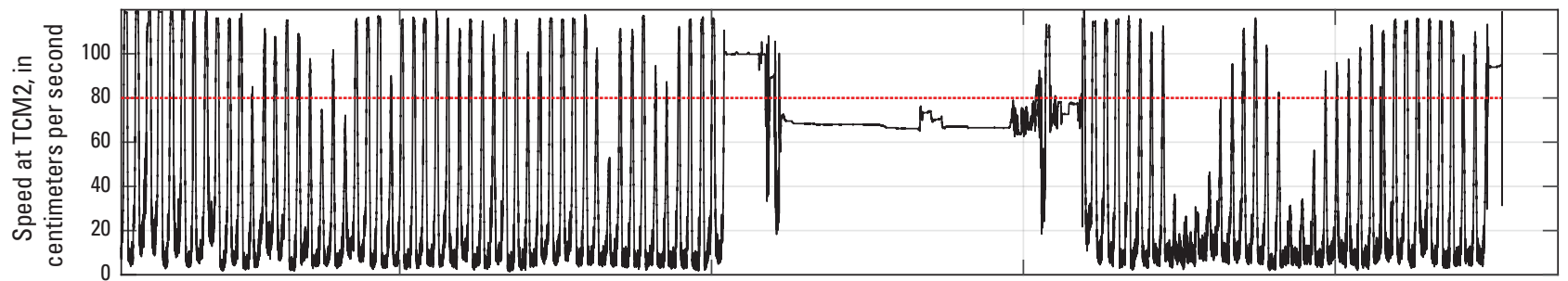

B

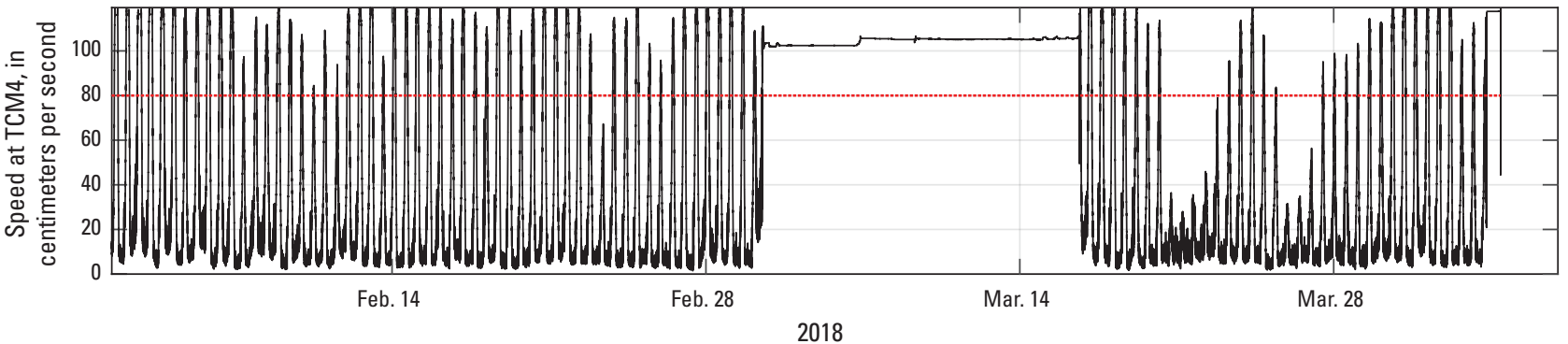

Figure 6. Time series of raw data from $A$, tilt current meter (TCM) 2 and $B$, TCM4, February to April 2018, in the Gandys Beach, New Jersey, living shoreline study area. Red lines show the recommended upper limit ( 80 centimeters per second) for accurate TCM reading.

\section{Data Analysis}

\section{Wave Characteristics}

From the wave energy spectrum $\left(S_{\eta \eta}\right)$, we can extract bulk wave characteristics such as zero-moment wave height $\left(H_{m 0}\right)$ and peak wave period $\left(T_{p}\right)$, respectively, by following equations as below:

$$
\begin{aligned}
& H_{m 0}=4 \sqrt{m_{0}}=4 \sqrt{\int_{f_{\text {min-cutoff }}}^{f_{\text {max-cutoff }}} S_{\eta \eta}(f) d f} \text { and } \\
& T_{p}=\frac{1}{f_{p}}
\end{aligned}
$$

where

$$
\begin{aligned}
& m_{0} \quad \text { is the zeroth moment of the wave energy } \\
& \text { spectrum, } \\
& f_{\text {min-cutoff }} \quad \text { is the minimum cutoff frequency, } \\
& f_{\text {max-cutoff }} \text { is the maximum cutoff with the maximum } \\
& \text { cutoff frequency, } \\
& f \quad \text { is the frequency, and } \\
& f_{p} \quad \text { is the peak frequency that is associated with } \\
& \text { the maximum value of } S_{\eta \eta}(f) \text {. }
\end{aligned}
$$

The OCEANLYZ toolbox allows partitioning of the wind sea and swell energies by following the method outlined in Hwang and others (2012). A separation frequency $\left(f_{\text {sep }}\right)$ is outputted together with $S_{\eta \eta}(f)$ from OCEANLYZ. In the wave energy spectrum, wave signals with $f$ less than $(<) f_{\text {sep }}$ are considered as swells, whereas wave signals with $f$ greater than $(>) f_{\text {sep }}$ are considered as wind seas. The maximum frequencies in the swell and wind sea portion of $S_{\eta \eta}(f)$ are denoted as $f_{p, s w e l l}$ and $f_{p, s e a}$, respectively. Accordingly, the peak swell period $\left(T_{p, s w e l l}\right)$ and peak wind sea period $\left(T_{p, \text { sea }}\right)$ are defined, respectively, as below:

$$
T_{p, \text { swell }}=\frac{1}{f_{p, \text { swell }}} \text { and } T_{p, \text { sea }}=\frac{1}{f_{p, \text { sea }}}
$$

The swell zero-moment wave heights $\left(H_{m 0, \text { swell }}\right)$ and wind sea zero-moment wave heights $\left(H_{m 0, \text { sea }}\right)$ are computed, respectively, as below:

$$
\begin{aligned}
& H_{m 0, \text { swell }}=4 \sqrt{\int_{f_{\text {min-cutoff }}}^{f_{\text {sep }}} S_{\eta \eta}(f) d f} \text { and } \\
& H_{m 0, \text { sea }}=4 \sqrt{\int_{f_{\text {sep }}}^{f_{\text {max-cutoff }}} S_{\eta \eta}(f) d f}
\end{aligned}
$$

\section{Current Patterns}

The TCM is designed for sites with low wave energy. The TCM is more accurate in relatively protected environments, such as protected harbors and coves, or deployed at least twice the wave height below the surface. Moreover, the TCM provides accurate current measurements only when it is completely submerged. TCM1 and the nearby WG4 are located in the shallowest water, a condition of $h_{W G 4}-2 H_{m o, W G 4}$ $>l_{T C M}$ (where $h_{W G 4}$ and $H_{m 0, W G 4}$ are the water depth and zeromoment wave height at WG4, respectively). $l_{T C M}$ is the TCM height. In this study, $l_{T C M}=0.76 \mathrm{~m}$ is employed to filter out inaccurate TCM measurements for all TCMs (fig. 7A) 
$\boldsymbol{A}$

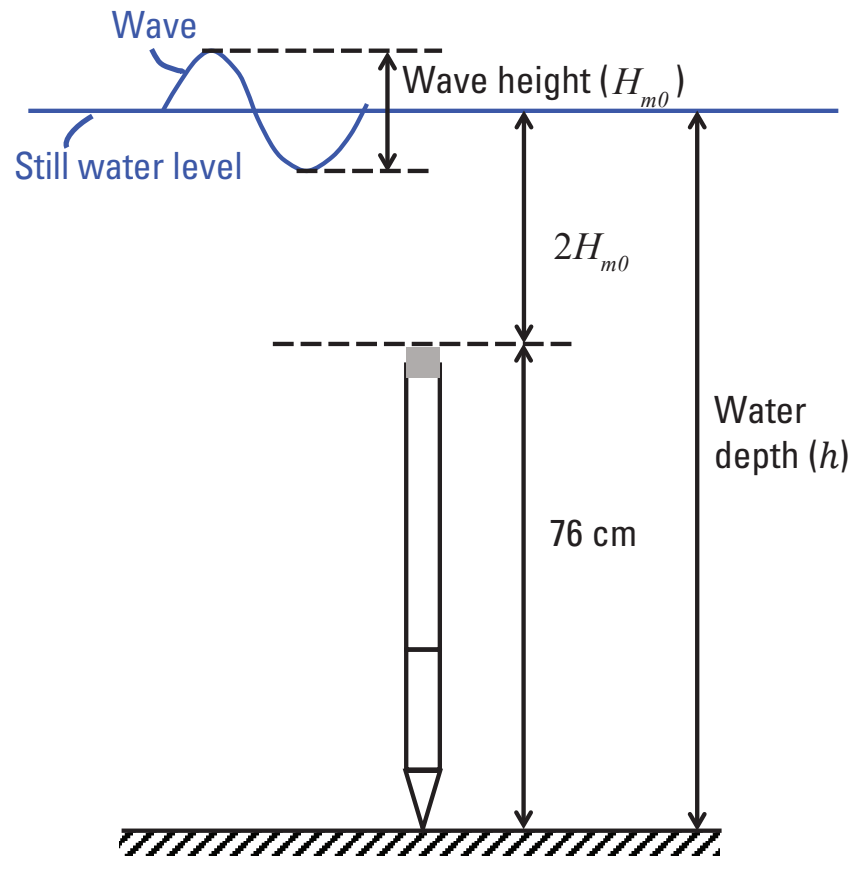

B

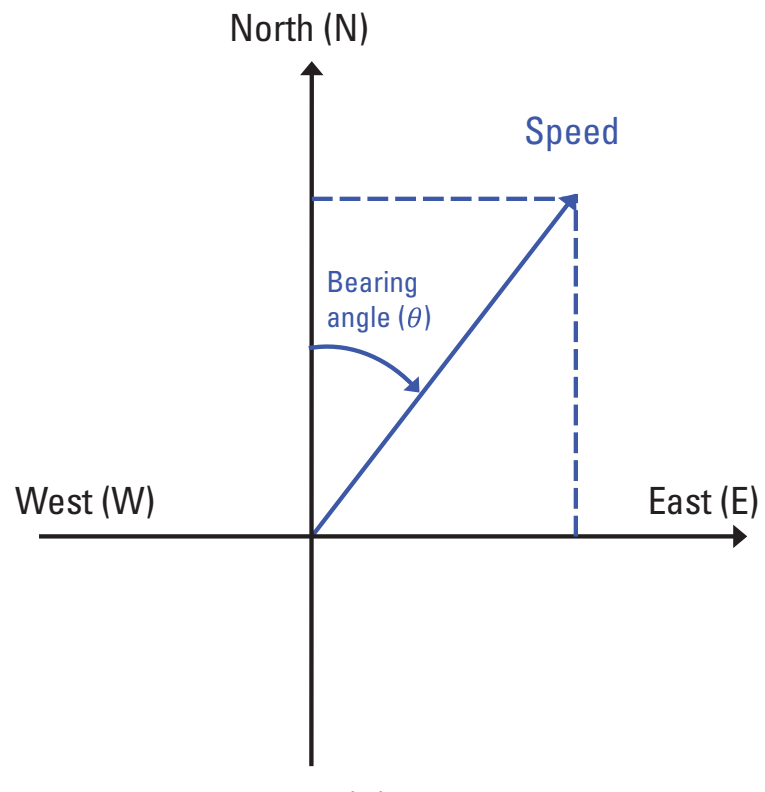

South (S)

Figure 7. A, A completely submerged tilt current meter, and $B$, the relation between current speed and bearing angle.

The following procedures were carried out to process the raw current data:

1. Time-averaging the raw current data over 20 minutes.

2. Capping the time-averaged data with $80 \mathrm{~cm} / \mathrm{s}$, which is the recommended upper limit for accurate TCM measurements.

3. Filtering the capped time-averaged data by using $h_{W G 4}$ $-2 H_{m 0, W G 4}>0.76 \mathrm{~m}$.
The bearing angle $(\theta)$ is defined as the angle relative to the north velocity component (fig. $7 B$ ). In this study, the flood and ebb tides are defined on the basis of the current directions at TCM5. The mean current speeds and directions during flood and ebb tides were calculated at all TCMs. Considering the orientation of Delaware Bay, the flood and ebb currents at the most offshore TCM location, TCM5, have relatively uniform bearing angles $(\theta)$ of $330^{\circ}$ and $150^{\circ}$, respectively (fig. 8). The current vectors are scaled by a factor of 0.2 to avoid overlapping vectors.

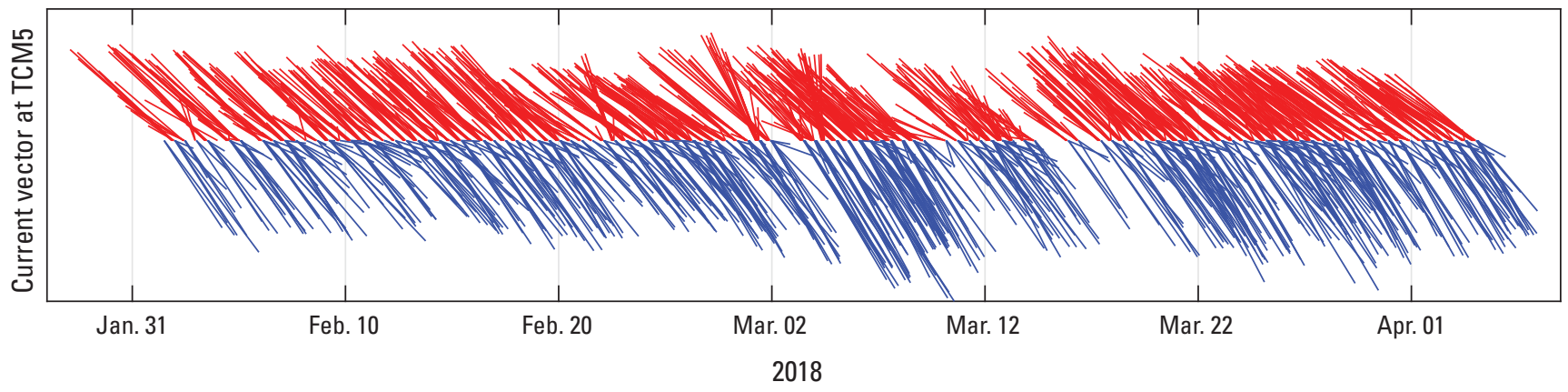

Figure 8. Time series of current vector at tilt current meter (TCM) 5, February to April 2018, in the Gandys Beach, New Jersey, living shoreline study area (red vectors correspond to the flood tides, and blue vectors correspond to the ebb tides). 


\section{Results}

\section{Wave Characteristics}

The temporal variations of water depth, water level, zeromoment wave height, and peak wave period at the six WGs are shown in figures 9-11. The large fluctuations in the water depth reflect the large tidal range at the study site. Figure 12 shows the wave action with water level at the oyster castles at 9:00, 9:30, 10:00, and 11:00 a.m. on February 5, 2018. From field measurements of water depth and wave height at these WG locations, a strong relation between water depth and wave height can be observed, suggesting that wave attenuation is water depth dependent.

Previous studies also indicated the decreasing wave attenuation with increasing water depth (for example, Ysebaert and others, 2011; Chowdhury and others, 2019). Comparisons of the zero-moment wave heights between different gage locations are provided in figure $13 A-F$. In this study, it was found that the wave height variations have a strong dependence on the ratio between the crest freeboard $\left(R_{c}\right)$ and the offshore wave heights measured at WG3 (that is, $R_{c} / H_{m 0}$, $\left.{ }_{W G 3}\right) \cdot R_{c} / H_{m 0, W G 3}$, combining wave properties and structure characteristics, is a good indicator for LSS attenuation capacity (for example, Wiberg and others, 2019; Zhu and others, 2020). At low tides with $R_{c}>-1.6 H_{m 0, W G 3}$, the oyster reefs are emergent or slightly submerged. From WG3 to WG5 (fig. 4A), most of the wave energy is blocked by the oyster reefs. Wave breaking and wave reflection lead to wave height decay by an average rate of 41 percent as shown by the orange circles in figure $13 A$. Waves are further attenuated from WG5 to WG1 (figs. $4 A, 13 B$ ) because of (1) the increased bottom friction from the mud and the roots of plants and (2) further wave breaking caused by the shallow water depth at WG1. Overall, waves undergo an average of 51-percent reduction in wave height from WG3 to WG1 at low-tide conditions (fig. 13C).

Under mid-tide and high-tide conditions with $R_{c}<$ $-1.6 H_{m 0, W G 3}$, the oyster reefs are fully submerged, and a considerable amount of wave energy can transmit over the reefs. In general, wave height variations from WG3 to WG5 range from 35-percent reduction to 70-percent increase as shown in figure $13 D$. From WG5 to WG1, waves with small wave heights are prone to shoaling, but much of the wave action is further attenuated by an average reduction rate of 13 percent (fig. $13 E$ ). Overall, for waves with large wave heights, there is a tendency of wave attenuation from WG3 to WG1 by the oyster castles. However, for waves with small wave heights, both wave height amplification and reduction could occur. Wave breaking (for example, Thornton and
Guza, 1983) and wave shoaling (for example, Kamphuis, 2010) are concurrent, leading to both wave attenuation and wave amplification from WG3 to WG5. Moreover, wave focusing/defocusing (for example, Kamphuis, 2010) due to bathymetric change plays a role in the wave height variation. The area around WG5 becomes a small headland under midtide and high-tide conditions. The wave propagation paths (or wave rays) bend around this headland, causing wave energy concentration (or wave focusing), and thus, the wave heights get increased at WG5 (Zhu and others, 2020).

The wave directions at the study site were not measured. However, the wave height variations shown in figure $13 A-F$ are consistent in different wind quadrants as shown in figure $14 A-D$.

The relation between the relative freeboard (defined as $R_{c} / H_{m 0, W G 3}$ ) and the wave height transmission coefficient (defined as $K_{t}=H_{m 0, W G 5} / H_{m 0, W G 3}$ ) from the study site is consistent with the empirical relations proposed in d'Angremond and others (1996) and van der Meer and others (2005). On the basis of a large collection of 2,337 laboratory experiments of low-crested breakwaters, van der Meer and others (2005) improved the empirical formula of transmission coefficient for permeable breakwaters from d'Angremond and others (1996). For a relative crest width (defined as $\left.B_{0}=B / H_{m 0, W G 3}\right)$ less than 10 , the empirical formula from d'Angremond and others (1996) listed as below is more accurate:

$$
K_{t}=-0.4 \frac{R_{c}}{H_{i}}+0.64\left(\frac{B}{H_{i}}\right)^{-0.31}\left(1-e^{-0.5 \xi}\right)
$$

where

$$
\begin{gathered}
H_{i} \quad \text { is the incident significant wave height, and } \\
\xi \quad \text { is the breaker parameter }\left(\xi=\tan \alpha / S_{o p}^{0.5},\right. \\
\text { with } \tan \alpha=\text { seaward slope of structure, } \\
\text { and } S_{o p}=2 \pi H_{i} /\left(g T_{p}^{2}\right)=\text { wave steepness). }
\end{gathered}
$$

This empirical formula has a 90-percent confidence band of $K_{t} \pm 0.10$ (d'Angremond and others, 1996). For relative crest width $B_{0}>10$, the empirical formula from van der Meer and others (2005) is listed as follows:

$$
K_{t}=-0.35 \frac{R_{c}}{H_{i}}+0.51\left(\frac{B}{H_{i}}\right)^{-0.65}\left(1-e^{-0.41 \xi}\right)
$$

The upper and lower limits of $K_{t}$ in equations 4 and 5 are $K_{t, \text { upper }}=-0.006 \mathrm{~B} / \mathrm{H}_{i}+0.93$ and $K_{t, \text { lower }}=0.05$, respectively (van der Meer and others, 2005). 

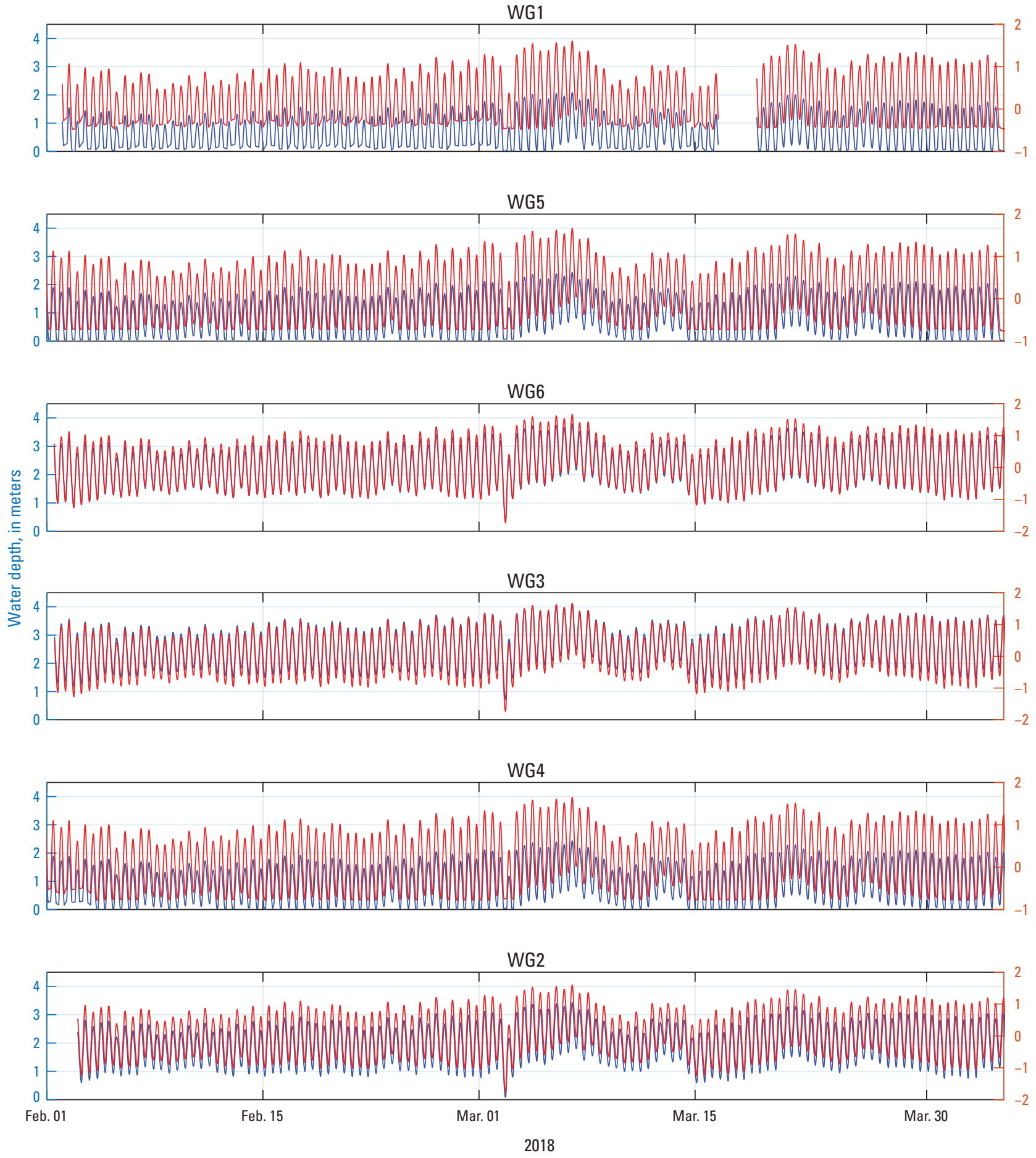

Figure 9. Time series of water depth and water level measured at six wave gages (WG), February to April 2018, in the Gandys Beach, New Jersey, living shoreline study area. 

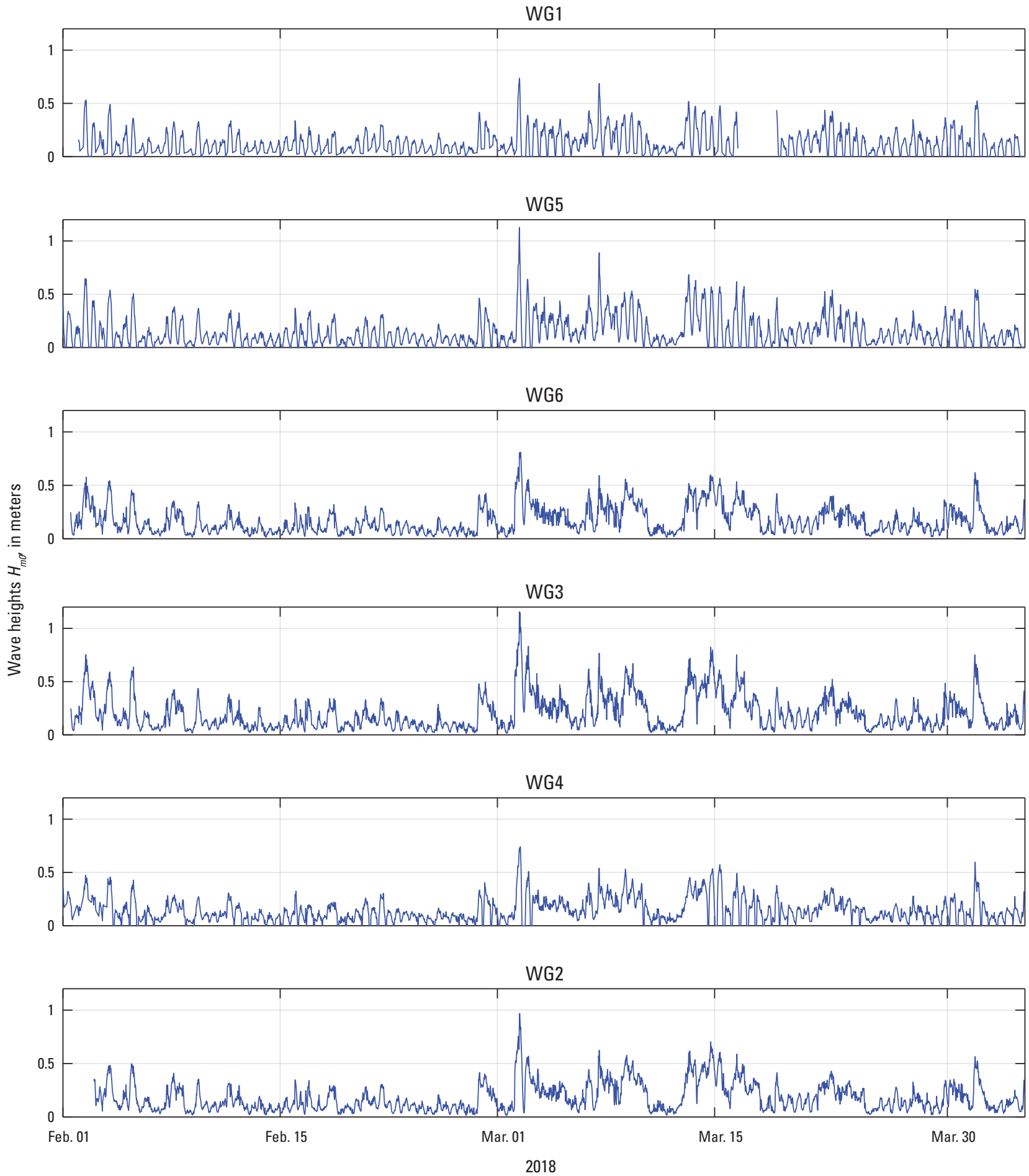

Figure 10. Time series of zero-moment wave heights measured at six wave gages (WG), February to April 2018, in the Gandys Beach, New Jersey, living shoreline study area. 
WG1

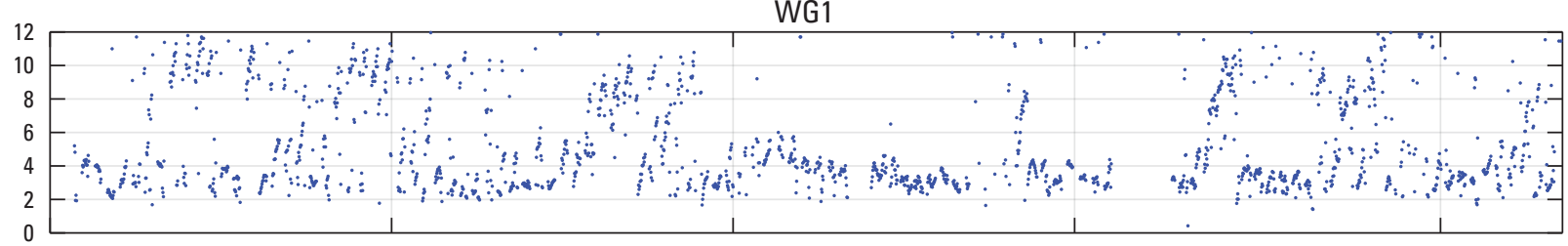

WG5
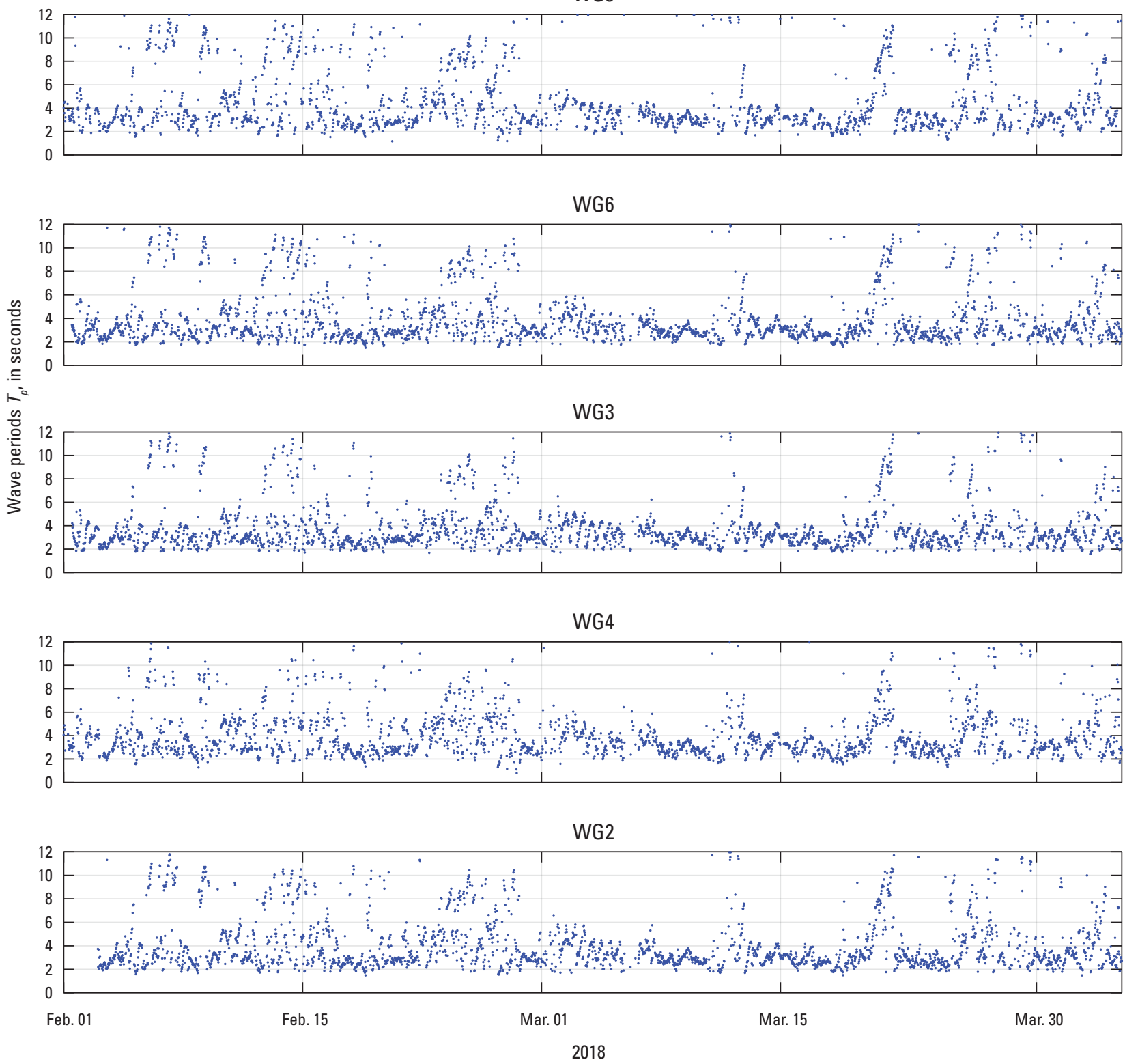

Figure 11. Time series of peak wave periods measured at six wave gages (WG), February to April 2018, in the Gandys Beach, New Jersey, living shoreline study area. 
Feb. 5, 2018
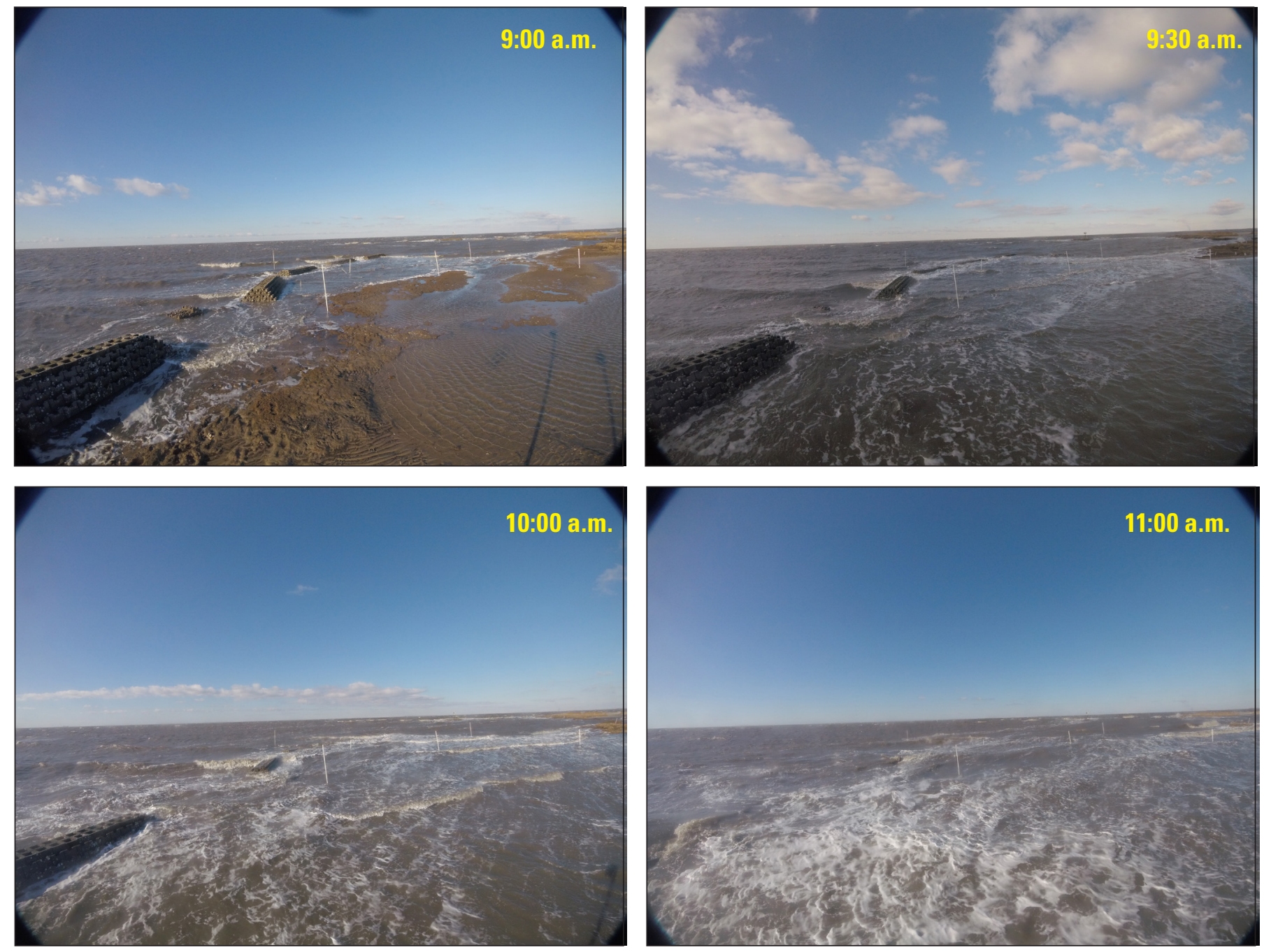

Figure 12. Wave action with water level at the oyster castles in the Gandys Beach, New Jersey, living shoreline study area at 9:00, 9:30, 10:00, and 11:00 a.m. on February 5, 2018. Photographs were taken using GoPro HER05 session cameras. 

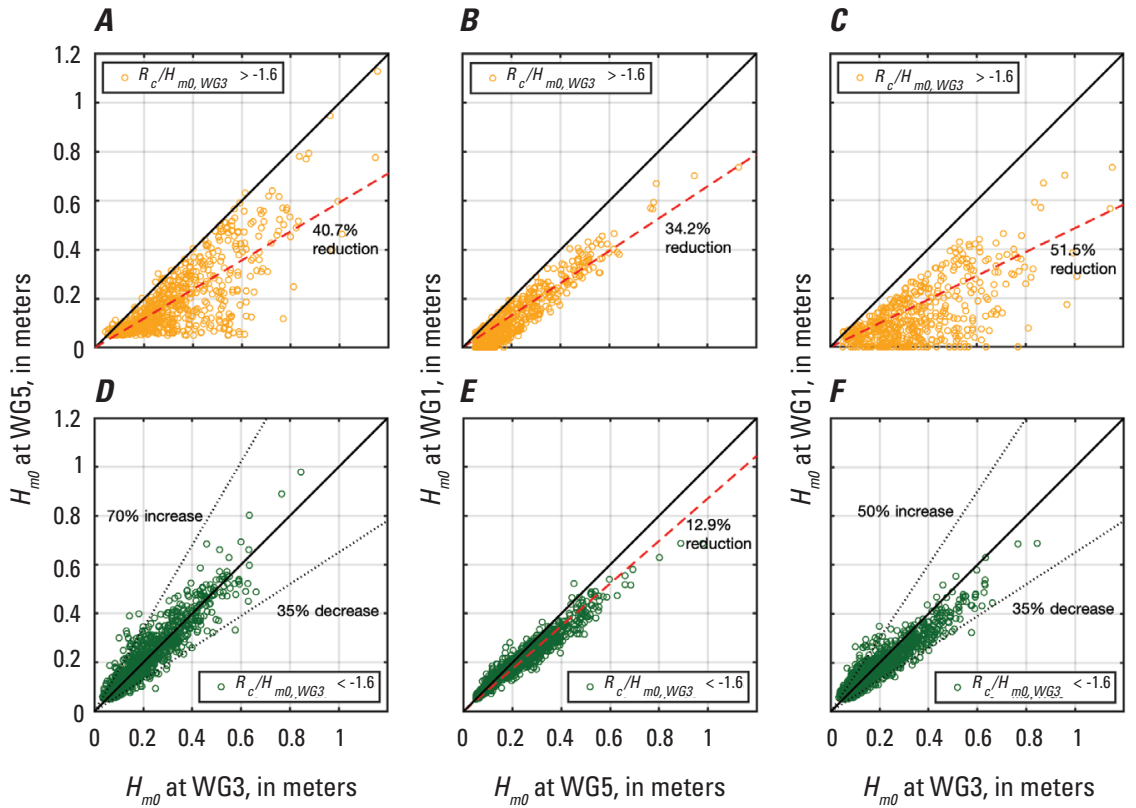

Figure 13. Intergage comparisons of zero-moment wave heights in the Gandys Beach, New Jersey, living shoreline study area during February to April 2018. $A$, Between WG3 and WG5, $B$, between WG1 and WG5, $C$, between WG1 and WG3 under $R_{c} / H_{m 0, W G 3}>-1.6$, $D$, between WG3 and WG5, $E$, between WG1 and WG5, $F$, between WG1 and WG3 under $R_{c} / H_{m 0, W G 3}<-1.6$.

$\boldsymbol{A}$

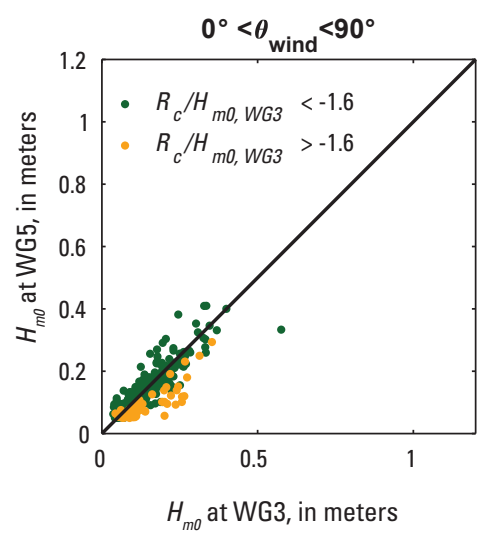

$B$

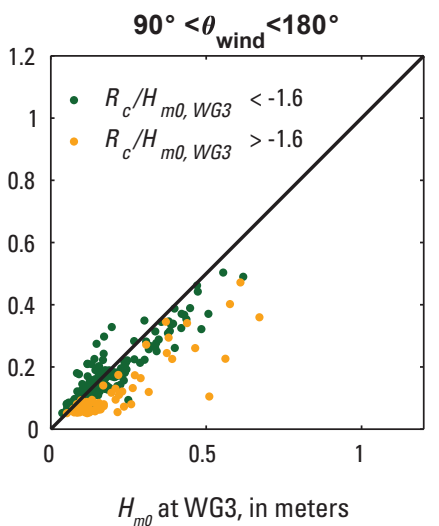

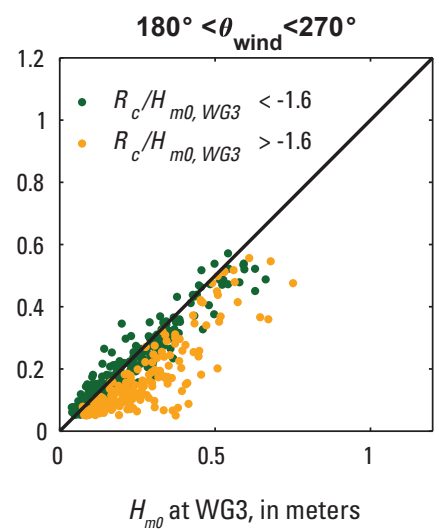

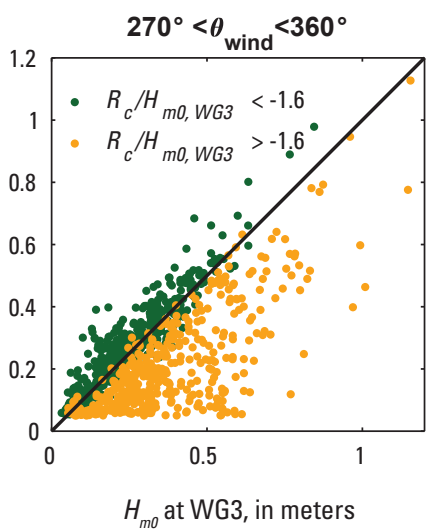

Figure 14. Comparisons of zero-moment wave heights at wave gage (WG) 3 and WG5 in four wind quadrants in the Gandys Beach, New Jersey, living shoreline study area. $A, 0^{\circ}<{ }^{\circ} \theta_{\text {wind }}<90^{\circ}, B, 90^{\circ}<{ }^{\circ} \theta_{\text {wind }}<180^{\circ}, C, 180^{\circ}<{ }^{\circ} \theta_{\text {wind }}<270^{\circ}, D, 270^{\circ}<{ }^{\circ} \theta_{\text {wind }}<360^{\circ}$. 
The measured $K_{t}$ and $K_{t}$ calculated from equations 4 and 5 are shown in figure 15 . For slightly submerged oyster reefs with $-1.6<R_{c} / H_{i}<0$, the measured $K_{t}$ fits the empirical $K_{t}$ well. For fully submerged oyster reefs with $R_{c} / H_{i}<-1.6$, some of the measured $K_{t}$ values go beyond 1.0 because of the wave focusing around WG5. However, for cases with measured $K_{t}<1$, around 75 percent of the measured $K_{t}$ fall within the 90-percent confidence interval band of the empirical formulas. For emergent oyster reefs with $R_{c} / H_{i}>0$, the empirical formulas sometimes overestimate the wave height reduction across the oyster reefs, especially for small incident waves with $B / H_{i}>3$ (that is, outliers in fig. 15). This is because the low-crested breakwaters in d'Angremond and others (1996) and van der Meer and others (2005) are continuous (one piece), and small waves mostly get reflected by emergent breakwaters, leading to $K_{t}$ close to 0.1 . In this study, the oyster reefs at the study site are segmented, and small waves can still pass the emergent structures through the gaps between individual oyster castles, leading to a relatively larger transmission coefficient.
Waves in the ocean are composed of a number of individual wave systems originating from different meteorological events including storms. Wave spectral partitioning based on wave surface elevation variance instead of frequency is necessary to give more insight into the processes and mechanisms of the spatial and temporal evolutions of individual wave systems. Waves in this study are separated into swells and wind seas. The temporal variations of swell and wind sea zero-moment wave heights at the six WGs are presented in figure 16. The swell zeromoment wave heights are generally less than $20 \mathrm{~cm}$, whereas the wind sea zero-moment wave heights can reach up to $1.12 \mathrm{~m}$. Comparisons between the swell and wind sea zeromoment wave heights at different gage locations are shown in figure $17 A-F$. The wind sea wave heights have similar evolution patterns as zero-moment wave heights. By contrast, the swell wave heights remain unchanged from WG3 to WG1 and from WG2 to WG4. Most of the swell waves can propagate without getting attenuated regardless of the oyster reefs. The outliers in figure $17 D-F$ are attributed to nearshore processes including shoaling, breaking, and focusing of swell waves.

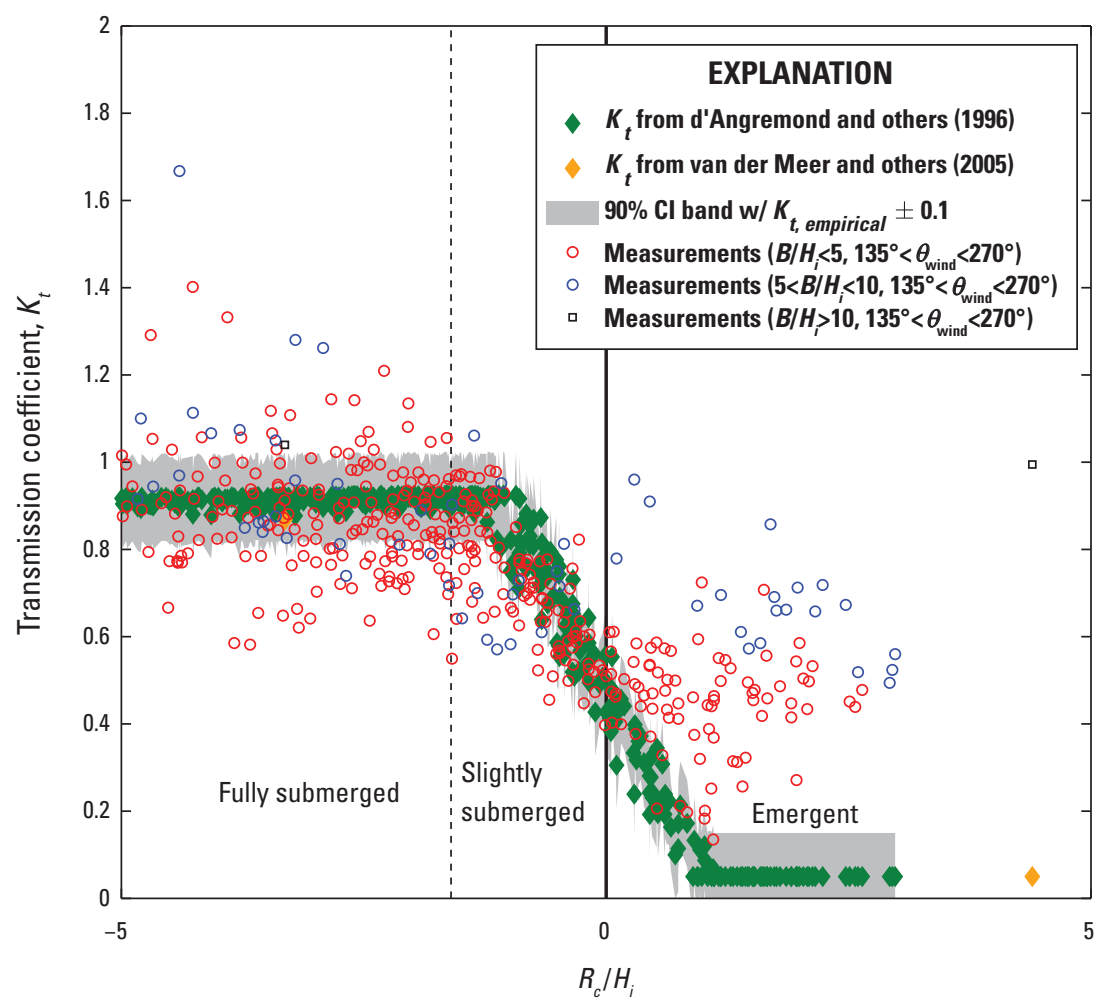

Figure 15. Relations among the relative freeboard $\left(R_{c} / H_{i}\right)$ and transmission coefficient $\left(K_{t}\right)$ from d'Angremond and others (1996), van der Meer and others (2005), and this study. Only measurements associated with wind direction from $135^{\circ}$ to $270^{\circ}$ (blowing from offshore to onshore) are presented. $B / H_{i}$ is relative crest width. 
In this study, wind seas were found to have larger wave height than swells, indicating that large wave energy coming from wind seas is the major force for shoreline and marsh erosion along the Gandys Beach shoreline. This finding is consistent with other coastal shoreline research in which marsh edge erosion was found mainly attributed to the locally generated wind waves (Sanford and Gao, 2018; Duvall and others, 2019; Everett and others, 2019). Leonardi and others (2016) presented a linear relation between the wave power of wind waves and the salt marsh erosion rate. On the basis of the wave spectral analysis using data collected from shoreline with and without LSS, it was found that LSS can reduce local wind seas, although effectiveness of LSS in reducing wave energy tends to vary with hydrodynamic conditions and structure characteristics (Wiberg and others, 2019).

\section{Current Characteristics}

Figure 18 shows the flood and ebb tides and the temporal variations of the water depth at WG4 (control site, fig. 4A). The red dots correspond to the flood tides, while the blue dots correspond to the ebb tides (fig. 18). The flood/ebb tides are defined on the basis of the current directions at TCM5 (the offshore site, fig. 4A). Figure 18 shows that the flood/ebb tides are out of phase with the increase/decrease of water depth at WG4.

The temporal variations of the mean current vector and current speed during flood and ebb tides at all of the TCMs are shown in figures 19-24. In general, the offshore TCM5 has the largest current speed among all TCMs, whereas TCM7, located in the largest gap between individual oyster castles, has the largest current speed among all nearshore TCMs. The time series of the vectors indicate the circulation pattern of currents. The current directions at TCM1 are affected by the small cove where TCM1 is located, whereas the current directions at TCM6 and TCM7 are affected by the cove behind the oyster reefs (locations shown in fig. $4 A$ ).

During flood tides, instead of being oriented onshore, the currents at TCM1, TCM6, and TCM7 are generally oriented offshore, with bearing angles at TCM6 and TCM7 mostly ranging from $90^{\circ}$ to $210^{\circ}$ and bearing angles at TCM1 mostly ranging from $90^{\circ}$ to $180^{\circ}$. By contrast, TCM 2 and TCM4 do not have an obvious tendency of orientations during flood tides. A snapshot of currents at all TCMs during a flood tide (March 21, 2018, at 9:00 a.m.) is provided in figure 25.

During ebb tides, the currents at TCM1 sometimes move onshore because of the flow circulation in the small cove, leading to bearing angles less than $90^{\circ}$. The currents at TCM2, TCM4, TCM6, and TCM7 generally move offshore. A snapshot of currents at all TCMs during an ebb tide (March 19, 2018, at 2:00 p.m.) is provided in figure 26. The circulation pattern at the nearshore TCMs is greatly affected by the surrounding bathymetry and can be quite complicated. Numerical models are recommended to help understand the nearshore circulation pattern. 

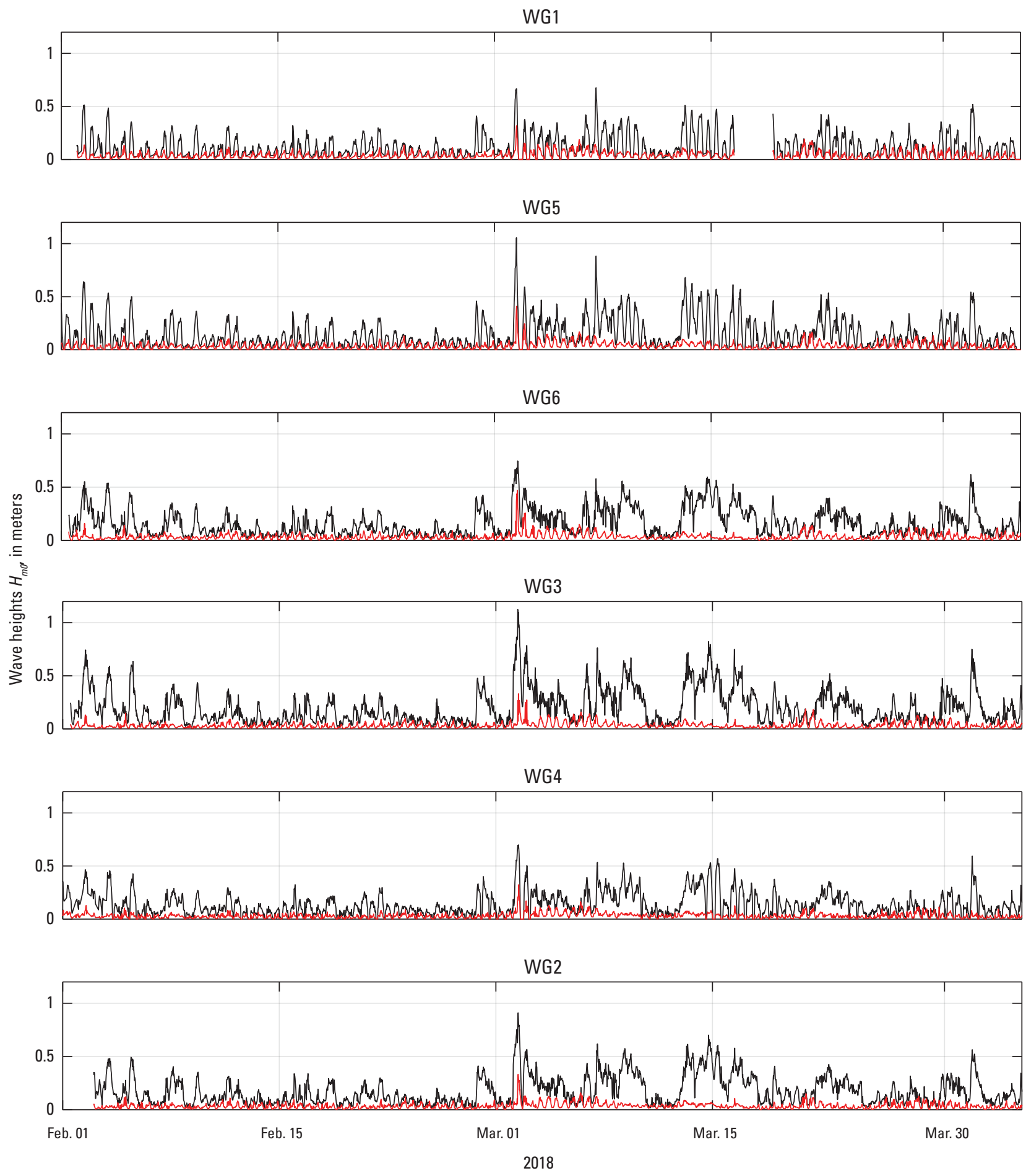

EXPLANATION

- Swell

Wind sea

Figure 16. Time series of swell and wind sea zero-moment wave heights $\left(H_{m 0}\right)$ measured at six wave gages (WG), February to April 2018, in the Gandys Beach, New Jersey, living shoreline study area. 

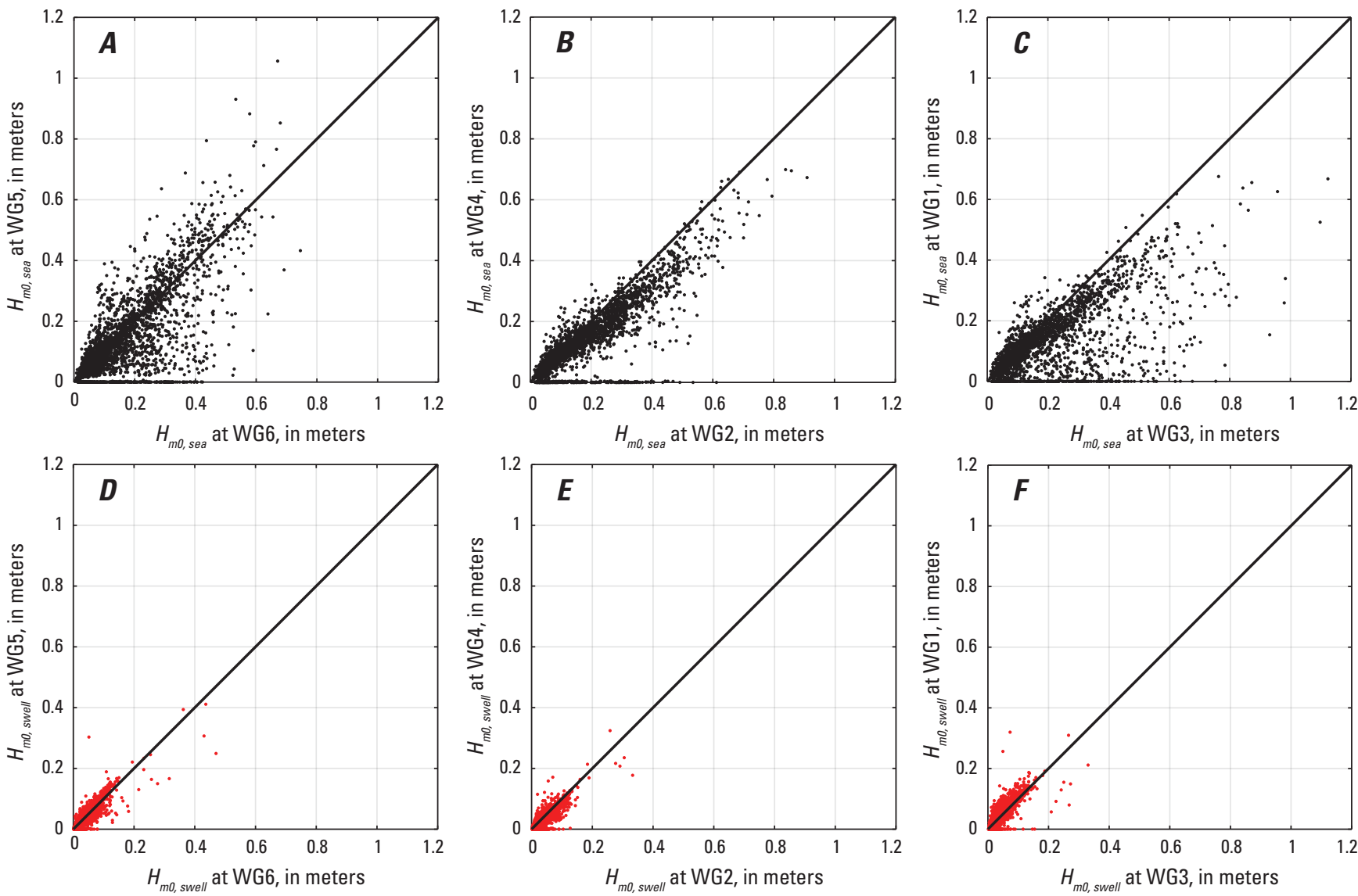

Figure 17. Intergage comparisons of swell and wind sea zero-moment wave heights $\left(H_{m 0}\right)$ measured at six wave gages (WG) in the Gandys Beach, New Jersey, living shoreline study area during February to April 2018. $A$, Wind sea zero-moment wave heights between WG5 and WG6, $B$, wind sea zero-moment wave heights between WG2 and WG4, $C$, wind sea zero-moment wave heights between WG1 and WG3, D, swell zero-moment wave heights between WG5 and WG6, $E$, swell zero-moment wave heights between WG2 and WG4, and $F$, swell zero-moment wave heights between WG1 and WG3.

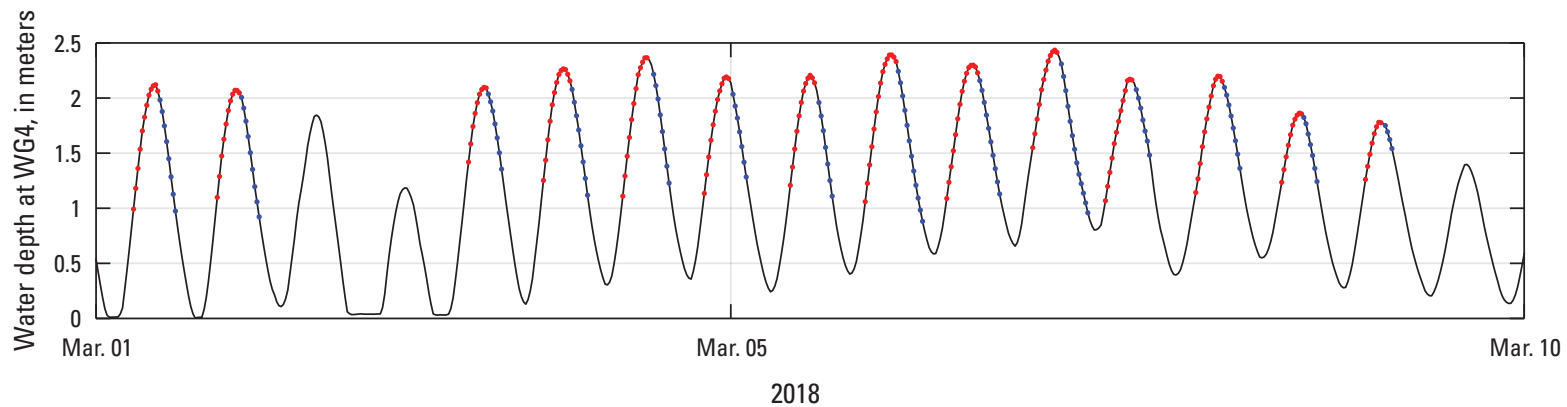

Figure 18. Time series of water depths at wave gage (WG) 4 in the Gandys Beach, New Jersey, living shoreline study area. Red and blue dots correspond to the flood and ebb tides, respectively. 
$\boldsymbol{A}$

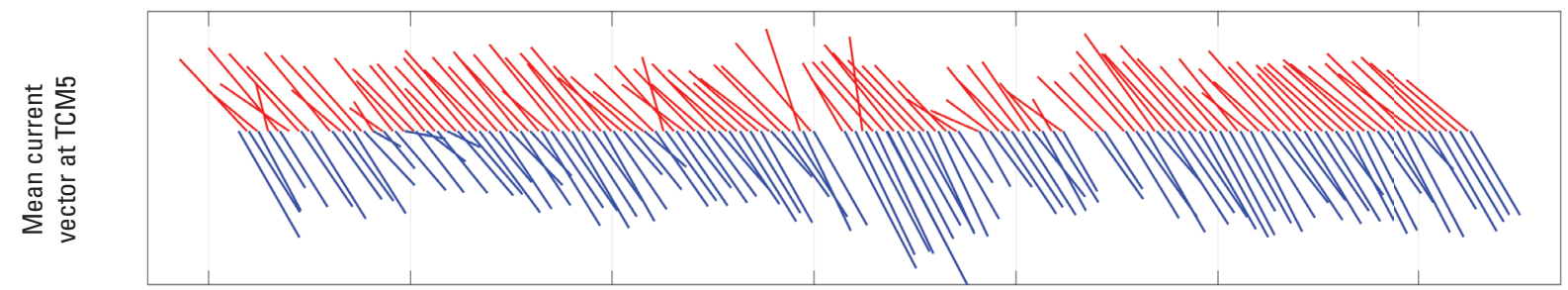

B

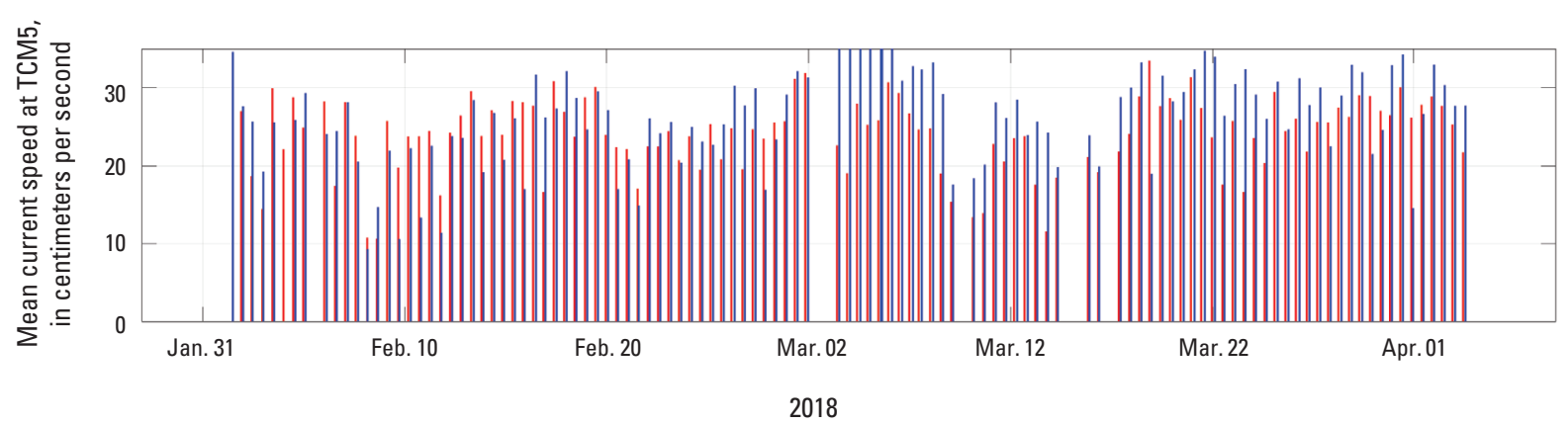

Figure 19. Time series of $A$, the mean current vector and $B$, the mean current speed during flood (red vectors and bars) and ebb (blue vectors and bars) tides at tilt current meter (TCM) 5, February to April 2018, in the Gandys Beach, New Jersey, living shoreline study area.

A

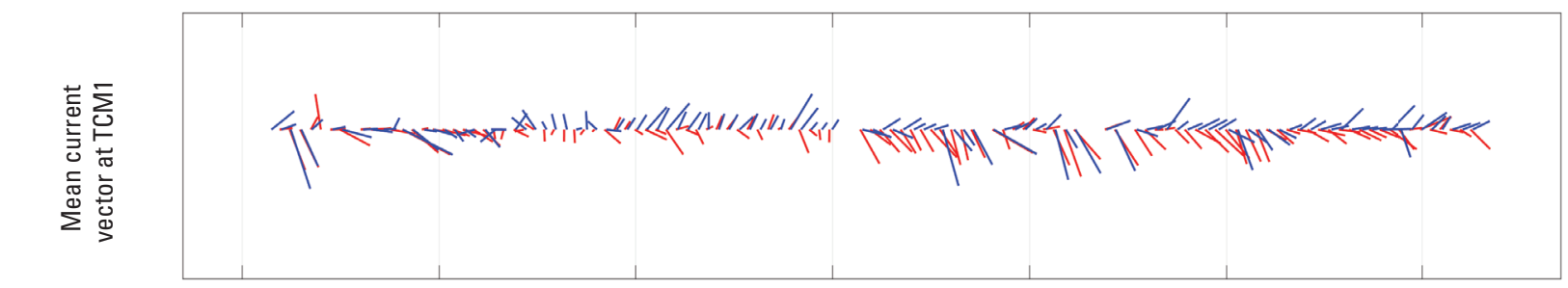

$\boldsymbol{B}$

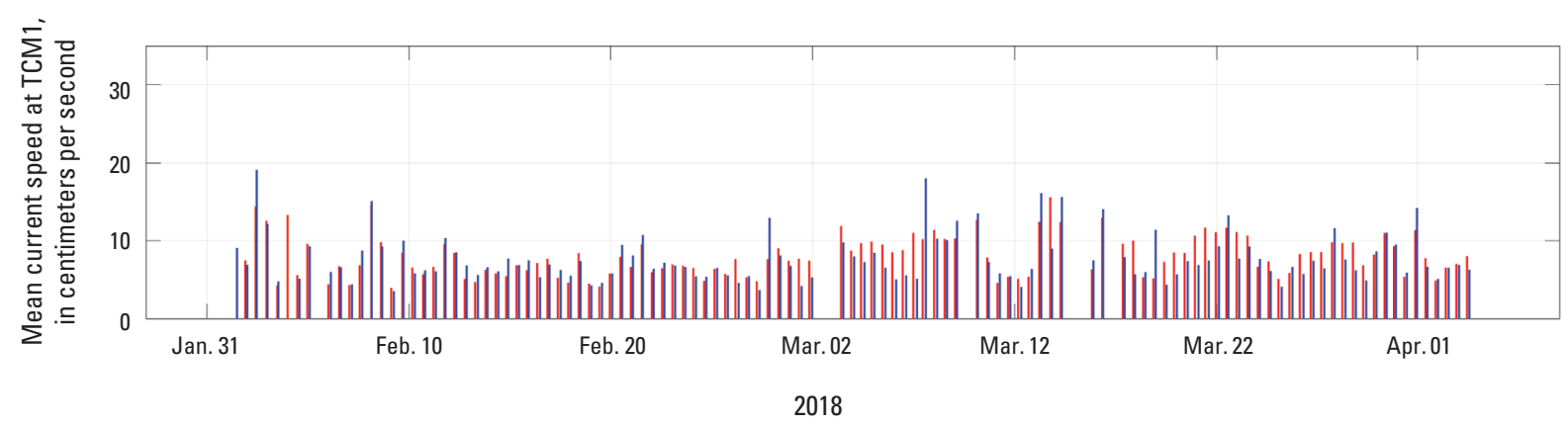

Figure 20. Time series of $A$, the mean current vector and $B$, the mean current speed during flood (red vectors and bars) and ebb (blue vectors and bars) tides at tilt current meter (TCM) 1, February to April 2018, in the Gandys Beach, New Jersey, living shoreline study area. 
$\boldsymbol{A}$

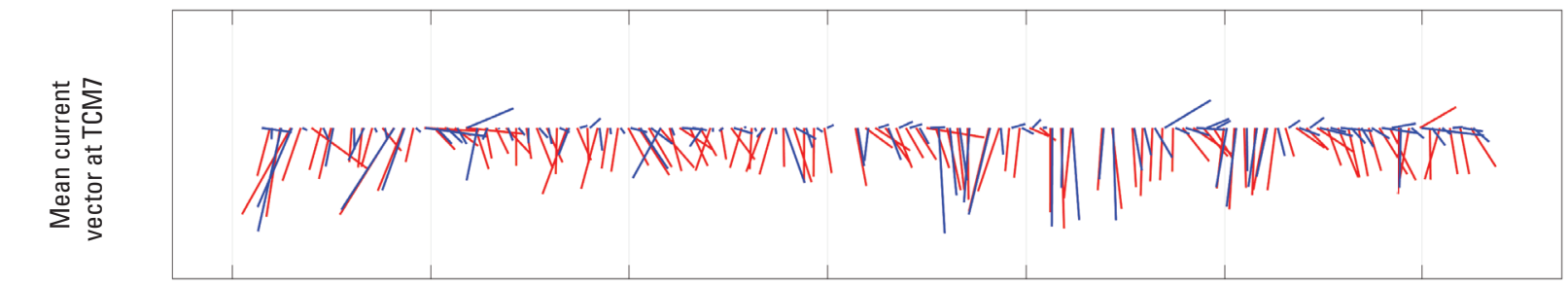

$B$

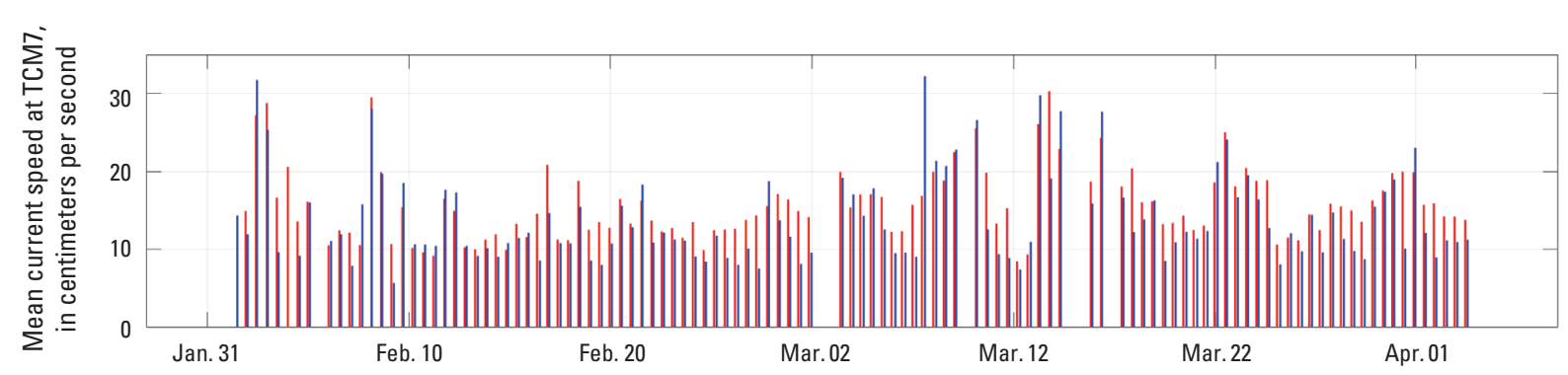

Figure 21. Time series of $A$, the mean current vector and $B$, the mean current speed during flood (red vectors and bars) and ebb (blue vectors and bars) tides at tilt current meter (TCM) 7, February to April 2018, in the Gandys Beach, New Jersey, living shoreline study area.

\section{$\boldsymbol{A}$}

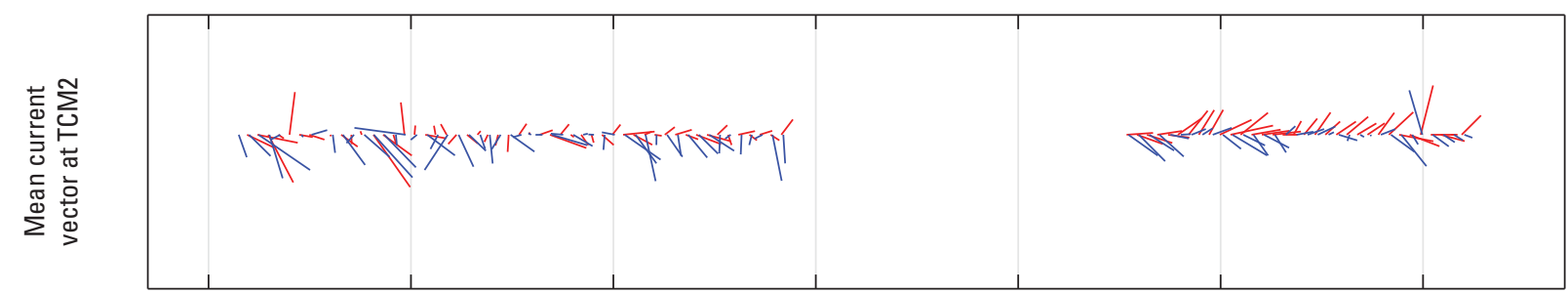

$B$

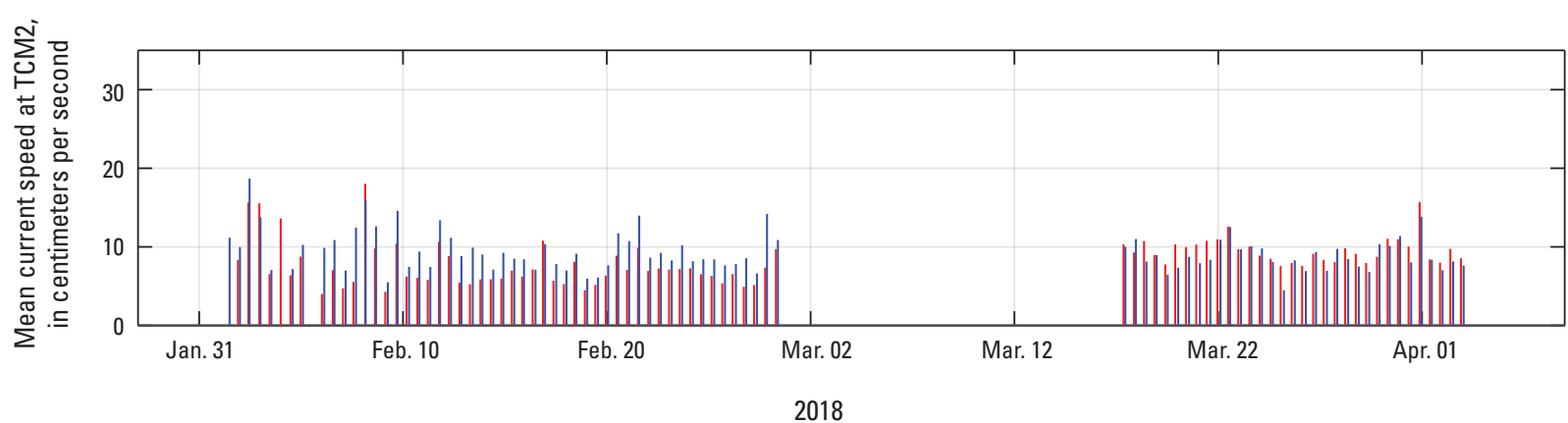

Figure 22. Time series of $A$, the mean current vector and $B$, the mean current speed during flood (red vectors and bars) and ebb (blue vectors and bars) tides at tilt current meter (TCM) 2, February to April 2018, in the Gandys Beach, New Jersey, living shoreline study area. 
$\boldsymbol{A}$

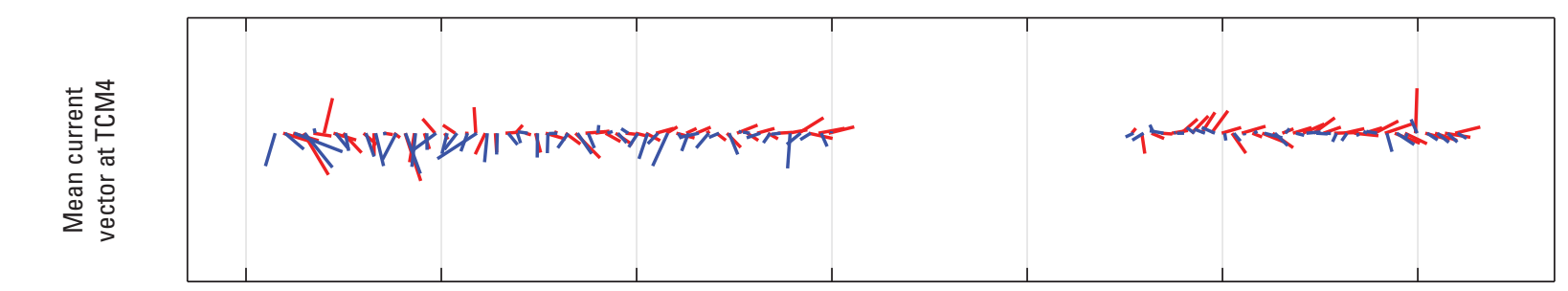

B

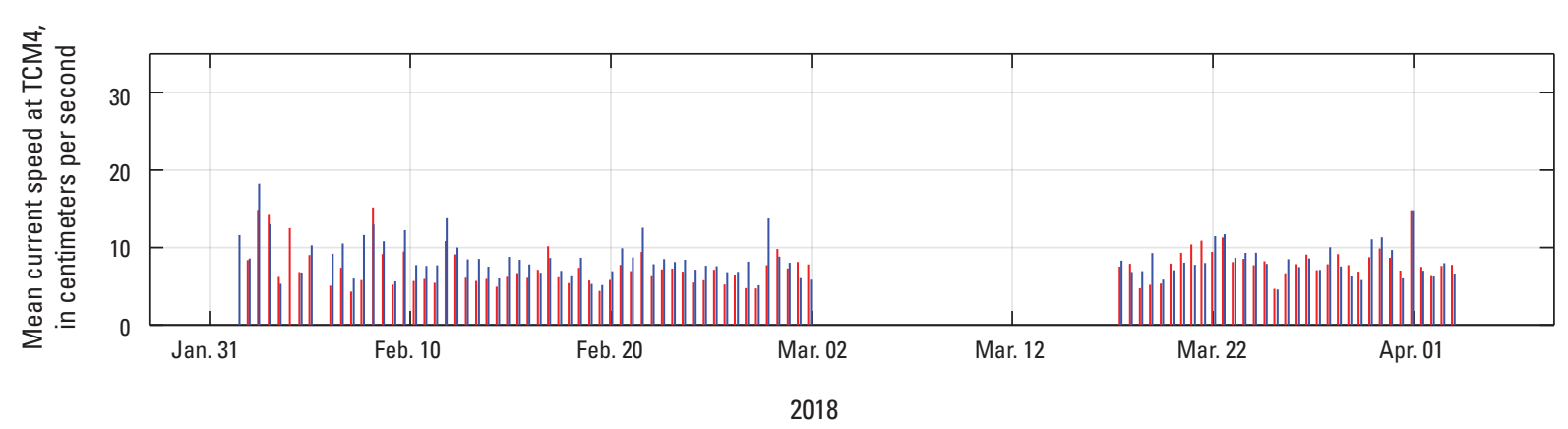

Figure 23. Time series of $A$, the mean current vector and $B$, the mean current speed during flood (red vectors and bars) and ebb (blue vectors and bars) tides at tilt current meter (TCM) 4, February to April 2018, in the Gandys Beach, New Jersey, living shoreline study area.

$\boldsymbol{A}$

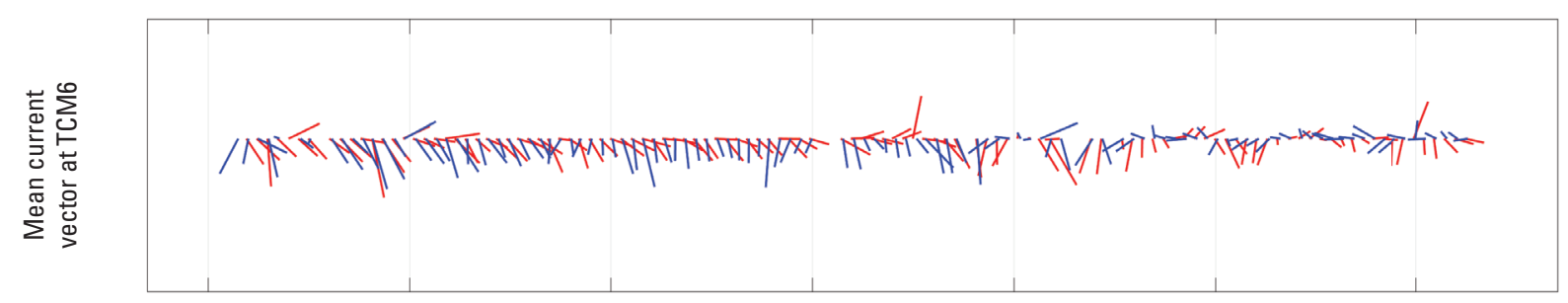

B

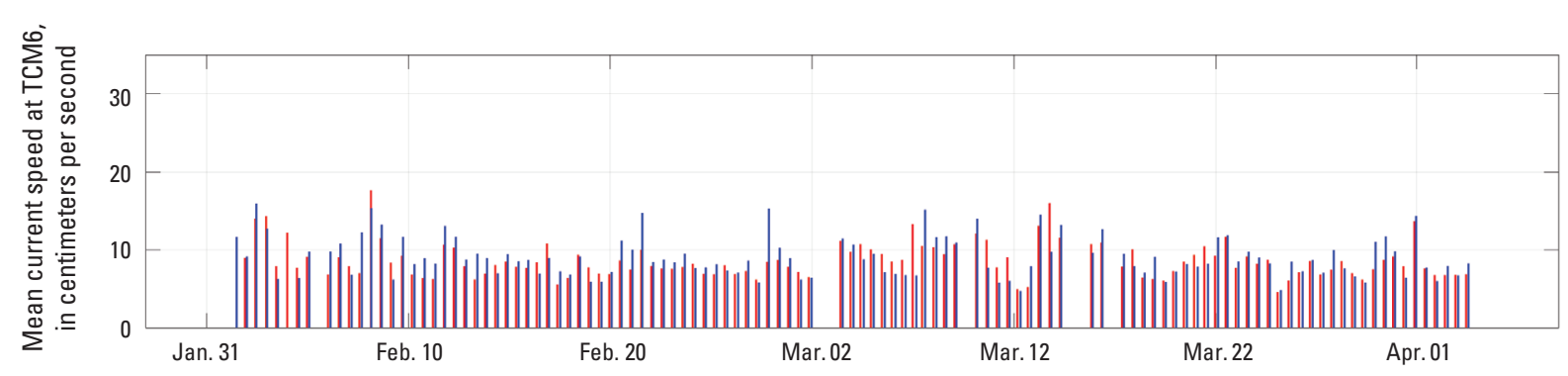

Figure 24. Time series of $A$, the mean current vector and $B$, the mean current speed during flood (red vectors and bars) and ebb (blue vectors and bars) tides at tilt current meter (TCM) 6, February to April 2018, in the Gandys Beach, New Jersey, living shoreline study area. 


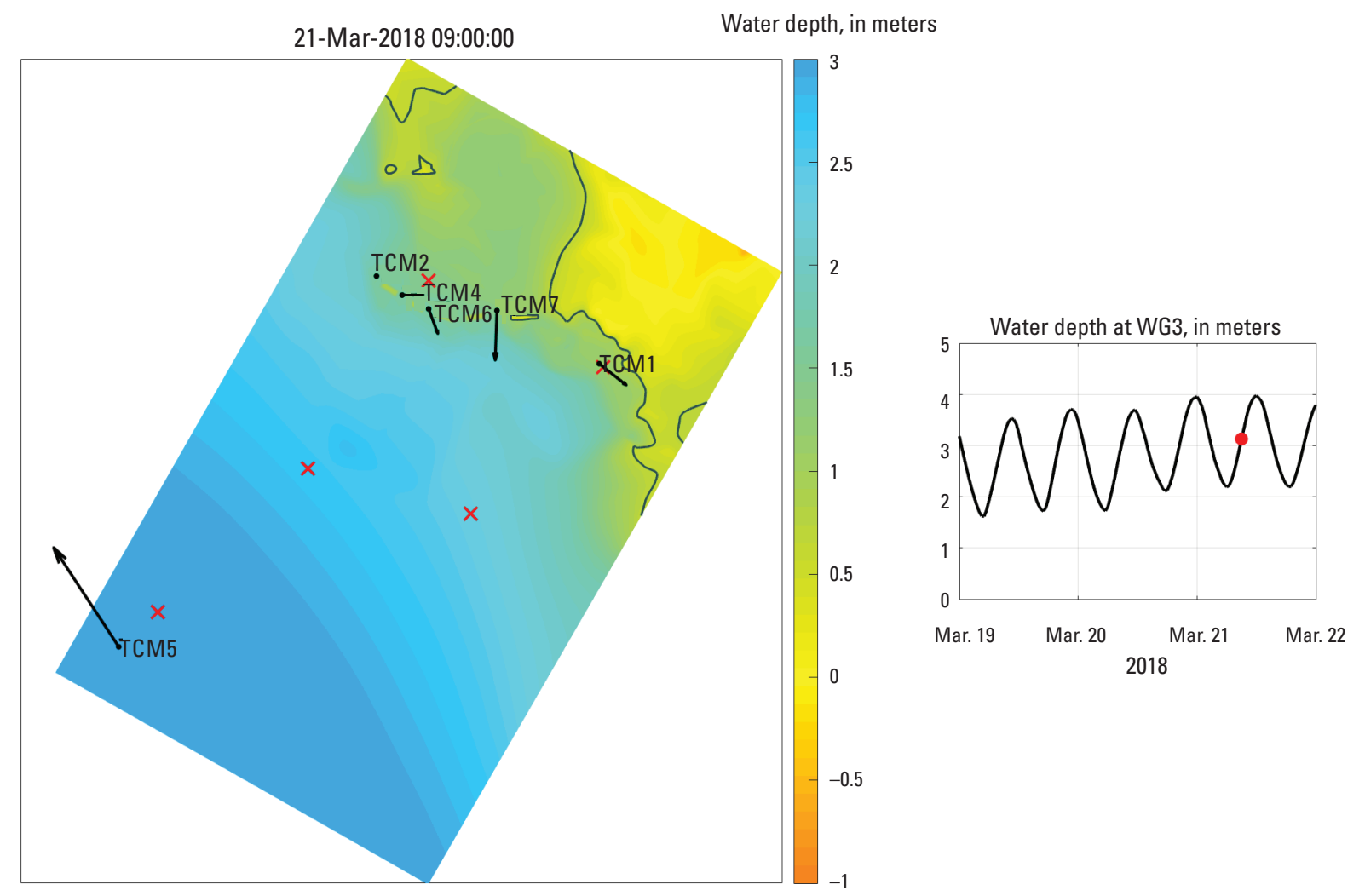

Figure 25. A snapshot of currents at all tilt current meters (TCM) during a flood tide on March 21, 2018, at 9:00 a.m., in the Gandys Beach, New Jersey, living shoreline study area. The black line shows the contour of zero mean sea level. $W G$, wave gage. 


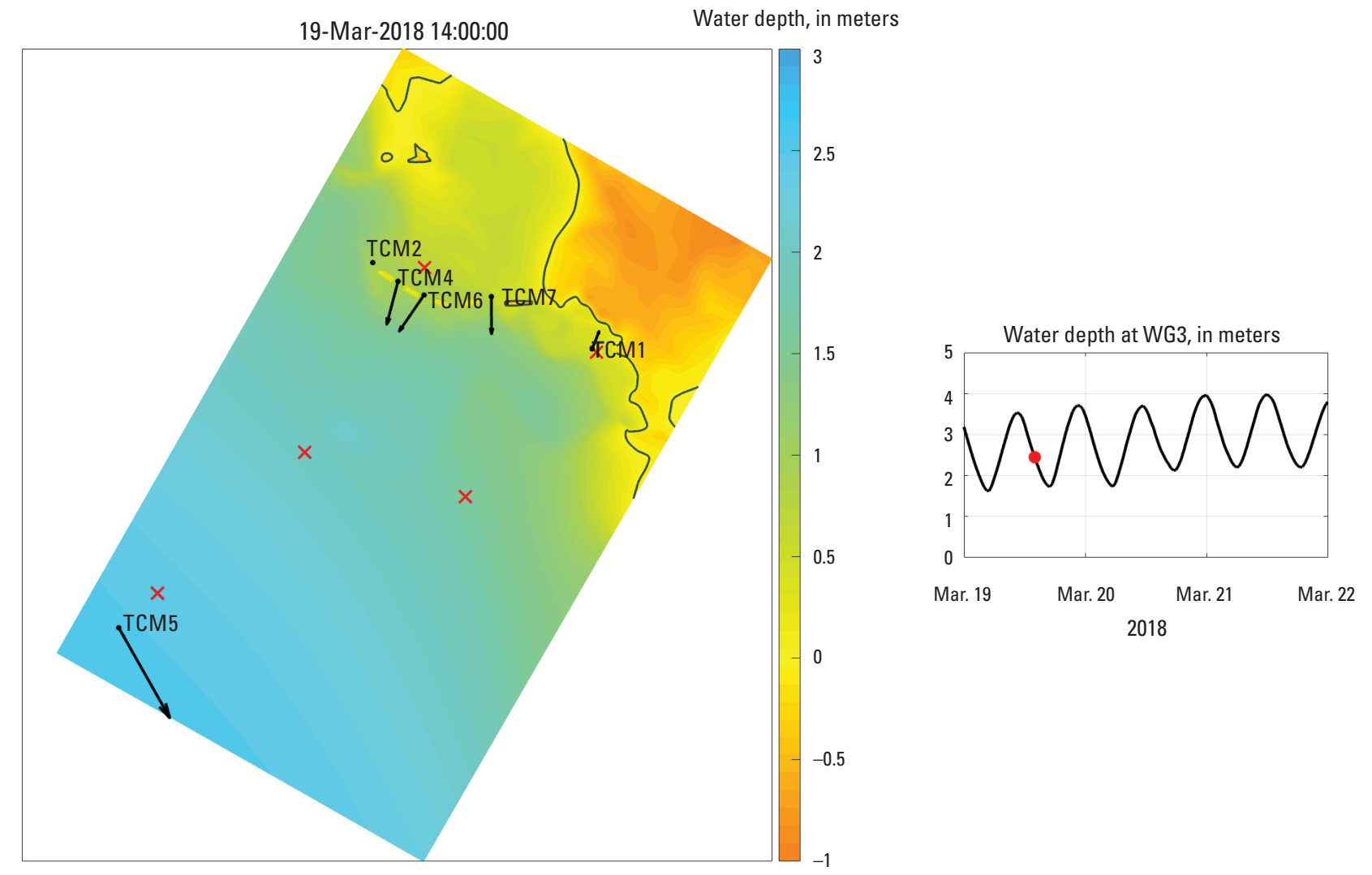

Figure 26. A snapshot of currents at all tilt current meters (TCM) during an ebb tide on March 19, 2018, at 2:00 p.m., in the Gandys Beach, New Jersey, living shoreline study area. The black line shows the contour of zero mean sea level. WG, wave gage. 


\section{Sediment Vertical Deposition and Erosion}

The vertical movement (up or down) of the intertidal marsh or mudflat platform behind the oyster castles and in the control area during the two winter months was estimated by the distance change during deployment and retrieval from the pins of the sediment pin/trap sets. To be able to use these measurements to describe the actual marsh or mudflat vertical movement reliably, information on any potential land subsidence is needed. The tops of the traps were measured to estimate the occurrence of land subsidence. The measurements were inconclusive because of the change of the position of each trap top (for example, it was not perpendicular to ground because of large wind impacts) between deployment and retrieval, the inconsistent collecting points and duration of total station measurements, and possibly other, unknown factors. Instead, measurements of the benchmark $\left(39^{\circ} 16^{\prime}\right.$ $37.20^{\prime \prime} \mathrm{N}$., $75^{\circ} 14^{\prime} 30.48^{\prime \prime} \mathrm{W}$., fig. 27) were used during deployment and retrieval to see if there was any vertical movement of the marsh sediment. The rod of the benchmark was pushed down $>1 \mathrm{~m}$ and could be used to indicate any vertical movement, and the benchmark was surveyed during deployment and retrieval to verify that there was no vertical movement during the study period. The measurements of the elevation of the benchmark during deployment and during retrieval were close and within the instrument accuracy during the two winter months, suggesting that no subsidence occurred; thus, the sediment pin's measured change of marsh and mudflat surface elevation can be used to describe the sediment erosion or deposition during the two winter months. If the retrieval elevation minus the deployment elevation is $>0$, then erosion occurred; otherwise, deposition occurred. Measurements of marsh and mudflat surface and vertical movement can be seen in table 2 .

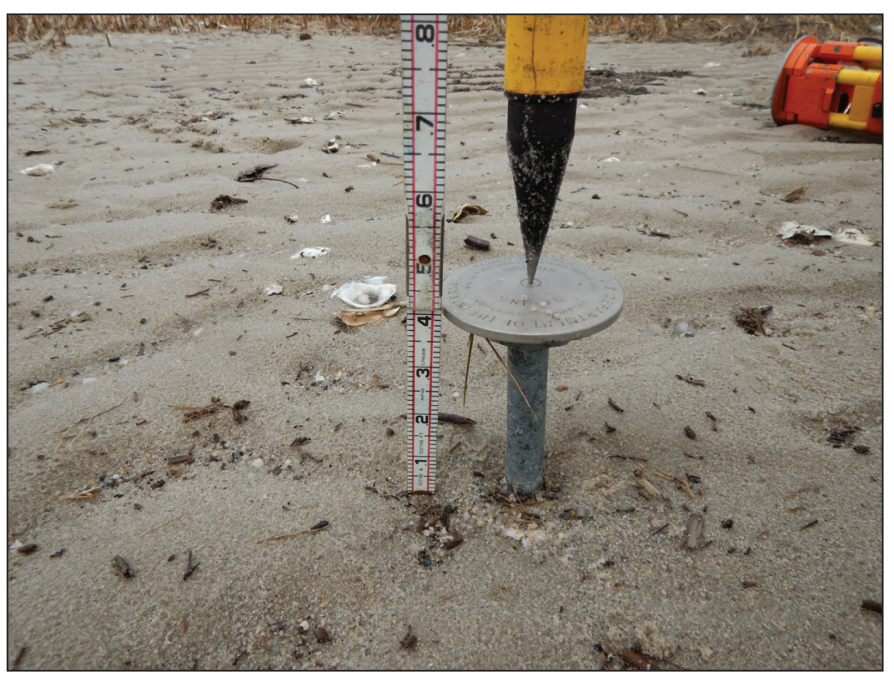

Figure 27. Vertical sediment erosion over the 2-month period from February to April 2018 at the benchmark location in the Gandys Beach, New Jersey, living shoreline study area. Photograph by Kelin Hu, Tulane University, used with permission.

Table 2. Sediment pin measurements and surface elevation change during February to April 2018 at pin/trap set locations in the Gandys Beach, New Jersey, living shoreline study area.

[H, distance from the pin top to sediment surface; ave, average; cm, centimeter; LSS, living shoreline structure. Locations of pin/trap sets shown in fig. 4B]

\begin{tabular}{|c|c|c|c|c|c|c|c|c|c|c|c|c|}
\hline \multirow{2}{*}{$\begin{array}{c}\text { Pin/ } \\
\text { trap set } \\
\text { number }\end{array}$} & \multicolumn{4}{|c|}{ Deployment (Feb. 1, 2018) } & \multicolumn{4}{|c|}{ Retrieval (Apr. 3, 2018) } & \multicolumn{4}{|c|}{ Change over 2 months } \\
\hline & H1 & H2 & H3 & Ave (cm) & H1 & H2 & H3 & Ave (cm) & H1 & H2 & H3 & Ave $(\mathrm{cm})$ \\
\hline \multicolumn{5}{|c|}{ Control (1-4) } & & & & & & & & 1.52 \\
\hline 1 & 128.93 & 129.54 & 128.63 & 129.03 & 131.98 & 131.06 & 131.67 & 131.57 & 3.05 & 1.52 & 3.05 & 2.54 \\
\hline 2 & 128.63 & 129.54 & 129.24 & 129.13 & 129.84 & 130.45 & 130.76 & 130.35 & 1.22 & 0.91 & 1.52 & 1.22 \\
\hline 3 & 129.24 & 128.93 & 130.45 & 129.54 & 131.06 & 132.28 & 131.98 & 131.78 & 1.83 & 3.35 & 1.52 & 2.24 \\
\hline 4 & 124.66 & 124.36 & 123.14 & 124.05 & 124.05 & 123.44 & 124.97 & 124.16 & -0.61 & -0.91 & 1.83 & 0.10 \\
\hline \multicolumn{5}{|c|}{ With LSS (5-8) } & & & & & & & & 0.25 \\
\hline 5 & 130.76 & 130.76 & 130.76 & 130.76 & 130.45 & 130.45 & 130.15 & 130.35 & -0.30 & -0.30 & -0.61 & -0.41 \\
\hline 6 & 131.06 & 130.76 & 129.54 & 130.45 & 130.76 & 130.45 & 129.54 & 130.25 & -0.30 & -0.30 & 0.00 & -0.20 \\
\hline 7 & 129.54 & 129.84 & 129.24 & 129.54 & 131.37 & 130.76 & 131.37 & 131.17 & 1.83 & 0.91 & 2.13 & 1.63 \\
\hline 8 & 128.02 & 127.10 & 127.41 & 127.51 & 127.71 & 127.41 & 127.41 & 127.51 & -0.30 & 0.30 & 0.00 & 0.00 \\
\hline
\end{tabular}


In the control area, the four pin/trap set locations (trap1, trap2, trap3, and trap4, fig. $4 B$ ) showed vertical sediment erosion over the 2 months ranging from 0.10 to $2.54 \mathrm{~cm}$, with an average erosion of $1.52 \mathrm{~cm}$ (table 2). In contrast, the pin/ trap set locations behind the oyster castles showed no change at trap8, erosion of $1.63 \mathrm{~cm}$ at trap7 and slight deposition of $0.20 \mathrm{~cm}$ at trap6, and $0.41 \mathrm{~cm}$ erosion at trap5, with an average erosion of $0.25 \mathrm{~cm}$ (table 2, fig. $4 B$ ). There was $10.16 \mathrm{~cm}$ (4 inches) of sediment erosion found at the benchmark location (fig. 27) during the 2 months most likely as a result of the four nor'easters. These results suggest that the oyster castles protected the marsh and mudflat behind them from erosion, and some locations may have sediment deposition compared to locations in the control area where marsh and mudflat still face wind and wave-driven erosion.

\section{Observation of Salt Marsh Edge Lateral Movement}

The three lateral erosion PVC pins placed on the marsh edge behind the oyster castles (pin1, pin2, and pin3, fig. 4B) were found stable with no lateral movement observed during the 2-month study period. In contrast, the three erosion pins placed on the marsh edge in the control area (pin4, pin5, and pin6, fig. 4B) were found separated from the original marsh edge (fig. 28A-C), indicating lateral marsh edge erosion over the two winter months. The lateral erosion measurements range from 3 to $11 \mathrm{~cm}$ with the average ranging from 5.3 to $9.7 \mathrm{~cm}$ (fig. $28 A-C$ ). The data show a general trend of reduced lateral marsh erosion with the protection of LSS during the two winter months with the occurrence of four nor'easters. Previous studies also showed this general trend (for example, Chowdhury and others, 2019). Chowdhury and others (2019) found that the retreat rate of salt marsh along a subtropical coast during monsoon season (high wind and wave conditions) was significantly reduced at the oyster castle sites compared to the control sites.

It should be noted that the wave-induced shoreline retreat rate at the Gandys Beach living shoreline study area could not be determined by the limited field data because of the difference in shoreline morphology between the control sites and the oyster castle sites. The edge of the control sites was close to a marsh with a high $(>0.5 \mathrm{~m})$ marsh surface to toe vertical distance, whereas the marsh next to the edge of the reef sites had a low $(<0.1 \mathrm{~m})$ marsh surface to toe vertical distance. There were no ideal control sites to be used for evaluation of wave-induced shoreline changes with and without oyster reefs in the Gandys Beach living shoreline study area (Zhu and others, 2020). Furthermore, lateral salt marsh movement tends to be seasonal with potential marsh seaward expansion during nonstormy periods as a result of sediment net deposition and landward retreat during stormy periods because of dominant erosional processes (Chowdhury and others, 2019). Therefore, in situ measurements of lateral
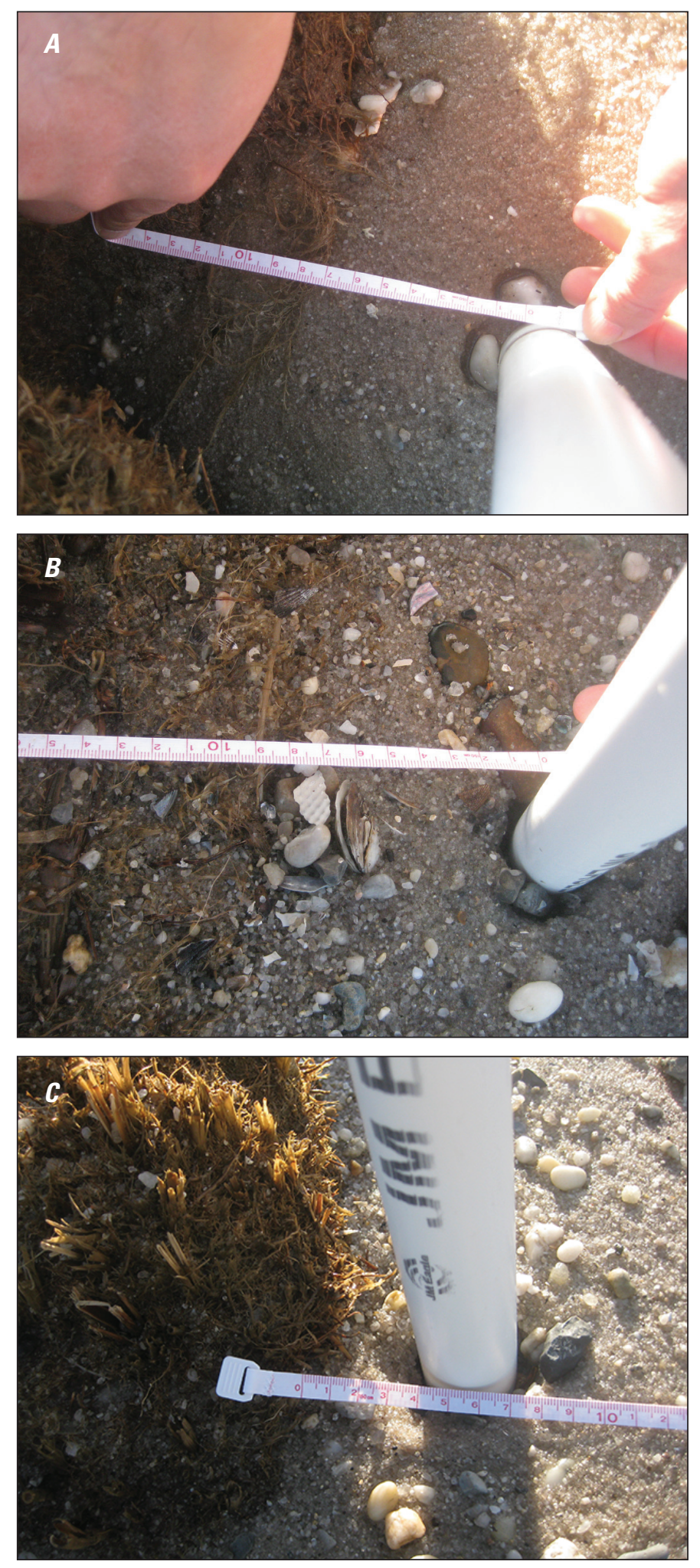

Figure 28. Lateral movement (marsh retreat landward) at the control sites $A$, pin4, $B$, pin5, and $C$, pin6 in the Gandys Beach, New Jersey, living shoreline study area. Photographs by Kelin $\mathrm{Hu}$, Tulane University, used with permission. 
shoreline movement (salt marsh and mudflat) from multiple seasons over multiple years are needed for determining the ecological effectiveness of LSS.

\section{Sediment Mass and Grain Size Distribution Trapped From Water Column}

The salt marsh and mudflat behind the oyster castles were found to trap more sediment than their counterparts in the control area during the study period. In addition, sites in the mudflats tended to accumulate more sediment than sites in the marsh areas with similar elevation for both the control sites and the sites behind the oyster castles. The average mass of sediment trapped was 29.1 grams ( $\mathrm{g}$ ) at sites behind the oyster castles, 3.5 times the control sites (8.3 g) (table 3 ). The mudflat sites behind the oyster castles could trap up to $53.9 \mathrm{~g}$ of sediment compared to the mudflat sites in the control area, where the highest mass trapped was $25.5 \mathrm{~g}$ (table 3 ). Marsh sites behind the oyster castles trapped 8.9-11.3 $\mathrm{g}$ of sediment, compared to $0.32 \mathrm{~g}$ at the marsh site in the control area (table 3). Furthermore, the ranges of sand percentage did not show a large difference between sites behind the oyster castles and sites in the control area. However, sediment with a larger sand percentage was captured at sites behind the oyster castles compared to the control sites For example, the average sand proportion is 87.3 percent at sites behind the oyster castles compared to 84.2 percent at sites in the control area (table 3 ). These results indicated that the intertidal salt marsh and mudflat protected by the oyster castles could trap more sand than could sites in the control area. Additionally, deposition of the sediment on the surface of the salt marsh or mudflat behind the oyster castles or loss of these sediments in the water column to ocean depends on wind, waves, current circulation, and their interaction.

\section{Salt Marsh and Mudflat Sediment Grain Size Distribution}

Sediment grain size distribution in the salt marsh and mudflat to a depth of $10 \mathrm{~cm}$ varies greatly in the Gandys Beach living shoreline study area. The 12 sediment cores revealed that sand percentage could range from $<1$ percent to $>95$ percent and that fine sediment could range from $\sim 4$ percent to $>99$ percent depending on the following factors related to location and position within the study area: on the marsh versus on the mudflat, elevation, and distance to the oyster castles (table 4). Since we did not collect sediment samples before the construction of the oyster castles, the change of sediment grain size distribution directly related to the oyster castles could not be assessed. However, grain size distribution showed that sites on the leeward side of the oyster castles (for example, core 3 , core 4 , and core5) potentially have a higher sand percentage (less fine sediment) than do the sites in front (seaward) of the structures (for example, core 10 and core12) (fig. $4 B$, table 4). Considering that sites behind the oyster castles could trap more sediment with a larger sand percentage from the trap data (table 3), it appears that the leeward side of the oyster castles in the study area (marsh or mudflat) trap and accumulate large grain size sediment. Since the sediment grain sizes on the seaward of the oyster castles tend to be smaller ( sand percentage $=25-32$ percent from core 10 and core 12 ) than behind the castles (sand percentage $=$ 25-83 percent from core 3 , core 4 , and core 5), it is likely that the source of sediment accumulated in soils/sediment behind the oyster castles may be from offshore or the nearshore area with a relatively large sandy component.

Table 3. Total sediment mass accumulated in sediment traps and sediment grain size distribution during February to April 2018 at mudflat and marsh sites in the Gandys Beach, New Jersey, living shoreline study area.

[m, meter; NAVD 88, North American Vertical Datum of 1988; g, gram; \%, percent; $\geq$, greater than or equal to; mm, millimeter; <, less than; ave, average; LSS, living shoreline structure]

\begin{tabular}{lclccc}
\hline Trap number & $\begin{array}{c}\text { Elevation } \\
\text { (m NAVD 88) }\end{array}$ & Site type & $\begin{array}{c}\text { Total sediment } \\
(\mathbf{g})\end{array}$ & $\begin{array}{c}\text { Sand \% } \\
(\geq \mathbf{0 . 0 6 3} \mathbf{~ m m})\end{array}$ & $\begin{array}{c}\text { Fine \% } \\
(<\mathbf{0 . 0 6 3} \mathbf{~ m m})\end{array}$ \\
\hline 1 & -1.17 & mudflat & 0.98 & 80.89 & 19.11 \\
2 & -2.52 & mudflat & 25.50 & 94.16 & 5.84 \\
3 & -2.56 & mudflat & 6.40 & 94.65 & 5.35 \\
4 & 0.95 & marsh & 0.32 & 67.00 & 33.00 \\
Control (1-4) ave & $-\mathbf{1 . 3 3}$ & & $\mathbf{8 . 3 0}$ & $\mathbf{8 4 . 1 7}$ & $\mathbf{1 5 . 8 3}$ \\
\hline 5 & 0.81 & marsh & 11.26 & 94.21 & 5.79 \\
6 & -1.00 & marsh & 8.93 & 89.72 & 10.28 \\
7 & -0.98 & mudflat & 42.29 & 79.82 & 20.18 \\
8 & -2.46 & mudflat & 53.89 & 85.35 & 14.65 \\
Behind LSS (5-8) ave & $\mathbf{- 0 . 9 1}$ & & $\mathbf{2 9 . 1 0}$ & $\mathbf{8 7 . 2 8}$ & $\mathbf{1 2 . 7 2}$ \\
\hline
\end{tabular}


Table 4. Sediment grain size distribution in salt marsh and mudflat in the Gandys Beach, New Jersey, living shoreline study area during February to April 2018.

[Locations of cores: 1, 2, and 6, marsh behind oyster castles; 3, 4, and 5, marsh edge behind oyster castles; 10 and 12, mudflat in front of oyster castles; 7 and 8 , marsh in control area; 9 and 11, mudflat in control area (see fig. 4B). \%, percent; $\geq$, greater than or equal to; mm, millimeter; $<$, less than]

\begin{tabular}{|c|c|c|c|c|c|c|c|c|c|c|c|c|}
\hline Core & 1 & 2 & 3 & 4 & 5 & 6 & 7 & 8 & 9 & 10 & 11 & 12 \\
\hline $\begin{array}{l}\text { Sand \% } \\
\qquad(\geq 0.063 \mathrm{~mm})\end{array}$ & 44.56 & 79.40 & 83.61 & 39.30 & 25.18 & 95.93 & 63.38 & 0.59 & 31.62 & 31.96 & 87.28 & 25.42 \\
\hline $\begin{array}{l}\text { Fine } \% \\
\qquad(<0.063 \mathrm{~mm})\end{array}$ & 55.44 & 20.60 & 16.39 & 60.70 & 74.82 & 4.07 & 36.62 & 99.41 & 68.38 & 68.04 & 12.72 & 74.58 \\
\hline
\end{tabular}

\section{Salinity Measurements and TSS Concentration}

Salinity in the study area was 14.4 (range: $14.2-14.5$ ) parts per thousand (ppt), indicating the potential influence from the nearby river system and precipitation. Historically, observed salinity is in the range of 12-20 ppt in the upper Delaware Estuary (Galvez, 2019). The optimal salinity range is 14-28 ppt for eastern oyster growth and distribution (Shumway, 1996). Regarding the relation between oyster reef development and salinity, Theuerkauf and others (2017) found that salinity is a statistically significant predictor of oyster reef presence-absence and that there was a narrow threshold salinity of $\sim 27 \mathrm{ppt}$ below which reefs were not present for eastern oysters in the Albemarle-Pamlico Estuary in North Carolina. Therefore, salinity in the Gandys Beach study area tended to be in the low end of the optimal salinity for both oyster growth and oyster reef development. More data are needed to determine the salinity threshold for oyster reef development and oyster growth along the living shoreline to select the optimum oyster castle construction sites in the Gandys Beach study area. Information from salinity data analysis, together with analysis of sediment data and wave attenuation capability of oyster castles, would help the final determination of LSS construction sites.

TSS concentration ranged from 109-145 milligrams per liter on the seaward side of the castles to 145-911 milligrams per liter behind the oyster castles. The increase in current velocity in the gaps between the oyster castles and changes in circulation patterns near the oyster castles compared to those in the control sites (no oyster castle protection) are likely responsible for the higher suspended solid concentration behind the LSS. Colden and others (2016) found that suspended sediment concentrations were highest adjacent to perpendicular reefs because of enhanced sediment resuspension/erosion from faster flow speeds over the reef crest followed by deposition of sediment adjacent to the reef. TSS concentrations are affected by tides (high, low, and tidal range), water depth, wind, wave, and current conditions, as well as other climate conditions such as precipitation, hurricanes and (or) storms (for example, Shi and others, 2015; Colden and others, 2016; Duvall and others, 2019). In this study, samples for suspended solid concentration were collected during field deployment of the WGs and TCMs under relatively low wind, wave, and tide conditions. In situ measurements of sediment concentrations during storms are needed for the accurate assessment of sediment deposition and erosion along the shoreline with and without protection of LSS and for the calibration and validation of morphodynamic models that incorporate processes such as wave- and currentinduced bed shear stress, bottom drag friction, sediment resuspension, transport, and settling.

\section{Discussion}

Very few studies have collected in situ measurements of hydrodynamic forcing (wave and current) and sedimentation simultaneously for shorelines equipped with LSS such as oyster reefs over long periods (for example, months or even a year), especially during storm periods. Chowdhury and others (2019) also identified the positive role of oyster reefs in trapping and accumulating mineral sediment compared to control sites. Nevertheless, the sediment dynamics along the shoreline (intertidal salt marsh and mudflat) equipped with LSS are complex because of the complicated hydrodynamic processes (wave, current circulation), local topographic features, vegetation and soil/sediment properties, and their interactions over space and time. For example, it was found that the sediment dynamics in coastlines of Bangladesh with protection of oyster reefs showed seasonal variations (premonsoon [March-May], monsoon [June-September], and postmonsoon [November-February] periods) (Chowdhury and others, 2019). The surface elevation change in vegetated area and mudflat at the reef sites compared to that of control sites varied with seasons because of various wind, wave, rainfall, and flow conditions. Higher wind wave energy during monsoon season resulted in erosion at seaward and leeward side of both the reef sites and the control sites. However, erosion was significantly reduced at the reef sites, whereas deposition occurred postmonsoon at the salt marshes of both reef and control sites. Meanwhile, significantly higher deposition was found at the salt marsh area of the reef sites than that of the control sites (Chowdhury and others, 2019). Changes in shoreline and marsh morphology along the Gandys Beach study area over a long period (for example, over years) 
could not be assessed using data collected in only wintertime even with multiple storms because sediment deposition during nonstorm periods/seasons was not investigated. However, with these data from two winter months, a coupled hydrodynamic and sediment transport numerical modeling system (Wang and others, 2017; Hu and others, 2018) can be calibrated and validated to simulate longer time periods.

Wave forcing was found to be the dominant factor for coastal shoreline and marsh edge erosion (Marani and others, 2011; Sanford and Gao, 2018). Shoreline erosion is determined by multiple factors including not only wave characteristics (for example, significant wave height, wave period, wavelength, wave spectrum, wave bottom velocity) but also local shoreline characteristics such as sea level, bank height, fraction of banks or marshes, sediment texture, and soil strength (for example, Sanford and Gao, 2018).

Shoreline and marsh edge erosion rates can be estimated from onshore wave power, sea level at mean tide, bank height, and shoreline cohesion (for example, Marani and others, 2011). Leonardi and others (2016) found that the erosion rates of marsh boundaries and the incident wave energy collapse into a unique linear relation. On the basis of the concept of critical shear stress threshold for erosion, a critical wave power threshold for shoreline erosion was proposed by Sanford and Gao (2018) because more frequent moderate waves (accumulated wave power above a critical threshold) play a more important role than less frequent extreme waves in shoreline and marsh edge erosion (Leonardi and others, 2016).

The marsh edge is protected from waves when the water level exceeds a certain elevation above the marsh platform or when the water level is below the scarp bottom. Everett and others (2019) used the mean high water and mean low water as a proxy of the elevation of the marsh platform and marsh toe, respectively, and defined an effective water level range of $1 \times H_{m 0}$ below the marsh toe to $1 \times H_{m 0}$ above the marsh platform. Using this effective water level range, the effective wave power (wave energy that is truly responsible for erosion of shoreline and marsh edge) can be calculated and used for the assessment of sediment transport, deposition, and erosion along shoreline dominated by salt marshes (Everett and others, 2019).

In this study, an effective water level range was proposed for wave power computation. The elevations of the marsh platform and toe are determined on the basis of the averaged elevation of the erosion pins installed next to identified marsh edges. At the control site, the elevations of marsh platform and marsh toe are $-0.43 \mathrm{~m}$ and $0.16 \mathrm{~m}$ (referenced to the North American Vertical Datum of 1988 [NAVD 88]), respectively. At the oyster castle site, the marsh platform elevation is $-0.48 \mathrm{~m}$ (NAVD 88 ), and the marsh toe elevation is approximated as the mean low water $(-0.896 \mathrm{~m}$, NAVD 88) at the nearby National Oceanic and Atmospheric Administration tide station (8537121) in Ship John Shoal, N.J. A more conservative water level range, from $1.5 \times H_{m 0}$ below the marsh toe to $1.5 \times H_{m 0}$ above the marsh platform, is taken in this study. The effective water level ranges, together with the marsh platform and toe at the oyster castle and control sites, are presented in figure 29 .

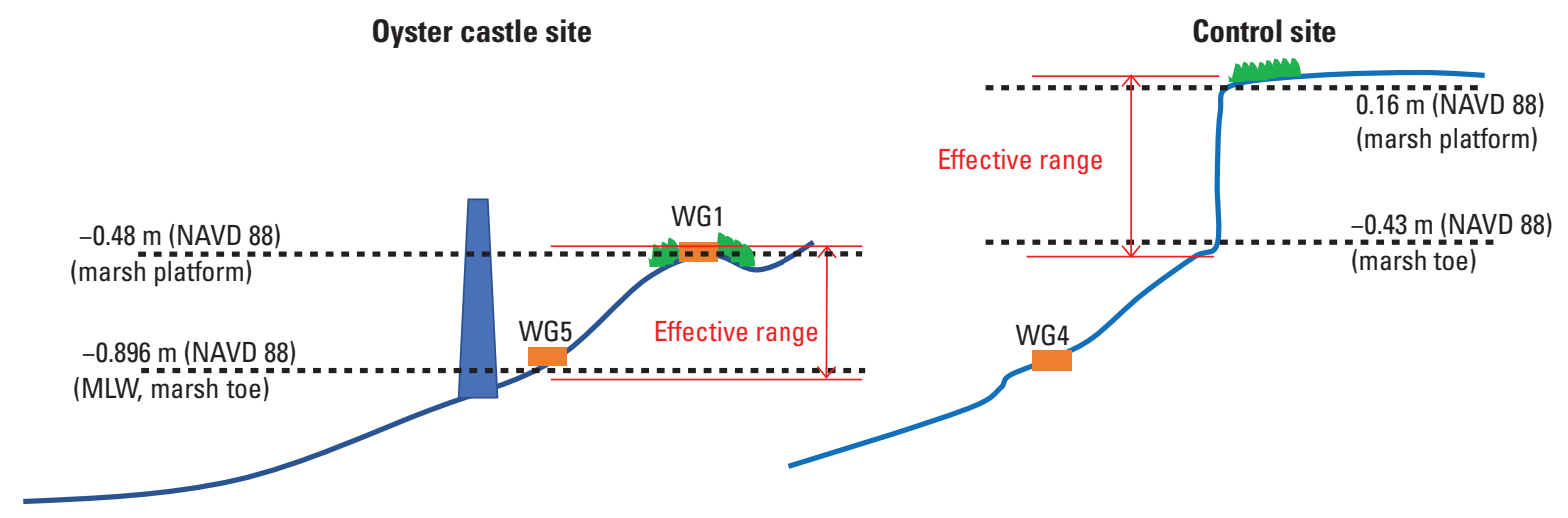

Figure 29. The marsh platform and toe and the proposed effective range at the oyster castle and control sites for wave power computation in the Gandys Beach, New Jersey, living shoreline study area. m, meter; MLW, mean low water; NAVD 88, North American Vertical Datum of 1988; WG, wave gage. 
Figure 30 shows the measured water level and the effective water level ranges of $\left[z_{\text {marsh toe }}-1.5 \times H_{m 0, W G 4}, z_{\text {marsh }}\right.$ platform $\left.+1.5 \times H_{m 0, W G 4}\right]$ and $\left[z_{\text {marsh toe }}-1.5 \times H_{\text {mo,WGS }}, z_{\text {marsh platform }}\right.$ $\left.+1.5 \times H_{m 0, W G 5}\right]$ at WG4 and WG5, respectively. The variables $z_{\text {marsh platorm }}$ and $z_{\text {marsh toe }}$ represent the elevation at the marsh platform and marsh toe, respectively. At WG5 (oyster castle site), the water level falls between the effective range for about 34 percent of the entire deployment duration, while at WG4 (control site), the water level falls between the effective range for about 46 percent of the entire deployment duration. Compared to the control site, the protected area behind the structure has lower platform and toe elevations and thus is more likely to be submerged in water at mid-tide and high-tide conditions. Consequently, the oyster castle site is less likely to be impacted by incoming waves at mid-tide and high-tide conditions.

The wave power $(P)$ is computed as below:

$$
P=\frac{\rho g H_{m 0}^{2}}{16} C_{g}
$$

where

$$
C_{g}=\frac{\omega_{p}}{2 k_{p}}\left(1+\frac{2 k_{p} h}{\sinh 2 k_{p} h}\right) \begin{aligned}
& \text { is the group velocity, and } \\
& \omega_{p} \text { and } k_{p} \begin{array}{l}
\text { are the angular wave } \\
\text { frequency and wave } \\
\text { number corresponding } \\
\text { to the peak wave period, } \\
\text { respectively. }
\end{array}
\end{aligned}
$$

The effective wave power $\left(P_{e}\right)$ is calculated for each burst when the water level falls between the effective water level range by using equation 6 . The mean $P_{e}$ is averaged over the 2-month deployment duration and the four nor'easters. Figure 31 demonstrates that the mean $P_{e}$ at WG5 is lower than that at WG4. This lower mean $P_{e}$ behind the structure is mainly attributed to its lower marsh toe and platform elevations. Field measurements showed that there was no lateral erosion at the oyster castle site (WG5) during the 2 months, whereas there was an average of 5.3-9.7 cm lateral erosion over the 2-month deployment duration at the control site (WG4). The computed mean $P_{e}$ values at these two sites are consistent with the lateral erosion rates measured by the erosion pins.
The wave-induced bottom shear stress is computed as below (from Swart, 1974):

$$
\tau_{w}=\frac{1}{2} \rho f_{w} \cdot u_{w b}^{2}
$$

where

$$
\begin{aligned}
& u_{w b}=\frac{\omega_{p} H_{r m s}}{2} \cdot \frac{1}{\operatorname{sinhsinh} k_{p} h} \begin{array}{l}
\text { is the wave orbital } \\
\text { velocity at the bottom, }
\end{array} \\
& \rho \text { is the fluid density, and } \\
& f_{w} \text { is the bottom friction } \\
& \text { factor determined as } \\
& \text { below: }
\end{aligned}
$$

$$
f_{w}=\left\{\begin{array}{c}
0.00251 \bullet \exp \left(5.21\left(\frac{A}{k_{s}}\right)^{-0.19}\right) \text { for } \frac{A}{k_{s}}>1.57 \\
0.3 \text { for } \frac{A}{k_{s}} \leq 1.57
\end{array}\right.
$$

where

$$
\begin{aligned}
& \text { A the near-bed wave orbital excursion } \\
& \text { amplitude, and } \\
& k_{s} \quad \text { is the wave-related bed roughness. }
\end{aligned}
$$

The results comparing the wave-induced bottom shear stress $\tau_{w}$ at WG4 (control site) and WG5 (site behind the oyster castles) are shown in figure $32 A$. The variations of $\tau_{w}$ and $H_{m 0}$ at these two sites share a similar pattern. At low-tide conditions, the oyster castles are emergent and are effective in reducing $\tau_{w}$ (fig. 32C). At high-tide and mid-tide conditions (fig. 32B), when the structures are submerged, the larger $\tau_{w}$ at the oyster castle site (that is, WG5) as shown in figure $32 B$ may suspend sediment as evidenced by the higher TSS concentration, and sediment in the upper water column over tidal flat can be effectively transported to marsh area behind the structure (for example, Duvall and others, 2019). However, the submerged structures may block the flow offshore and retain sediments, resulting in the increase of surface elevation. Along coastal shorelines, bottom shear stress can be induced by not only waves but also tidal current, both of which contribute to the sediment erosion and deposition, resulting in gain or loss of shoreline over time. Nevertheless, wave-induced bottom shear stress tends to play a larger role than current-induced shear stress in erosion because of the larger wave-induced shear stress than critical shear stress (for example, Shi and others, 2015), especially for erosion in a high wave energy coastal area like Gandys Beach. However, determination of the critical shear stress for erosion and deposition to link the wave-induced shear stress to bed elevation change would have required continuous bed-level monitoring during the two winter months at the sites with and without protection of the oyster castles. 


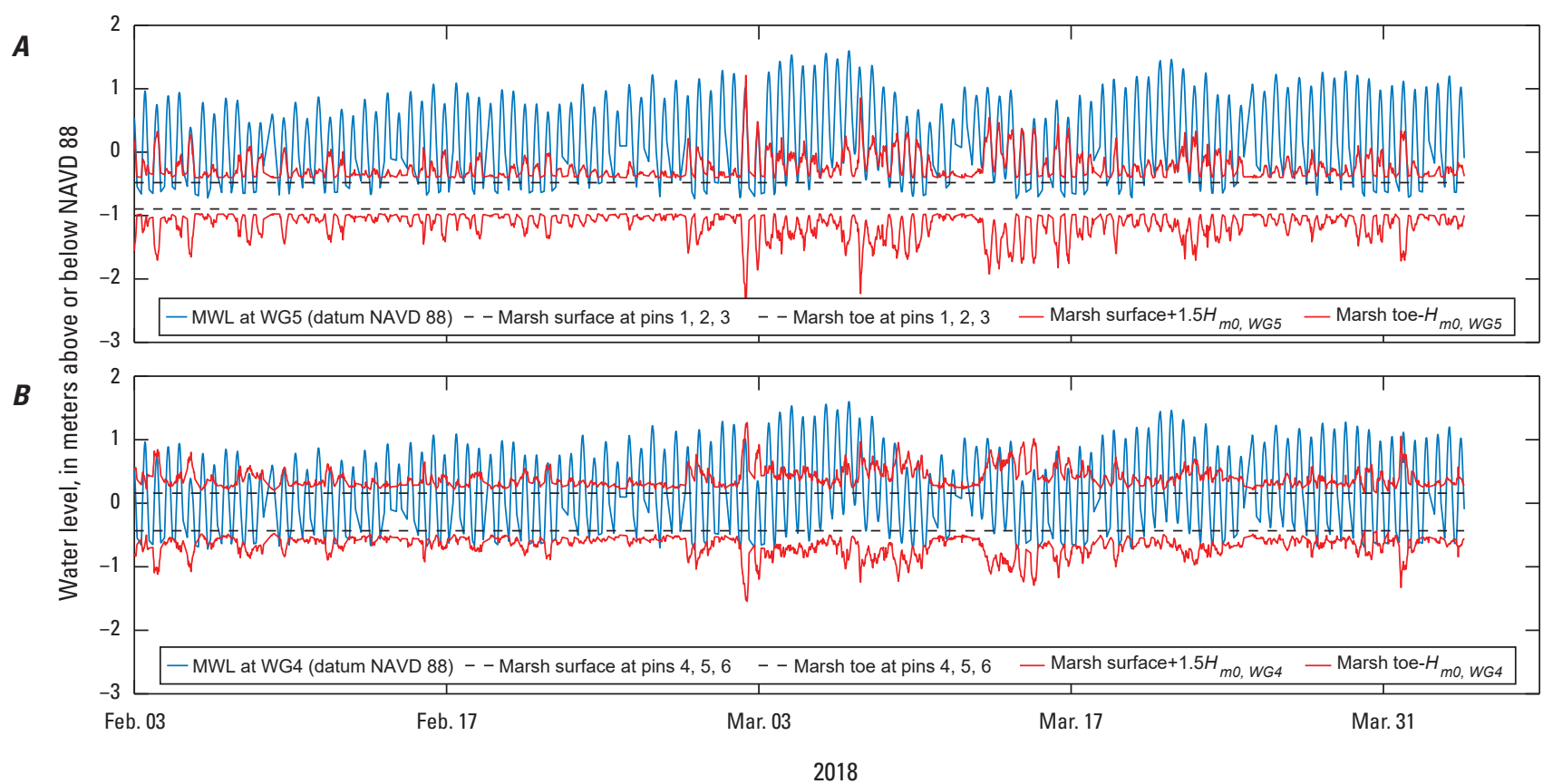

Figure 30. The mean water level (MWL) and the effective ranges at $A$, the oyster castle site (wave gage [WG] 5) and $B$, the control site (WG4), February to April 2018, in the Gandys Beach, New Jersey, living shoreline study area. $H_{m 0^{\prime}}$ wave height; NAVD 88, North American Vertical Datum of 1988.

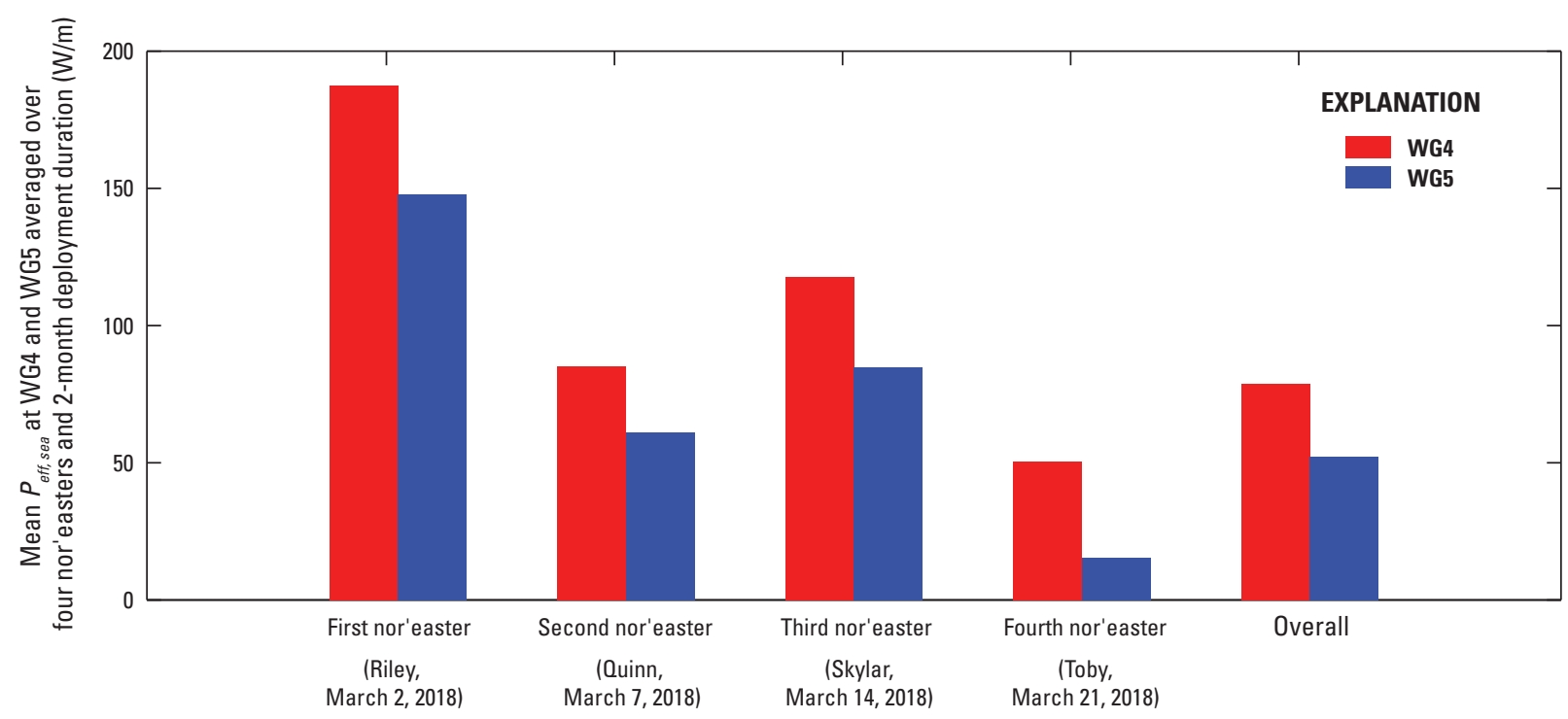

Figure 31. The mean effective wave power $\left(P_{e}\right)$ at wave gage (WG) 4 and WG5 averaged over the four nor'easters and the 2-month deployment duration, February to April 2018, in the Gandys Beach, New Jersey, living shoreline study area. W/m, watts per meter. 

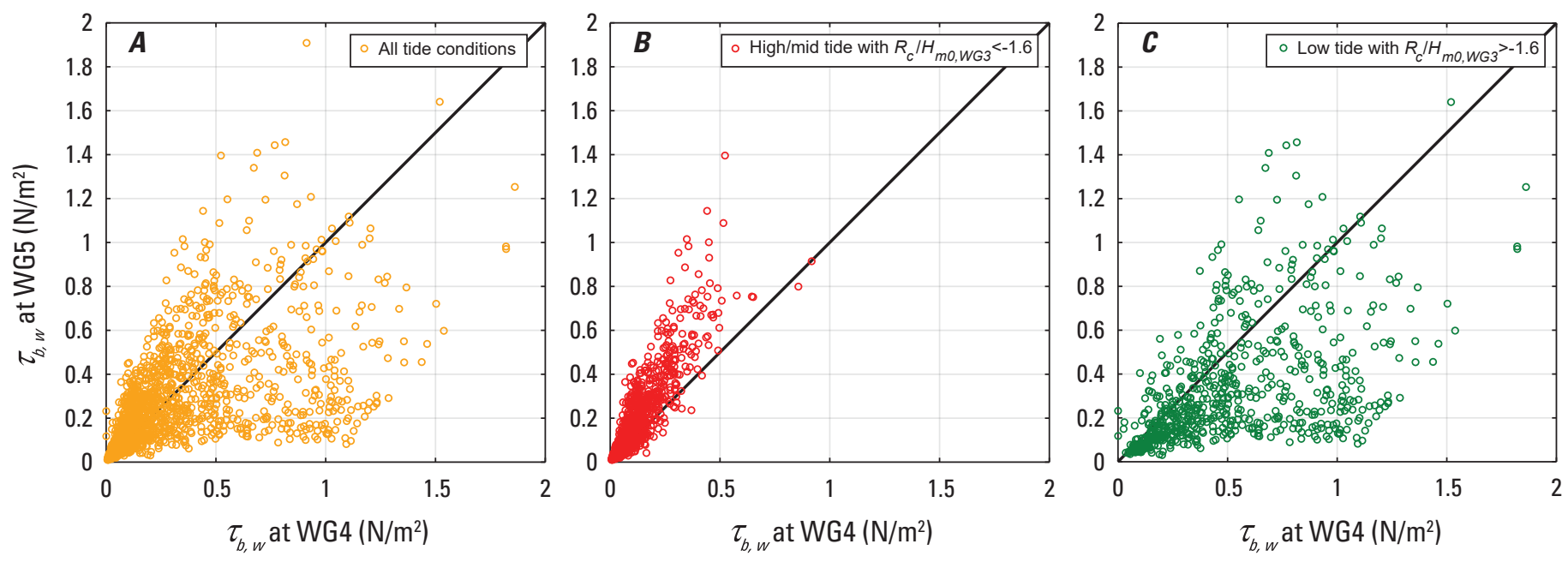

Figure 32. Comparisons of the wave-induced bottom shear stress $\left(\tau_{b, w}\right)$ at wave gage (WG) 4 and WG5 in $A$, all tide conditions, $B$, hightide to mid-tide conditions, and $C$, low-tide conditions, February to April 2018, in the Gandys Beach, New Jersey, living shoreline study area. $\mathrm{N} / \mathrm{m}^{2}$, Newtons per square meter; $R_{c} / H_{m 0^{\prime}}$ relative freeboard.

Data on sediment grain size at the study area prior to oyster castle construction were not available. If the grain size data for the area seaward of the oyster castles were representative of data prior to castle construction, then this result is different from previous similar studies, where oyster reefs tended to trap and accumulate fine sediments compared to preconstruction conditions (for example, Colden and others, 2016; Chowdhury and others, 2019). The difference might be due to the large wave energy and complicated wave-induced current pattern around the LSS. The oyster castles tended to be submerged most (over 85 percent) of the time (Zhu and others, 2020). Increased flow velocity larger than $10 \mathrm{~cm} / \mathrm{s}$ and up to $30 \mathrm{~cm} / \mathrm{s} \mathrm{(fig.} \mathrm{22)} \mathrm{in} \mathrm{the} \mathrm{gaps} \mathrm{between} \mathrm{the} \mathrm{oyster} \mathrm{castles}$ was seen during the study period across the oyster castles compared to less than $10 \mathrm{~cm} / \mathrm{s}$ in the control site (figs. 23-25). A velocity of larger than $10 \mathrm{~cm} / \mathrm{s}$ is a critical value above which oyster feeding could be inhibited (see literature review in Wang and others, 2017). The highest suspended sediment concentrations tended to be associated with the fastest current velocity for oyster reefs that are oriented perpendicular to the prevailing tidal current (Colden and others, 2016). It was found that the interaction between wave action and the relative height of oyster reefs could probably affect sediment grain characteristics and sediment deposition (Chowdhury and others, 2019). Additionally, grain size distribution along shorelines could vary with seasons in addition to the impact of LSS. For example, Chowdhury and others (2019) found that sediment clay percentage in oyster-reef-protected shoreline dropped from $\sim 96$ percent during the nonmonsoon period to less than 84 percent when affected by monsoon-driven winds and waves. In the Gandys Beach shoreline area, relatively large variation in the grain size distribution was found after oyster castle construction. Unfortunately, sediment grain size distribution data prior to oyster castle construction were not available, making it difficult to examine the real changes in grain size distribution due to oyster castle construction. More sediment samples across different seasons over a longer term (for example, multiple years) and more analysis are needed to understand sediment mass and texture changes with and without LSS.

Moreover, the grain size of sediment surrounding oyster reefs was found to be a significant predictor of oyster reef presence or absence (Theuerkauf and others, 2017). Theuerkauf and others (2017) found that natural intertidal oyster reefs generally are absent in sand bottom areas (mean grain size of $0.15 \mathrm{~mm}$ ) and that most oyster reefs occur in areas of soft sediment such as sandy mud $(0.0156 \mathrm{~mm})$ and muddy sand $(0.04 \mathrm{~mm})$. Oyster reef height was found to decrease with increases in sediment grain size because, as sediment deposition becomes large, the critical shear stress for erosion increases as grain size increases, leading to burial of oyster reefs by sediment (Housego and Rosman, 2016). Housego and Rosman (2016) identified a size of $0.08 \mathrm{~mm}$ as a critical threshold for oyster reefs at which reef growth outpaces sediment accumulation. In this study, 5 out of 12 sediment samples collected in the Gandys Beach area had sandy $(>0.063 \mathrm{~mm}$ ) percentage $>50$ percent (table 4$)$, suggesting that the selected area for oyster castle construction may not represent the optimal site from the perspective of sediment grain size distribution. 


\section{Summary}

This study was conducted by the U.S. Geological Survey and Northeastern University in cooperation with the U.S. Fish and Wildlife Service and The Nature Conservancy. A field investigation was carried out to monitor the wave, water level, current field, and sediment deposition and erosion around living shorelines in Gandys Beach, New Jersey, a small cove in upper Delaware Bay. The intertidal salt marshes and beaches at the study site are protected by segmented constructed oyster reefs (CORs), which were constructed after Hurricane Sandy (2012) for shoreline protection and the enhancement of habitats for fish and shellfish species. Six wave gages and six tilt current meters were deployed on the sediment floor, and sediment deposition and erosion were measured at locations with and without the protection of the CORs from January 31 to April 2, 2018, during which four winter storms (nor'easters) occurred. The collected dataset (wave, current, and sediment) provides valuable information about the wave and current characteristics and sediment dynamics at the marsh edge and mudflat along the CORbased living shorelines. With this dataset, the effectiveness of CORs in wave energy attenuation under different tidal and bathymetric conditions can be further investigated. Additionally, the relation between hydrodynamic forcing and sediment transport, deposition, and erosion can be assessed for the adaptive management of living shoreline restoration projects.

Because of the large tidal range at the study area, the CORs are submerged most of the time. The wave height changes across the CORs are strongly dependent on the ratio between the freeboard of the CORs and the offshore wave heights. Besides the expected wave height reduction on the leeward side of the CORs, wave height amplification is also observed, which is opposite to our expectation. This phenomenon is attributed to complex nearshore processes including wave shoaling, wave diffraction, and wave focusing. The leeward side behind the CORs at the study site forms a small headland at mid-tide and high-tide conditions, which can cause wave focusing in this area.

The field observations demonstrate complex wave spectral characteristics and current patterns at the study area. Under normal weather conditions, swell waves from the Atlantic Ocean are observed in wave spectra, whereas during windy days, wind sea signals are dominant in wave spectra. The wave spectral partitioning technique was employed to separate the wave spectrum into swell and wind sea portions. It was found that swell energy can transmit through the CORs without getting damped regardless of the submergence of CORs, whereas wind seas are more impacted by the CORs. Wind seas were found to result in high onshore wave power, thus producing shoreline erosion. By employing the concept of effective wave power (that is, the wave power that is responsible for marsh edge erosion), we have demonstrated that the CORs are effective in reducing the wave impact on the salt marshes protected by the CORs, as less marsh edge erosion was observed compared to the control area. The combined effect of living shoreline structures on wave attenuation and the change in circulation patterns over the study period resulted in the reduction of erosion of salt marsh and shore sediment both vertically and laterally compared to the control sites. Meanwhile, grain size distribution in both the water column and the salt marsh and mudflat areas changed with the construction of CORs.

In summary, the wave energy attenuation, current pattern changes, and sedimentation across the CORs are complicated and depend on factors including the oyster reef configurations (for example, crest freeboard), the surrounding bathymetry, sediment texture (that is, grain size distribution), and the local wave environment (for example, swell dominant or wind sea dominant). The in situ measurements made in this study provide useful information for the assessment and adaptive management of oyster-reef-based living shorelines. From the shoreline protection perspective, it is desirable to build oyster-reef-based living shoreline structures with enough height (to increase the time they are emergent) to reduce wave energy in proximity to the shore. On the other hand, from the perspective of oyster reef development and oyster growth, oyster-reef-based living shoreline structures need to be submerged to provide a subtidal or intertidal condition for oysters to settle and grow on the reefs. Therefore, further studies are needed in the context of a "wave-bathymetrystructure" holistic system across multiple spatial and temporal scales along the living shorelines. With the holistic system approach, the optimal design and implementation of future living shoreline projects can be reached to achieve maximum benefits of shoreline protection and habitat enhancement in this study area and other coastal areas. The field data collected in this study will benefit the calibration and validation of hydrodynamic, wave and sediment transport models and help resource managers evaluate the effectiveness of living shoreline projects and make design improvements to oysterreef-based living shoreline structures.

\section{References Cited}

Chen, Q., Chakrabarti, A., Karimpour, A., and Johnson, C., 2016, Optimizing the design of shoreline protection to reduce marsh edge erosion based on integrated field observations and modeling: Baton Rouge, La., Final report prepared for the Louisiana Coastal Protection and Restoration Authority, May 20, 2016, 59 p.

Chowdhury, M.S.N., Walles, B., Sharifuzzaman, S.M., Hossain, M.S., Ysebaert, T., and Smaal, A.C., 2019, Oyster breakwater reefs promote adjacent mudflat stability and salt marsh growth in a monsoon dominated subtropical coast: Scientific Reports, v. 9, no. 8549, p. 1-12, accessed January 20, 2020, at https://doi.org/10.1038/s41598-01944925-6. 
Colden, A.M., Fall, K.A., Cartwright, G.M., and Friedrichs, C.T., 2016, Sediment suspension and deposition across restored oyster reefs of varying orientation to flowImplications for restoration: Estuaries and Coasts, v. 39, no. 5, p. 1435-1448, accessed January 20, 2020, at https:// doi.org/10.1007/s12237-016-0096-y.

Conrad, K., 2015, Final environmental assessment for the Gandys Beach/Money Island living shoreline project: Pleasantville, N.J., U.S. Fish and Wildlife Service New Jersey Field Office, 112 p. [Also available at https://www. fws.gov/hurricane/sandy/pdf/GandysBeachEA.pdf.]

d'Angremond, K., van der Meer, J.W., and de Jong, R.J., 1996, Wave transmission at low crested structures, in International Conference on Coastal Engineering, 25th, Orlando, Florida, September 2-6, 1996, Proceedings: Reston, Va., American Society of Civil Engineers, p. 3305-3318. [Also available at https://www.researchgate.net/publication/228526517 Wave_transmission_at_low-crested_structures_including oblique_wave_attack.]

Dugan, J.E., Emery, K.A., Alber, M., Alexander, C.R., Byers, J.E., Gehman, A.M., McLenaghan, N., and Sojka, S.E., 2018, Generalizing ecological effects of shoreline armoring across soft sediment environments: Estuaries and Coasts, v. 41, p. 180-196, accessed January 31, 2020, at https://doi. org/10.1007/s12237-017-0254-x.

Duvall, M.S., Wiberg, P.L., and Kirwan, M.L., 2019, Controls on sediment suspension, flux, and marsh deposition near a bay-marsh boundary: Estuaries and Coasts, v. 42, no. 2, p. 403-424, accessed February 15, 2020, at https://doi. org/10.1007/s12237-018-0478-4.

Everett, T., Chen, Q., Karimpour, A., and Twilley, R., 2019, Quantification of swell energy and its impact on wetlands in a deltaic estuary: Estuaries and Coasts, v. 42 , no. 1, p. 68-84, accessed December 10, 2019, at https://doi. org/10.1007/s12237-018-0454-z.

Galvez, B.A., 2019, Trophic ecology of juvenile weakfish (Cynoscion regalis) in the Delaware Bay using stomach content and stable isotope analysis: Dover, Del., Delaware State University, master's thesis, 230 p. [Also available at https://www.researchgate.net/ publication/333389406_TROPHIC_ECOLOGY_OF_ JUVENILE_WEAKFISH_CYNOSCION_REGÄLIS IN_THE_DELAWARE_BAY_USING_STOMACH CONTENT_AND_STABLE_ISOTOPE_ANALYSES.]

Guy, H.P., 1969, Laboratory theory and methods for sediment analysis-Fluvial sediment concepts: U.S. Geological Survey Techniques and Methods, book 3, chap. C1, 64 p. [Also available at https://pubs.usgs.gov/twri/twri3-c1/pdf/ TWRI_3-C1.pdf.]
Housego, R.M., and Rosman, J.H., 2016, A model for understanding the effects of sediment dynamics on oyster reef development: Estuaries and Coasts, v. 39, no. 2, p. 495509, accessed January 30, 2020, at https://doi.org/10.1007/ s12237-015-9998-3.

Hu, K., Chen, Q., Wang, H., Hartig, E.K., and Orton, P.M., 2018, Numerical modeling of salt marsh morphological change induced by Hurricane Sandy: Coastal Engineering, v. 132, p. 63-181, accessed January 31, 2020, at https://doi. org/10.1016/j.coastaleng.2017.11.001.

Hwang, P.A., Ocampo-Torres, F.J., and Garcia-Nava, H., 2012, Wind sea and swell separation of $1 \mathrm{~d}$ wave spectrum by a spectrum integration method: Journal of Atmospheric and Oceanic Technology, v. 29, no. 1, p. 116-128, accessed January 15, 2020, at https://doi.org/10.1175/ JTECH-D-11-00075.1.

Kamphuis, J.W., 2010, Introduction to coastal engineering and management (2d ed.): Singapore, World Scientific Publishing, $564 \mathrm{p}$.

Karimpour, A., and Chen, Q., 2017, Wind wave analysis in depth limited water using OCEANLYZ, a MATLAB toolbox: Computers \& Geosciences, v. 106, p. 181-189, accessed October 30, 2019, at https://doi.org/10.1016/j. cageo.2017.06.010.

Leonardi, N., Ganju, N.K., and Fagherazzi, S., 2016, A linear relationship between wave power and erosion determines salt-marsh resilience to violent storms and hurricanes: Proceedings of the National Academy of Sciences of the United States of America, v. 113, no. 1, p. 64-68, accessed January 31, 2020, at https://doi.org/10.1073/ pnas. 1510095112.

Manis, J.E., Garvis, S.K., Jachec, S.M., and Walters, L.J., 2015, Wave attenuation experiments over living shorelines over time-A wave tank study to assess recreational boating pressures: Journal of Coastal Conservation, v. 19, no. 1, p. 1-11, accessed October 10, 2019, at https://doi. org/10.1007/s11852-014-0349-5.

Marani, M., D'Alpaos, A., Lanzoni, S., and Santalucia, M., 2011, Understanding and predicting wave erosion of marsh edges: Geophysical Research Letters, v. 38, no. 21, L21401, accessed October 30, 2019, at https://doi. org/10.1029/2011GL048995.

Nolte, S., Butzeck, C., Baldwin, A.H., Felton, G.K., and Jensen, K., 2019, Efficiency of varying sediment traps under experimental conditions simulating tidal inundations: Journal of Coastal Research, v. 35, no. 4, p. 920-924, accessed January 20, 2020, at https://doi.org/10.2112/ JCOASTRES-D-18-00009.1. 
Polk, M.A., and Eulie, D.O., 2018, Effectiveness of living shorelines as an erosion control method in North Carolina: Estuaries and Coasts, v. 41, no. 8, p. 2212-2222, accessed February 10, 2020, at https://doi.org/10.1007/s12237-0180439-y.

Priestas, A.M., and Fagherazzi, S., 2011, Morphology and hydrodynamics of wave-cut gullies: Geomorphology, v. 131, nos. 1-2, p. 1-13, accessed October 30, 2019, at https://doi.org/10.1016/j.geomorph.2011.04.004.

Sanford, L.P., and Gao, J., 2018, Influences of wave climate and sea level on shoreline erosion rates in the Maryland Chesapeake Bay: Estuaries and Coasts, v. 41, no. S1, p. 19-37, accessed January 15, 2020, at https://doi. org/10.1007/s12237-017-0257-7.

Sharma, S., Goff, J., Cebrian, J., and Ferraro, C., 2016, A hybrid shoreline stabilization technique-Impact of modified intertidal reefs on marsh expansion and nekton habitat in the northern Gulf of Mexico: Ecological Engineering, v. 90, p. 352-360, accessed January 10, 2020, at https://doi.org/10.1016/j.ecoleng.2016.02.003.

Shi, B., Wang, Y., Yang, Y., Li, M., Li, P., Ni, W., and Gao, J., 2015, Determination of critical shear stress for erosion and deposition based on in situ measurements of currents and waves over an intertidal mudflat: Journal of Coastal Research, v. 31, no. 6, p. 1344-1356, accessed October 30, 2019, at https://doi.org/10.2112/ JCOASTRES-D-14-00239.1.

Shumway, S.E., 1996, Natural environmental factors, in Kennedy, V.S., Newell, R.I., and Eble, A.F., eds., The eastern oyster-Crassostrea virginica: College Park, Md., Maryland Sea Grant, p. 467-511, accessed October 30, 2019, at https://www.researchgate.net/ publication/262728827_Natural_Environmental_Factors.

Swart, D.H., 1974, Offshore sediment transport and equilibrium beach profiles: Delft Hydraulics Laboratory Publication 131, 211 p., accessed January 15, 2020, at https://repository.tudelft.nl/islandora/object/uuid:057cb1365f5b-484a-878d-5616fbaeda4e.

Theuerkauf, S.J., Eggleston, D.B., Puckett, B.J., and Theuerkauf, K.W., 2017, Wave exposure structures oyster distribution on natural intertidal reefs, but not on hardened shorelines: Estuaries and Coasts, v. 40, no. 2, p. 376-386, accessed January 15, 2020, at https://doi.org/10.1007/ s12237-016-0153-6.

Thornton, E.B., and Guza, R.T., 1983, Transformation of wave height distribution: Journal of Geophysical Research, Oceans, v. 88, no. C10, p. 5925-5938, accessed March 31, 2019, at https://doi.org/10.1029/JC088iC10p05925.
U.S. Department of the Interior Metrics Expert Group, 2015, Recommendations for assessing the effects of the DOI Hurricane Sandy Mitigation and Resilience Program on ecological system and infrastructure resilience in the Northeast coastal region: Report for the Department of the Interior, June 2015, 64 p., accessed March 31, 2019, at https://www.doi.gov/sites/doi.gov/files/migrated/news/ upload/Hurricane-Sandy-project-metrics-report.pdf.

Van der Meer, J.W., Briganti, R., Zanuttigh, B., and Wang, B., 2005, Wave transmission and reflection at low-crested structures-Design formulae, oblique wave attack and spectral change: Coastal Engineering, v. 52, nos. 10-11, p. 915-929, accessed December 1, 2019, at https://doi. org/10.1016/j.coastaleng.2005.09.005.

Wang, H., Capurso, W.D., Chen, Q., Zhu, L., Niemoczynski, L.M., and Snedden, G., 2021, Field observation of current velocities (2018) in Gandys Beach, New Jersey with living shoreline structures: U.S. Geological Survey data release, https://doi.org/10.5066/P9N4NOWZ.

Wang, H., Chen, Q., La Peyre, M.K., Hu, K., and La Peyre, J.F., 2017, Predicting the impacts of Mississippi River diversions and sea-level rise on spatial patterns of eastern oyster growth rate and production: Ecological Modelling, v. 352, p. 40-53, accessed March 30, 2020, at https://doi. org/10.1016/j.ecolmodel.2017.02.028.

Wang, H., Zhu, L., Chen, Q., Capurso, W.D., Niemoczynski, L.M., Hu, K., and Snedden, G., 2020, Field observations and spectral evolution of wind waves in Upper Delaware Bay with living shorelines: U.S. Geological Survey data release, accessed November 31, 2020, at https://doi. org/10.5066/P9YEUNTM.

Wiberg, P.L., Taube, S.R., Ferguson, A.E., Kremer, M.R., and Reidenbach, M.A., 2019, Wave attenuation by oyster reefs in shallow coastal bays: Estuaries and Coasts, v. 42, no. 2, p. 331-347, accessed March 30, 2020, at https://doi. org/10.1007/s12237-018-0463-y.

Ysebaert, T., Yang, S., Zhang, L., He, Q., Bouma, T.J., and Herman, P.M.J., 2011, Wave attenuation by two contrasting ecosystem engineering salt marsh macrophytes in the intertidal pioneer zone: Wetlands, v. 31, no. 6, p. 10431054, accessed March 30, 2020, at https://doi.org/10.1007/ s13157-011-0240-1.

Zhu, L., Chen, Q., Wang, H., Capurso, W., Niemoczynski, L., Hu, K., and Snedden, G., 2020, Field observations of wind waves in upper Delaware Bay with living shorelines: Estuaries and Coasts, v. 43, no. 4, p. 739-755, accessed March 30, 2020, at https://doi.org/10.1007/s12237-01900670-7. 
For more information about this publication, contact

Director, Wetland and Aquatic Research Center

U.S. Geological Survey

7920 NW 71st St.

Gainesville, FL 32653

For additional information, visit https://www.usgs.gov/centers/wetland-and-aquatic-research-center-warc

Publishing support provided by

Lafayette Publishing Service Center 

